\title{
A Thin Film Approach to Engineering Functionality into Oxides
}

\author{
Darrell G. Schlom, ${ }^{\dagger \dagger \dagger, \ddagger}$ Long-Qing Chen, ${ }^{\ddagger}$ Xiaoqing Pan, ${ }^{\S}$ Andreas Schmehl, ${ }^{\ddagger},{ }^{\oplus}$ and Mark A. Zurbuchen \\ ${ }^{\ddagger}$ Department of Materials Science and Engineering, Pennsylvania State University, University Park, Pennsylvania \\ $16802-5005$
}

${ }^{\S}$ Department of Materials Science and Engineering, University of Michigan, Ann Arbor, Michigan 48109-2136

"Experimentalphysik VI, Elektronische Korrelationen und Magnetismus, Institut für Physik, Universität Augsburg, D86159 Augsburg, Germany

"The Aerospace Corporation, Microelectronics Technology Department, El Segundo, California 90245

The broad spectrum of electronic and optical properties exhibited by oxides offers tremendous opportunities for microelectronic devices, especially when a combination of properties in a single device is desired. Here we describe the use of reactive molecularbeam epitaxy and pulsed-laser deposition to synthesize functional oxides, including ferroelectrics, ferromagnets, and materials that are both at the same time. Owing to the dependence of properties on direction, it is often optimal to grow functional oxides in particular directions to maximize their properties for a specific application. But these thin film techniques offer more than orientation control; customization of the film structure down to the atomic-layer level is possible. Numerous examples of the controlled epitaxial growth of oxides with perovskite and perovskite-related structures, including superlattices and metastable phases, are shown. In addition to integrating functional oxides with conventional semiconductors, standard semiconductor practices involving epitaxial strain, confined thickness, and modulation doping can also be applied to oxide thin films. Results of fundamental scientific importance as well as results revealing the tremendous potential of utilizing functional oxide thin films to create devices with enhanced performance are described.

\section{Oxides Beyond $\mathrm{SiO}_{2}$}

$\mathrm{U}$ NTIL recently, the word "oxide" could only mean one thing to anyone working in the semiconductor industry- $-\mathrm{SiO}_{2}$.

D. Green—contributing editor

\footnotetext{
Manuscript No. 24429. Received March 17, 2008; approved June 1, 2008.

This work was financially supported by the National Science Foundation under grants DMR-0507146 and DMR-0213623, the Office of Naval Research under grant N00014-04-10426 monitored by Dr. Colin Wood, and the U.S. Department of Energy through grants DE-FG02-03ER46063 and DE-FG02-07ER46417. This work was supported by The Aerospace Corporation's Independent Research and Development Program.

Author to whom correspondence should be addressed. e-mail: schlom@ cornell.edu

${ }^{\dagger}$ Current Address: Department of Materials Science and Engineering, Cornell University, Ithaca, NY 14853-1501
}

But as every ceramist knows, oxides are an exciting class of electronic materials in their own right. Oxides exhibit the full spectrum of electronic, optical, and magnetic behavior: insulating, semiconducting, metallic, superconducting, ferroelectric, pyroelectric, piezoelectric, ferromagnetic, multiferroic, and nonlinear optical effects are all possessed by structurally compatible oxides. The unparalleled variety of physical properties of oxides holds tremendous promise for electronic applications. Analogous to today's semiconductor device structures, many device concepts utilizing oxides will likely use alternately layered structures where dimensions are minute enough to observe quantum size effects (nanometer-scale thicknesses).

The physical behavior of oxides confined to quantum size dimensions is not well established, and an understanding of the effect of such confinement (reduced dimensionality) on the physical properties of these structures cannot be achieved without the controlled preparation of well-ordered crystalline samples. Equally exciting are the new functionalities that can emerge at oxide interfaces. For instance, the interface between appropriate antiferromagnetic materials has been shown to be ferromagnetic. ${ }^{1-7}$ Similarly, charge transfer at the interface between appropriate nonmagnetic insulators ${ }^{8}$ can give rise to a magnetic ${ }^{9}$ or superconducting ${ }^{10}$ electron gas. These examples offer a glimpse of the new or enhanced functionalities that can be achieved by nanoengineering oxide heterostructures with atomic layer precision. As we show in this article, it is possible to structurally engineer crystalline oxides with a precision that rivals the structural control achieved in today's most advanced semiconductor structures.

Examples of the functional properties of specific oxides are listed in Table I. The oxides chosen were those with exceptional properties for each category. These include the oxide with the highest known electron mobility $\left(\mathrm{SrTiO}_{3}\right),{ }^{11}$ change in resistance at a metal-insulator transition $(\mathrm{EuO}),{ }^{12}$ superconducting transition temperature $\left(\mathrm{HgBa}_{2} \mathrm{Ca}_{2} \mathrm{Cu}_{3} \mathrm{O}_{8+x}\right){ }_{13}^{13}$ switchable spontaneous polarization $\left(\mathrm{PbZr}_{0.2} \mathrm{Ti}_{0.8} \mathrm{O}_{3}{ }^{14}\right.$ and $\mathrm{BiFeO}_{3}{ }^{15-18}$ ), piezoelectric coefficient $\left(\mathrm{PbZn}_{1 / 3} \mathrm{Nb}_{2 / 3} \mathrm{O}_{3}-\mathrm{PbTiO}_{3}\right),{ }^{19}$ magnetization $(\mathrm{EuO}){ }^{20}$ magnetoresistance $\left(\mathrm{Pr}_{0.7} \mathrm{Sr}_{0.04} \mathrm{Ca}_{0.26} \mathrm{MnO}_{3-\delta}\right){ }^{21}$ magnetostrictive coefficient $\left(\mathrm{Co}_{0.8} \mathrm{Fe}_{2.2} \mathrm{O}_{4}\right),{ }^{22}$ Verdet constant $(\mathrm{EuO})^{23}-$ a measure of the strength of the Faraday effect, spin polarization $\left(\mathrm{CrO}_{2}\right),{ }^{24,25}$

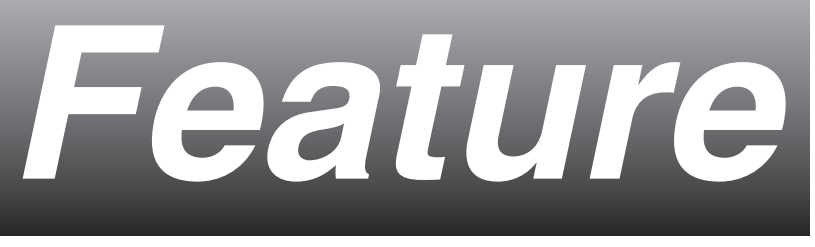


Table I. Examples of the Properties of Oxides

\begin{tabular}{|c|c|c|c|}
\hline Property & Value & Oxide material & References \\
\hline Mobility & $\mu=22000 \mathrm{~cm}^{2} \cdot(\mathrm{V} \cdot \mathrm{s})^{-1}(2 \mathrm{~K})$ & $\mathrm{SrTiO}_{3}$ & Tufte and Chapman ${ }^{11}$ \\
\hline Metal-insulator transition & $\Delta R / R_{T_{\mathrm{low}}}>10^{13}$ & $\mathrm{EuO}$ & Petrich et al. ${ }^{12^{1}}$ \\
\hline Superconductivity & $T_{\mathrm{c}}=135 \mathrm{~K}$ & $\mathrm{HgBa}_{2} \mathrm{Ca}_{2} \mathrm{Cu}_{3} \mathrm{O}_{8+x}$ & Schilling et al. $^{13}$ \\
\hline Ferroelectricity & $P_{\mathrm{s}}=105 \mu \mathrm{C} / \mathrm{cm}^{2}$ & $\mathrm{PbZr}_{0.2} \mathrm{Ti}_{0.8} \mathrm{O}_{3}$ & Vrejoiu et al. ${ }^{14}$ \\
\hline & $P_{\mathrm{s}}=100 \mu \mathrm{C} / \mathrm{cm}^{2}$ & $\mathrm{BiFeO}_{3}$ & $\begin{array}{l}\text { Wang et al. } .^{15} \mathrm{Li} \text { et al. }{ }^{16} \\
\text { Das et al. }{ }^{17}{ }^{18} \mathrm{Dho} \text { et al } .^{18}\end{array}$ \\
\hline Piezoelectricity & $d_{33}=2500 \mathrm{pC} / \mathrm{N}$ & $\mathrm{PbZn}_{1 / 3} \mathrm{Nb}_{2 / 3} \mathrm{O}_{3}-\mathrm{PbTiO}_{3}$ & Park et al. ${ }^{19}$ \\
\hline Ferromagnetism & $M_{\mathrm{s}}=6.9 \mu_{\mathrm{B}} / \mathrm{Eu}$ & $\mathrm{EuO}$ & Matthias et al. ${ }^{20}$ \\
\hline Colossal magnetoresistance & $\Delta R / R_{\mathrm{H}}>10^{11}(5 \mathrm{~T})$ & $\mathrm{Pr}_{0.7} \mathrm{Sr}_{0.04} \mathrm{Ca}_{0.26} \mathrm{MnO}_{3-\delta}$ & Maignan et al. ${ }^{21}$ \\
\hline Magnetostriction & $\lambda_{100}=-590 \times 10^{-6}$ & $\mathrm{Co}_{0.8} \mathrm{Fe}_{2.2} \mathrm{O}_{4}$ & Bozorth et al. ${ }^{22}$ \\
\hline Faraday effect & $v=4 \times 10^{50} \cdot(\mathrm{T} \cdot \mathrm{cm})^{-1}$ & $\mathrm{EuO}$ & Ahn and Shafer ${ }^{23}$ \\
\hline Spin polarization & $P>98 \%$ & $\mathrm{CrO}_{2}$ & Soulen et al. ${ }^{24}$ Anguelouch et al. ${ }^{25}$ \\
\hline Ferromagnetic & $T_{\mathrm{C}}=105 \mathrm{~K}$ & $\mathrm{BiMnO}_{3}$ & Hill and Rabe, ${ }^{29}$ Moreira dos \\
\hline $\begin{array}{l}\text { and } \\
\text { ferroelectric }\end{array}$ & & & $\begin{array}{l}\text { Santos et al.. }{ }^{28} \text { Sharan } \text { et al., }{ }^{30} \\
\text { Baettig et al. } .^{31}\end{array}$ \\
\hline simultaneously & $T_{\mathrm{C}}=250 \mathrm{~K}$ & $\mathrm{LuFe}_{2} \mathrm{O}_{4}, \mathrm{FeTiO}_{3}$ & Ikeda et al., Fennie ${ }^{27}$ \\
\hline
\end{tabular}

and the ferromagnetic ferroelectric with the highest reported ${ }^{26}$ $\left(\mathrm{LuFe}_{2} \mathrm{O}_{4}\right)$ or predicted ${ }^{27}\left(\mathrm{FeTiO}_{3}\right)$ transition temperature. A challenge with materials that are simultaneously ferromagnetic and ferroelectric is that they are often too conductive for the fabrication of conventional ferroelectric switching devices. The ferromagnetic ferroelectric with the highest transition temperature on which a conventional polarization-electric field hysteresis measurement has been reported is $\mathrm{BiMnO}_{3}(\mathrm{TC} \sim 105 \mathrm{~K}){ }^{28}$

\section{(1) Perovskites}

The crystal structures of the oxides with the outstanding properties listed in Table I are shown in Fig. $1{ }^{32}$ Half of the oxides belong to the same structural family-perovskite. The perovskite $\mathrm{ABO}_{3}$ structure can accommodate with $100 \%$ substitution some 30 elements on the $A$ site and over half the periodic table on the $B$ site, as shown in Fig. $2 .{ }^{33}$ Given the chemical and structural compatibility between many perovskites, this malleable structural host offers an opportunity to customize electronic, magnetic, and optical properties in thin films in ways not possible with conventional semiconductors.

The electroceramics industry currently utilizes the diverse electrical properties of oxides in separate components made primarily by bulk synthesis and thick-film methods for capacitors, sensors, actuators, night vision, and other applications. A significant opportunity exists, however, to combine these

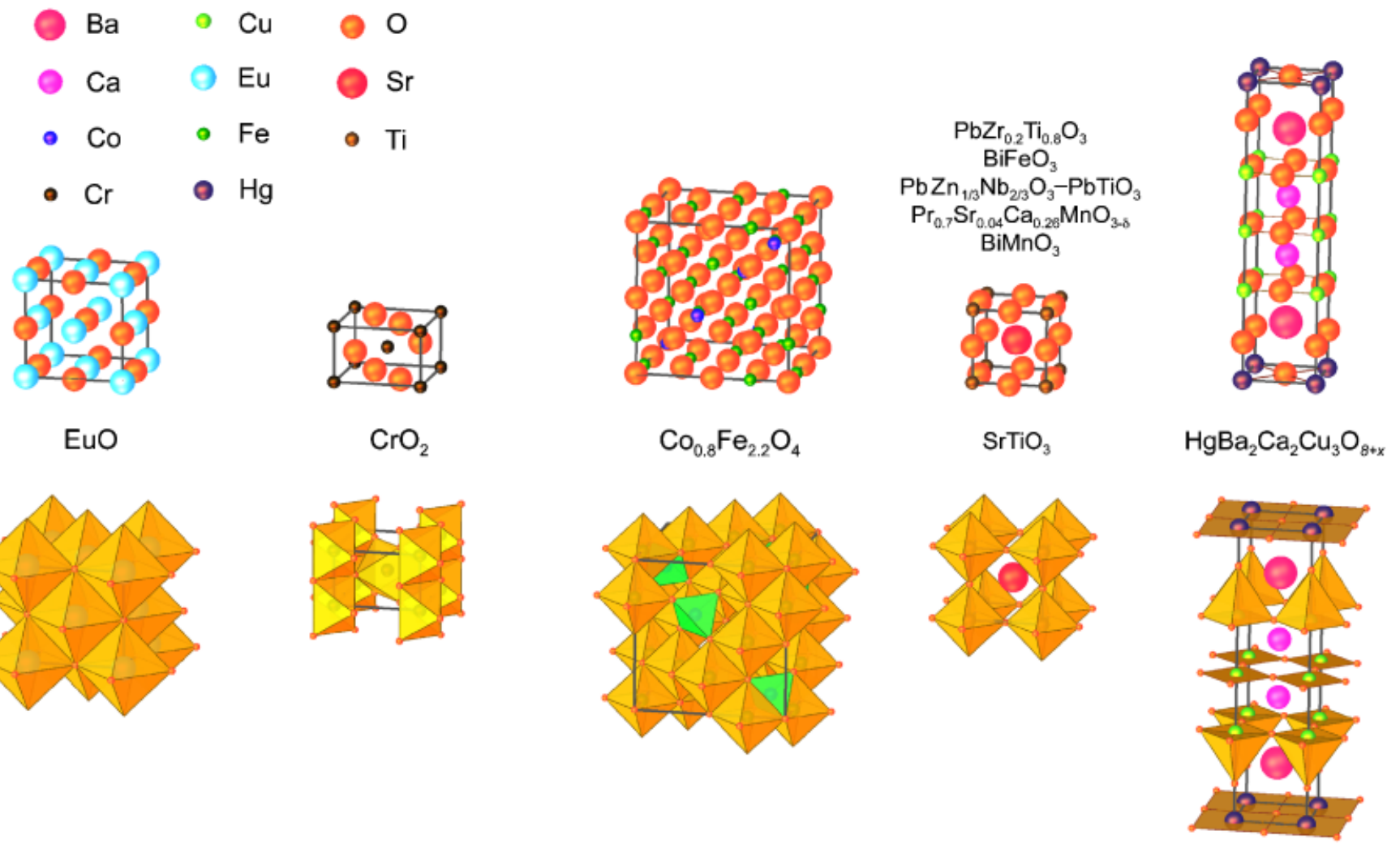

Fig. 1. The crystal structures of the oxides with the exceptional properties described in Table I. Two equivalent representations of these crystal structures are shown: the atomic positions (above) and the coordination polyhedra (below). The oxygen atoms occupy the vertices of the coordination polyhedra. Color is used to distinguish the two types of oxygen coordination polyhedra in $\mathrm{Co}_{0.8} \mathrm{Fe}_{2} \mathrm{O}_{4}$, octahedra (orange), and tetrahedra (green). The pseudocubic subcell of the perovskites $\mathrm{PbZr}_{0.2} \mathrm{Ti}_{0.8} \mathrm{O}_{3}, \mathrm{BiFeO}_{3}, \mathrm{PbZn}_{1 / 3} \mathrm{Nb}_{2 / 3} \mathrm{O}_{3}-\mathrm{PbTiO}_{3}, \mathrm{Pr}_{0.7} \mathrm{Sr}_{0.04} \mathrm{Ca}_{0.26} \mathrm{MnO}_{3-\delta}$, and $\mathrm{BiMnO}_{3}$ is shown for clarity. The relative sizes of the atoms reflect their relative ionic radii as given by Shannon. ${ }^{32}$ 


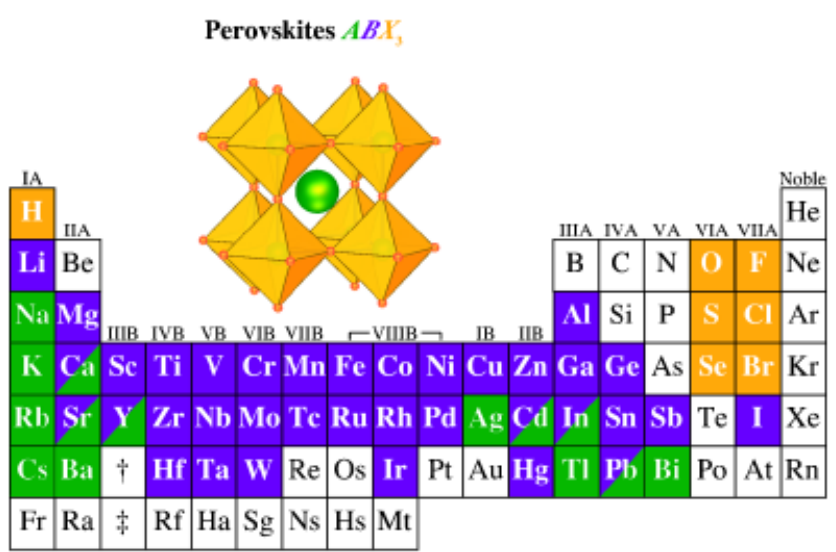

$\dagger$ La Ce Pr No Pm Sm Eu Gd To Dy Ho Er Tm Yb Lu

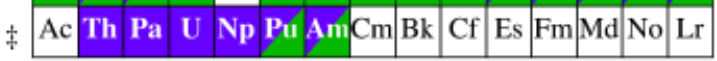

Fig. 2. A compilation of elements of the periodic table that can occupy the three sites $(A, B$, and $X)$ of the perovskite crystal structure with $100 \%$ occupancy (based on the data in Landolt-Boernstein ${ }^{33}$ ).

properties together in oxide heterostructures where multiple properties can be utilized to yield functional integrated devices. Integration of epitaxial stacks of oxide crystals is motivated by the similarity in crystal structure (the perovskite oxides listed in Table I all have perovskite subcell dimensions in the 3.85-4.05 range), the chemical compatibility that exists between many oxides, and the directional dependence of properties that can be optimized for particular applications by controlling the orientation of a single crystalline film. In addition to synthesizing oxide heterostructures that integrate relatively thick layers of different oxides together, new oxides can be engineered at the atomic-layer level. Although now commonplace in the growth of semiconductors, such an ability is relatively new to oxides and makes possible the discovery/engineering of higher performance smart materials by exploiting the exceptional electrical, optical, and magnetic properties of oxides and building a coupling between these properties into oxide heterostructures.

\section{(2) Perovskite-Related Phases}

Structure-property relations have been studied for a great many oxides using solid-state synthesis methods. Many cases have been found where the property of a structurally related family of oxides (i.e., a homologous series) changes drastically from one end to the other of the series. Examples include the $\mathrm{Sr}_{n+1}$ $\mathrm{Ru}_{n} \mathrm{O}_{3 n+1}$ Ruddlesden-Popper homologous series ${ }^{34-36}$ shown in Fig. 3. In this series the positive integer $n$ corresponds to the number of perovskite layers that are sandwiched between double $\mathrm{SrO}$ rock-salt layers. The $n=1\left(\mathrm{Sr}_{2} \mathrm{RuO}_{4}\right)$ member of the series is paramagnetic and at very low temperature $(<1.5 \mathrm{~K})$ superconducting, ${ }^{37}$ whereas the $n=\infty\left(\mathrm{SrRuO}_{3}\right)$ member of the series is ferromagnetic. ${ }^{38}$ The structural change accompanying this drastic change in properties involves going from a corner sharing $\mathrm{RuO}_{6}$ octahedral network that is connected in all three dimensions for the $n=\infty$ member $\left(\mathrm{SrRuO}_{3}\right)$ to the $n=1 \mathrm{mem}-$ ber $\left(\mathrm{Sr}_{2} \mathrm{RuO}_{4}\right)$, where the $\mathrm{RuO}_{6}$ octahedra are only connected in two dimensions and double $\mathrm{SrO}$ layers completely disrupt all corner sharing of the $\mathrm{RuO}_{6}$ octahedra along the $c$-axis. Many other equally fascinating homologous series exist in perovskiterelated oxide structures showing interesting variation in ferromagnetic, ferroelectric, superconducting, and metal-insulator behavior.

An example of an important ferroelectric homologous series is the Aurivillius homologous series with general formula $\mathrm{Bi}_{2} \mathrm{O}_{2}\left(A_{n-1} B_{n} \mathrm{O}_{3 n+1}\right)$ shown in Fig. 4. Here again the positive integer $n$ denotes the number of perovskite layers that in this

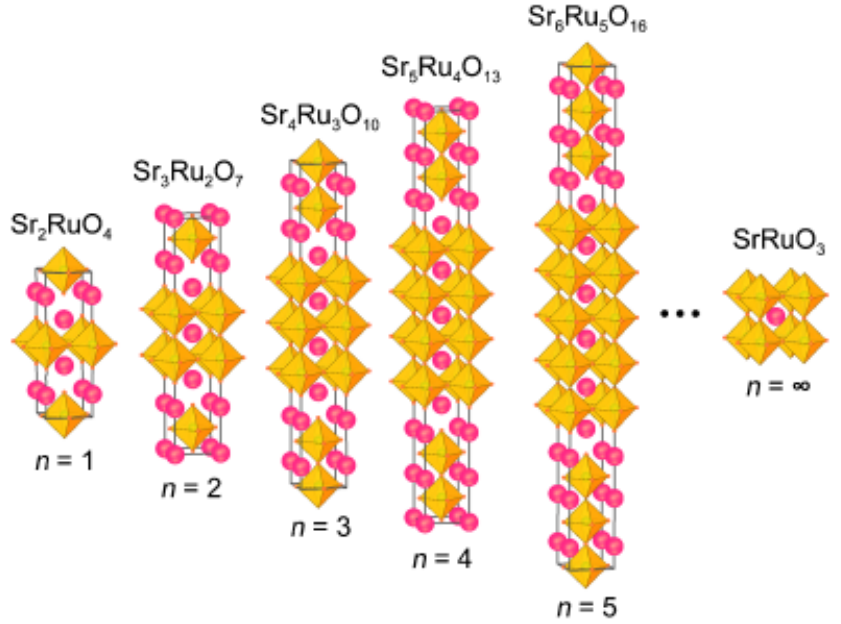

Fig. 3. The $n=1 \quad\left(\mathrm{Sr}_{2} \mathrm{RuO}_{4}\right), n=2\left(\mathrm{Sr}_{3} \mathrm{Ru}_{2} \mathrm{O}_{7}\right), n=3\left(\mathrm{Sr}_{4} \mathrm{Ru}_{3} \mathrm{O}_{10}\right)$, $n=4\left(\mathrm{Sr}_{5} \mathrm{Ru}_{4} \mathrm{O}_{13}\right), n=5\left(\mathrm{Sr}_{6} \mathrm{Ru}_{5} \mathrm{O}_{16}\right)$, and $n=\infty\left(\mathrm{SrRuO}_{3}\right)$ members of the homologous Ruddlesden-Popper series of compounds $\mathrm{Sr}_{n+1} \mathrm{Ru}_{n} \mathrm{O}_{3 n+1}$. $\mathrm{Ru}^{4+}$ lie at the center of oxygen coordination polyhedra (octahedra). The filled circles represent $\mathrm{Sr}^{2+}$ ions (reprinted from Haeni et al., ${ }^{80}$ with permission; (C)2001 American Institute of Physics).

case are sandwiched between $\mathrm{Bi}_{2} \mathrm{O}_{2}$ layers. The structures shown include the layered $n=2$ Aurivillius compound $\mathrm{SrBi}_{2} \mathrm{Ta}_{2} \mathrm{O}_{9}$ widely used in ferroelectric random access memories (FeRAM). ${ }^{39}$ Over 500 million FeRAM chips containing either $\mathrm{SrBi}_{2} \mathrm{Ta}_{2} \mathrm{O}_{9}$ or $\mathrm{Pb}(\mathrm{Zr}, \mathrm{Ti}) \mathrm{O}_{3}$ ferroelectrics have been made and worldwide production currently exceeds 70 million units per year. ${ }^{40}$ Also included in Fig. 4 is an $n=6$ Aurivillius compound $\mathrm{Bi}_{7}(\mathrm{Mn}, \mathrm{Ti})_{6} \mathrm{O}_{21}$ into which the ferromagnetic perovskite $\mathrm{BiMnO}_{3}$ has been inserted, ${ }^{41}$ and at the end of the series is the $n=\infty$ three-dimensional perovskite structure.

When one desires to study the change in a property that occurs as $n$ is varied in detail, however, solid-state synthesis methods often fall short. Invariably researchers have only been able to find conditions of temperature and pressure yielding singlephase products for low values of $n$ and for $n=\infty$. Attempts to make intermediate $n$ values result in uncontrolled intergrowths. ${ }^{13,41-72}$ Calculation of the energy of formation of several homologous series of layered oxide phases indicates the reason for this difficulty-differences in formation energy become smaller and smaller as $n$ increases. ${ }^{73,74}$ Thus, apart from theoretical calculations, little is known about how the properties of a series of structures vary with $n$ as the dimensionality of the structure changes. Because of correlated electron effects in many

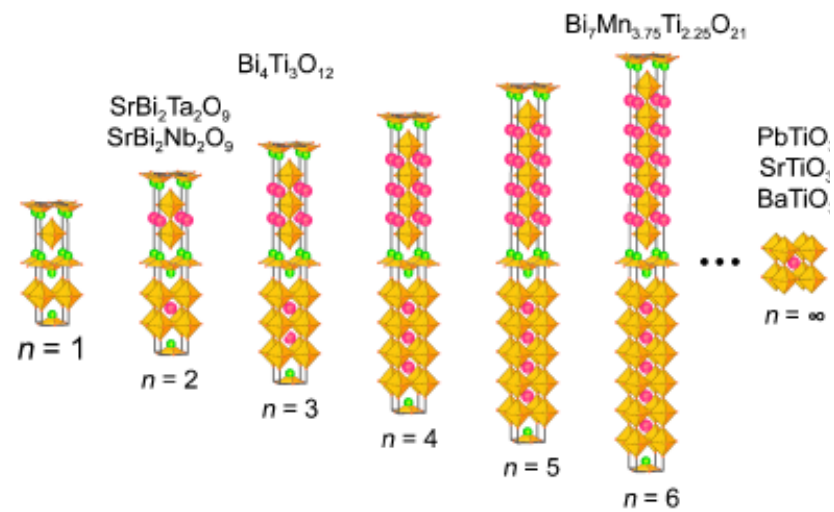

Fig. 4. Examples of the $n=1, n=2\left(\mathrm{SrBi}_{2} \mathrm{Ta}_{2} \mathrm{O}_{9}, \mathrm{SrBi}_{2} \mathrm{Nb}_{2} \mathrm{O}_{9}\right), n=3$ $\left(\mathrm{Bi}_{4} \mathrm{Ti}_{3} \mathrm{O}_{12}\right), n=4, n=5$, and $n=\infty\left(\mathrm{PbTiO}_{3}, \mathrm{SrTiO}_{3}\right.$, and $\left.\mathrm{BaTiO}_{3}\right)$ members of the Aurivillius homologous series of compounds with general formula $\mathrm{Bi}_{2} \mathrm{O}_{2}\left(A_{n-1} B_{n} \mathrm{O}_{3 n+1}\right)$. $B$ ions lie at the center of the oxygen coordination polyhedra (octahedra). The filled circles represent $A$ ions. These structures consist of alternating sheets of $\mathrm{Bi}_{2} \mathrm{O}_{2}$ and $n A B \mathrm{O}_{3}$ perovskite layers. 
homologous series of interest, experimental measurements are an important part of understanding the effect of dimensionality on these oxides. ${ }^{75}$

A key advantage of the use of thin film techniques for the preparation of oxide heterostructures is that single-phase epitaxial films with intermediate $n$ values can often be synthesized even though nearby phases have similar formation energies. ${ }^{76-80}$ This is made possible by the ability to supply incident species in any desired sequence with submonolayer composition control. A particular phase can often be grown by supplying the constituents in an ordered sequence corresponding to the atomic arrangement of these constituents in the desired phase.

\section{Synthesis of Epitaxial Oxide Films by Pulsed-Laser Deposition (PLD) and Molecular-Beam Epitaxy (MBE)}

Significant advances in deposition technologies and substrates over the past two decades have enabled the growth of oxide thin films with high structural perfection and the ability to customize oxide layering down to the atomic layer level. These advances were spurred by the discovery of high-temperature superconductivity over 20 years ago. ${ }^{81,82}$ Existing thin film deposition techniques were rapidly adapted to the challenges of functional oxides, including PLD, ${ }^{83-88}$ high-pressure ${ }^{89-94}$ and off-axis sputtering, ${ }^{95-102}$ reactive coevaporation, ${ }^{103-105}$ and reactive MBE. ${ }^{76,106-114}$ These physical vapor deposition techniques yielded high-quality oxide superconductor films just a few nanometers in thickness, ${ }^{115-117}$ superlattices of superconducting oxides with atomic-scale thickness control and abrupt interfaces, ${ }^{110,118-126}$ and the construction of new oxide superconducting phases with atomic layer precision. ${ }^{76,127}$ Chemical techniques including metal-organic chemical vapor deposition (MOCVD) $)^{128-143}$ and chemical solution deposition (CSD) ${ }^{144-148}$ have also been adapted and applied to functional oxides, particularly ferroelectrics. In recent years, a growing cadre of researchers has applied these physical and chemical techniques with increasing precision to the growth of an ever-broadening set of functional oxide materials. Relevant achievements include the synthesis of oxide superlattices with atomic-scale thickness control and abrupt interfaces ${ }^{79,113,117,149-157}$ and the synthesis of metastable oxides. $^{76,158-161}$ These advances in thin film deposition technology have made it possible to customize oxide heterostructures with subnanometer precision.

\section{(1) PLD}

The PLD technique is ideally suited to the rapid investigation of multicomponent functional oxides because it (1) allows them to be grown in a relatively compact and inexpensive chamber, (2) provides nearly stoichiometric composition transfer from the target to the sample if the growth conditions are optimized, (3) is compatible with oxidant pressures ranging from ultra-high vacuum (UHV) to atmospheric, (4) is amenable to the growth of superlattices with nanometer precision, ${ }^{126,150,152-155}$ and (5) is capable of ablating a wide variety of materials. ${ }^{86,162-165}$

A schematic of a PLD system is shown in Fig. 5. The process amounts to flash evaporation of the surface of a multicomponent target. Its key elements are an UV laser capable of vaporizing the surface layer of the multicomponent target when suitably focused down to a high energy density (fluence) by a lens. The vaporized material, containing a variety of atomic, molecular, and excited species, is transported through the low vacuum environment (typically 100 mTorr of $\mathrm{O}_{2}$ ) where it condenses on the substrate. If the substrate presents a suitable template for the depositing species, epitaxial growth can occur in which the deposited species follow the crystalline template of the substrate to extend the crystal.

A schematic showing how the presence of a substrate may influence the crystallization of a multicomponent mixture of depositing species is shown in Fig. $6 .{ }^{166}$ In the example shown, the growth of $\mathrm{SrBi}_{2} \mathrm{Nb}_{2} \mathrm{O}_{9}$ (or equivalently $\mathrm{SrBi}_{2} \mathrm{Ta}_{2} \mathrm{O}_{9}$ ) on $\mathrm{SrTiO}_{3}$, the film and substrate have different chemistries and crystal

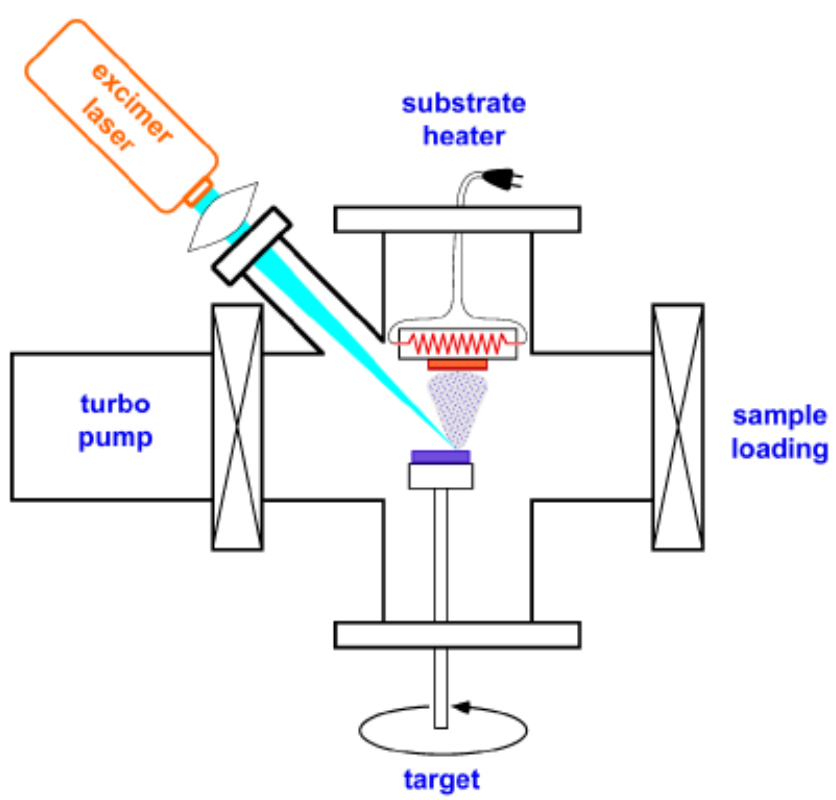

Fig.5. A schematic diagram of a pulsed-laser deposition system dedicated to the controlled synthesis of oxide heterostructures. The key components are the UV laser whose output is focused by a lens to a sufficient fluence to vaporize the surface of the multicomponent oxide target. The vaporized material from the target is deposited on the heated substrate to form an epitaxial film. For the deposition of multilayers, a multiple-target carousel is used.

structures, yet just like the game Tetris ${ }^{\mathrm{TM}}$ the depositing atoms find low-energy configuration(s) to extend the single-crystal substrate into an epitaxial overlayer. In Fig. 6(a) the lowenergy configuration is unique and the resulting epitaxial film is single crystalline with an orientation relationship (001) $\mathrm{SrBi}_{2} \mathrm{Nb}_{2} \mathrm{O}_{9} \|(001) \quad \mathrm{SrTiO}_{3}$ and [100] $\mathrm{SrBi}_{2} \mathrm{Nb}_{2} \mathrm{O}_{9} \| \quad[1 \overline{1} 0]$ $\mathrm{SrTiO}_{3}{ }^{+\ddagger}, 167$ In the other two cases, Figs. 6(b) and (c), several energetically degenerate low-energy configurations exist, leading to an epitaxial film with two or three types of domains related to each other via $180^{\circ}$ or $120^{\circ}$ rotational twinning, respectively. In Fig. 6(b) the (110) $\mathrm{SrTiO}_{3}$ surface is shown faceted as has been observed to occur at the growth conditions for $\mathrm{SrBi}_{2} \mathrm{Nb}_{2} \mathrm{O}_{9}$ films. ${ }^{168}$ Thus, the epitaxy is actually occurring locally on the (100) and (010) faces of the faceted (110) $\mathrm{SrTiO}_{3}$ substrate as has also been reported for the growth of epitaxial films of other perovskite-related phases on (110) $\mathrm{SrTiO}_{3} \cdot{ }^{169-171}$ The orientation relationship for Fig. 6(b) is $\sim(116) \mathrm{SrBi}_{2} \mathrm{Nb}_{2} \mathrm{O}_{9} \|(110)$ $\mathrm{SrTiO}_{3}$ and (i) [001] $\mathrm{SrBi}_{2} \mathrm{Nb}_{2} \mathrm{O}_{9} \|[100] \mathrm{SrTiO}_{3}$ and (ii) [001] $\mathrm{SrBi}_{2} \mathrm{Nb}_{2} \mathrm{O}_{9} \|[010] \mathrm{SrTiO}_{3}$ for the two growth twins. ${ }^{\ddagger, 168}$ For Fig. 6(c) the orientation relationship is (103) $\mathrm{SrBi}_{2} \mathrm{Nb}_{2} \mathrm{O}_{9} \|(111)$ $\mathrm{SrTiO}_{3}$ and approximately (i) [001] $\mathrm{SrBi}_{2} \mathrm{Nb}_{2} \mathrm{O}_{9} \|[100] \mathrm{SrTiO}_{3}$, (ii) [001] $\mathrm{SrBi}_{2} \mathrm{Nb}_{2} \mathrm{O}_{9} \|[010] \mathrm{SrTiO}_{3}$, and (iii) [001] $\mathrm{SrBi}_{2}$ $\mathrm{Nb}_{2} \mathrm{O}_{9} \|[001] \mathrm{SrTiO}_{3}$ for the three growth twins. ${ }^{\ddagger 1}, 172,173$ For clarity, another view of the threefold degenerate epitaxial relationship of the growth of $\mathrm{SrBi}_{2} \mathrm{Nb}_{2} \mathrm{O}_{9}$ on (111) $\mathrm{SrTiO}_{3}$ is shown in Fig. 6(d), where it can be more clearly seen that the three possibilities for the orientation of the $c$-axis of the $\mathrm{SrBi}_{2} \mathrm{Nb}_{2} \mathrm{O}_{9}$ lie approximately parallel to the $\langle 100\rangle$ axes of the $\mathrm{SrTiO}_{3}$ substrate.

The chief advantages of PLD are its relatively modest cost and, after optimization of the growth conditions, the nearly faithful composition transfer from target to substrate, which allows a single multicomponent target with the same composition as the desired film to be used, ${ }^{86,162-165}$ alleviating the need for accurate composition control. PLD offers an extremely

\footnotetext{
${ }^{7}$ In addition to the $h k l \mathrm{SrBi}_{2} \mathrm{Nb}_{2} \mathrm{O}_{9}$ indices given, $k h l \mathrm{SrBi}_{2} \mathrm{Nb}_{2} \mathrm{O}_{9}$ indices are also implied. The latter indices are omitted for clarity, but arise because of transformation twinning
that occurs on cooling as the tetragonal $\mathrm{SrBi}_{2} \mathrm{Nb}_{2} \mathrm{O}_{9}$ (the stable polymorph at growth temperature) goes through a phase transition where it becomes orthorhombic at room temperature with $a \approx b$ and $a$ being the axis of the ferroelectric along which the spontaneous polarization exists.
} 


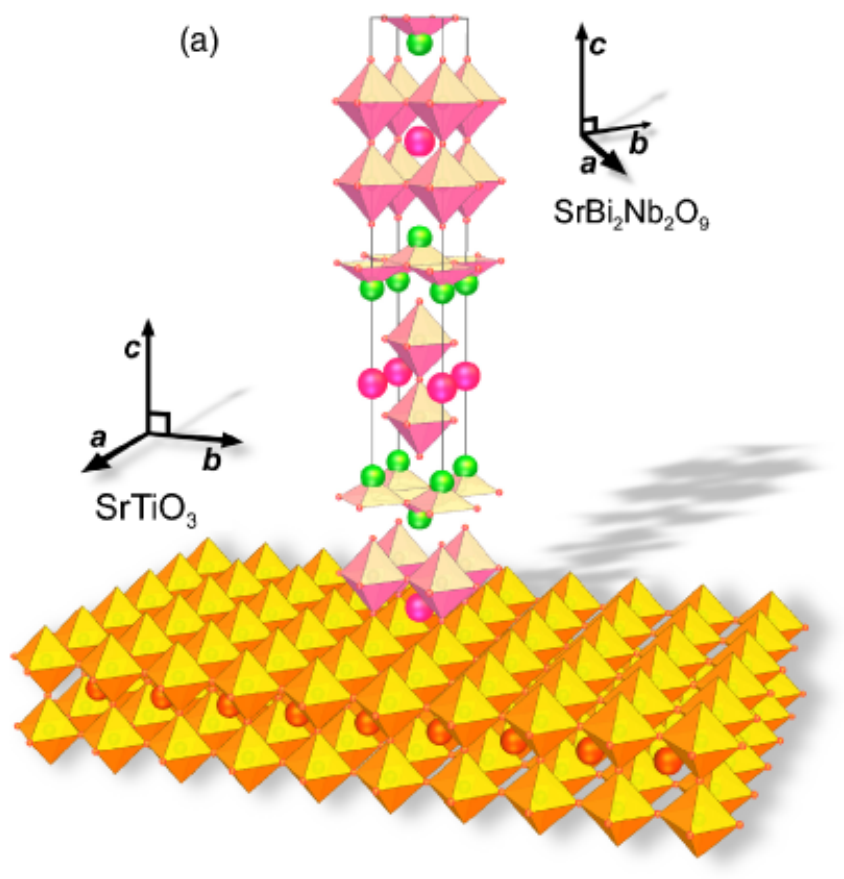

(c)

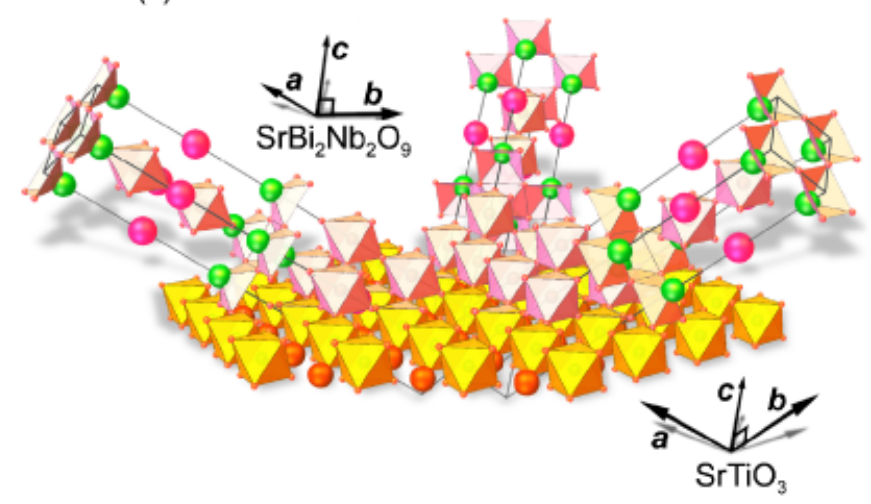

(b)
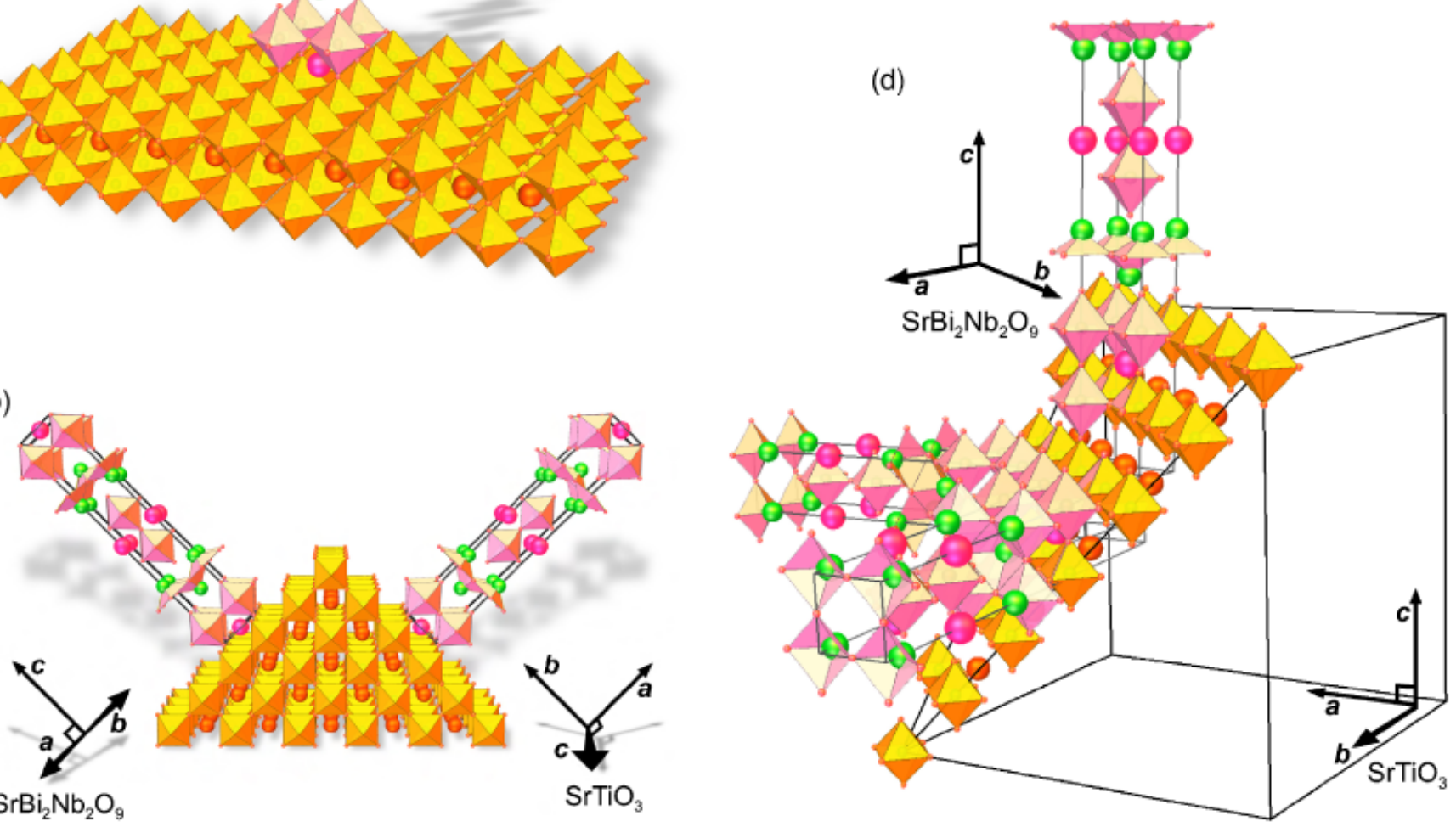

Fig. 6. The crystal structure and orientation of $\mathrm{SrBi}_{2} \mathrm{Nb}_{2} \mathrm{O}_{9}$ (or equivalently $\mathrm{SrBi}_{2} \mathrm{Ta}_{2} \mathrm{O}_{9}$ ) grown on (a) (001) $\mathrm{SrTiO}_{3}$, (b) (110) $\mathrm{SrTiO}_{3}$, and (c) (111) $\mathrm{SrTiO}_{3}$, showing the low-energy epitaxial orientation relationship(s). Another view of the threefold degenerate epitaxial relationship of $\mathrm{SrBi}_{2} \mathrm{Nb}_{2} \mathrm{O}_{9}$ on (111) $\mathrm{SrTiO}_{3}$ is shown in (d) for clarity (reprinted from Lettieri et al., ${ }^{172}$ with permission; (C) 2000 American Institute of $\mathrm{Physics}$. $\mathrm{SrBi}_{2} \mathrm{Nb}_{2} \mathrm{O}_{9}$ and $\mathrm{SrBi}_{2} \mathrm{Ta}_{2} \mathrm{O}_{9}$ grow epitaxially on (001) $\mathrm{SrTiO}_{3}$ with the $c$-axis parallel to the substrate surface normal, on (110) $\mathrm{SrTiO}_{3}$ in a twofold twin structure with the $c$-axes tilted by $\pm 45^{\circ}$ from the surface normal, and on (111) $\mathrm{SrTiO}_{3}$ in a threefold twin structure with the $c$ axes tilted by $57^{\circ}$ away from the surface normal. The $\mathrm{SrBi}_{2} \mathrm{Nb}_{2} \mathrm{O}_{9}$ is drawn and its unit cell is outlined in its tetragonal state above its Curie temperature $\left(\sim 430^{\circ} \mathrm{C}\right.$, Landolt-Boernstein $\left.{ }^{166}\right)$. Note that the growth temperature is well above the Curie temperature of $\mathrm{SrBi}_{2} \mathrm{Nb}_{2} \mathrm{O}_{9}$, and so the crystallography shown is relevant during nucleation and growth of the epitaxial film. After cooling through the Curie temperature, each of the growth twins shown is twinned further due to $a-b$ twinning, leading to a doubling of the expected twin states at room temperature. The orthorhombic axes of only one of the twin variants of the $\mathrm{SrBi}_{2} \mathrm{Nb}_{2} \mathrm{O}_{9}$ films are drawn.

powerful means of scouting for materials with promising properties by enabling the rapid preparation of new materials in epitaxial form: thin single crystalline extensions of the underlying crystalline template provided by the substrate. Its key disadvantages are the micrometer-sized "boulders" common to PLD films ${ }^{86,162-165}$ as well as the energetic species present, which can lead to interlayer mixing and extended lattice constants due to ion bombardment effects. ${ }^{174-179}$ Stating that PLD provides stoichiometric composition transfer from target to substrate is an oversimplification. Careful studies have shown that only with careful tuning of deposition parameters (chamber pressure, laser fluence, target-substrate distance, etc.) can films with composition near to that of the target be attained. ${ }^{178}$

Techniques that can be used during film deposition to provide information on the nucleation and growth mechanisms in real time, rather than relying on "pathology" after the growth, are extremely useful for improving the quality of oxide thin films. Reflection high-energy electron diffraction (RHEED) is particularly useful in this context. Differential pumping has enabled RHEED to be used at the relatively high pressures of PLD ${ }^{180,181}$ leading to tremendous improvements in the ability to tailor oxides at the atomic level. Because of the many possible phases and phase transitions in functional oxide systems, such in situ analytical tools that increase our understanding of the growth process and allow the growth conditions to be adjusted during growth are crucial to achieving improvements in the atomic layer engineering of oxides.

\section{(2) Oxide $\mathrm{MBE}$}

The MBE method of thin film growth may be thought of as atomic spray painting, as shown in Fig. 7 in which an oxide 

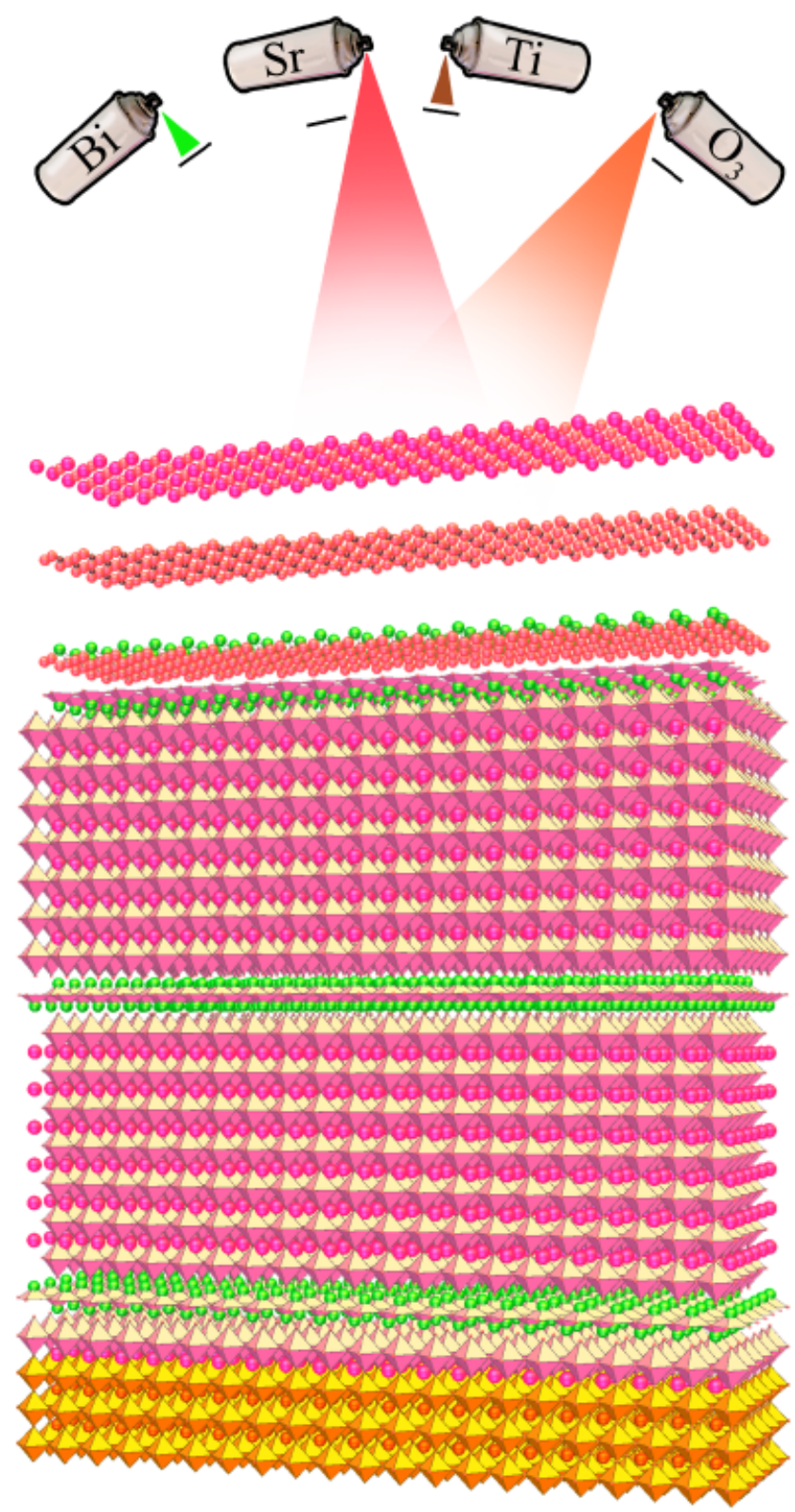

Fig. 7. A highly schematic representation of the molecular-beam epitaxy (MBE) growth of a (001) $\mathrm{Sr}_{4} \mathrm{Bi}_{4} \mathrm{Ti}_{7} \mathrm{O}_{24}$ film on a (001) $\mathrm{LaAlO}_{3}$ $\mathrm{Sr}_{2} \mathrm{AlTaO}_{6}$ (LSAT) substrate by reactive MBE.

ferroelectric structure, e.g., $\mathrm{Sr}_{4} \mathrm{Bi}_{4} \mathrm{Ti}_{7} \mathrm{O}_{24}$ (an $n=7$ Aurivillius phase) is schematically assembled layer by layer. The flux of spray from each atomic or molecular beam is controlled by the temperature (and thus vapor pressure) of the effusion cell in which each species is contained. The duration of spray is individually controlled for each beam by shutters, which control not only the open time (and thus dose), but also the sequence in which species reach the growth surface. By controlling the shutters and temperature of the evaporant (which control dose and flux, respectively), the layering sequence of the desired structure can be customized. This technique is capable of controlling the layering of oxides on a unit cell level. ${ }^{76-80,110,113,117,119,124,157} \mathrm{~A}$ low growth temperature is frequently used to kinetically minimize subsequent bulk reordering and to minimize the loss of the customized (and often metastable) layered structures. The huge difference between surface and bulk diffusion rates in oxides $^{182,183}$ enables the growth of films with excellent structural order while at the same time preserving the potentially metastable layering of an oxide superlattice.

$\mathrm{MBE}$ is a vacuum deposition method in which well-defined thermal beams of atoms or molecules react at a crystalline surface to produce an epitaxial film. It was originally developed for the growth of $\mathrm{GaAs}$ and $(\mathrm{Al}, \mathrm{Ga}) \mathrm{As},{ }^{184}$ but due to its unparalleled ability to control layering at the monolayer level and compatibility with surface-science techniques to monitor the growth process as it occurs, its use has expanded to other semiconductors as well as metals and insulators. ${ }^{185,186}$ Epitaxial growth, a clean UHV deposition environment, in situ characterization during growth, and the notable absence of highly energetic species are characteristics that distinguish MBE from other thin film methods used to prepare functional oxide thin films. These capabilities are key to the precise customization of oxide heterostructures at the atomic layer level. MBE is traditionally performed in UHV chambers to avoid impurities. In addition to molecular beams emanating from heated crucibles containing individual elements, molecular beams of gases may also be introduced, for example to form oxides or nitrides. This variant of MBE is known as "reactive MBE" 187 in analogy to its similarity to "reactive evaporation," which takes place at higher pressures where well-defined molecular beams are absent. Reactive evaporation has also been extensively used to grow functional oxide films, ${ }^{188}$ but here we limit our discussion to reactive MBE.

$\mathrm{MBE}$ has enjoyed significant success in the preparation of semiconductor microstructures with nanoscale thickness control and exceptional device characteristics. Examples of the thickness control achieved in semiconductors include interspersing layers as thin as one monolayer $(0.28 \mathrm{~nm})$ of AlAs at controlled locations into a GaAs film ${ }^{189}$ and alternating monolayers of GaAs and AlAs to make a one-dimensional superlattice. ${ }^{190}$ This nanoscale control has enabled tremendous flexibility in the design, optimization, and manufacturing of new devices, especially those making use of quantum effects. ${ }^{191}$

The use of MBE to grow functional oxides dates back to 1985, when it was used to grow $\mathrm{LiNbO}_{3}$ films. ${ }^{192,193}$ Since that time it has been used to grow the oxide superconductors $(\mathrm{Ba}, \mathrm{K}) \mathrm{BiO}_{3}, \quad(\mathrm{Ba}, \mathrm{Rb}) \mathrm{BiO}_{3}, \quad(\mathrm{La}, \mathrm{Sr})_{2} \mathrm{CuO}_{4}, \quad \mathrm{YBa}_{2} \mathrm{Cu}_{3} \mathrm{O}_{7-\delta}$, $\mathrm{NdBa}_{2} \mathrm{Cu}_{3} \mathrm{O}_{7-\delta}, \quad \mathrm{SmBa}_{2} \mathrm{Cu}_{3} \mathrm{O}_{7-\delta}, \quad \mathrm{DyBa}_{2} \mathrm{Cu}_{3} \mathrm{O}_{7-\delta}, \quad$ and $\mathrm{Bi}_{2} \mathrm{Sr}_{2} \mathrm{Ca}_{n-1} \mathrm{Cu}_{n} \mathrm{O}_{2 n+4}$ for $n=1-11^{76,110,117,119}$; the oxide ferroelectrics $\mathrm{LiNbO}_{3},{ }^{192-195} \mathrm{LiTaO}_{3},{ }^{194} \mathrm{BaTiO}_{3},{ }^{79,196-205}$ $\mathrm{PbTiO}_{3}{ }^{79,112,206}$ and $\mathrm{Bi}_{4} \mathrm{Ti}_{3} \mathrm{O}_{12}{ }^{79,207,208}$; the incipient ferroelectric $\mathrm{SrTiO}_{3}{ }^{79,114,197,198,204,209-218}$; the ferromagnets $(\mathrm{La}, \mathrm{Ca}) \mathrm{MnO}_{3},{ }^{219,220}(\mathrm{La}, \mathrm{Sr}) \mathrm{MnO}_{3},{ }^{219,221}$ and $\mathrm{EuO}^{222-227}$; the ferrimagnet $\mathrm{Fe}_{3} \mathrm{O}_{4}{ }^{228}$; the magnetoelectric $\mathrm{Cr}_{2} \mathrm{O}_{3}{ }^{228}$; the multiferroics $\mathrm{BiFeO}_{3}{ }^{229-231}$ and $\mathrm{YMnO}_{3}{ }^{232,233}$; and superlattices of these phases. ${ }^{4-7,76,79,110,119,124,157,199,234-237}$ Although the use of MBE to grow functional oxides is much less mature than its use for compound semiconductors, examples included in this article show how the layering capabilities of MBE can control the composition profile of multicomponent functional oxides along the growth direction with subnanometer precision. This capability is relevant to the fabrication of epitaxial device structures and to the nanoengineering of new functional materials.

The configuration of an MBE system for the growth of ferroelectric oxides differs in several important ways from today's more conventional MBE systems designed for the growth of semiconductors. The major differences are the required presence of an oxidant species, more stringent composition control, and to have adequate pumping to handle the oxidant gas load.

A schematic diagram of the growth chamber of an $\mathrm{MBE}$ system used in the growth of functional oxides is shown in Fig. 8. The particular example shown is a Veeco 930 (Veeco Compound Semiconductor Inc., MBE Operations, St. Paul, MN). A single-crystal substrate, heated to the desired growth temperature, is located near the center of the MBE growth chamber. Aimed at the substrate are molecular beams of the constituent elements of the functional oxide to be grown. Each molecular beam is created by a separate effusion cell, each at a different temperature to provide the desired flux of the particular element contained in a crucible within each effusion cell. Elements are used because multicomponent mixtures (especially oxides) rarely evaporate congruently. ${ }^{238,239}$ In such 

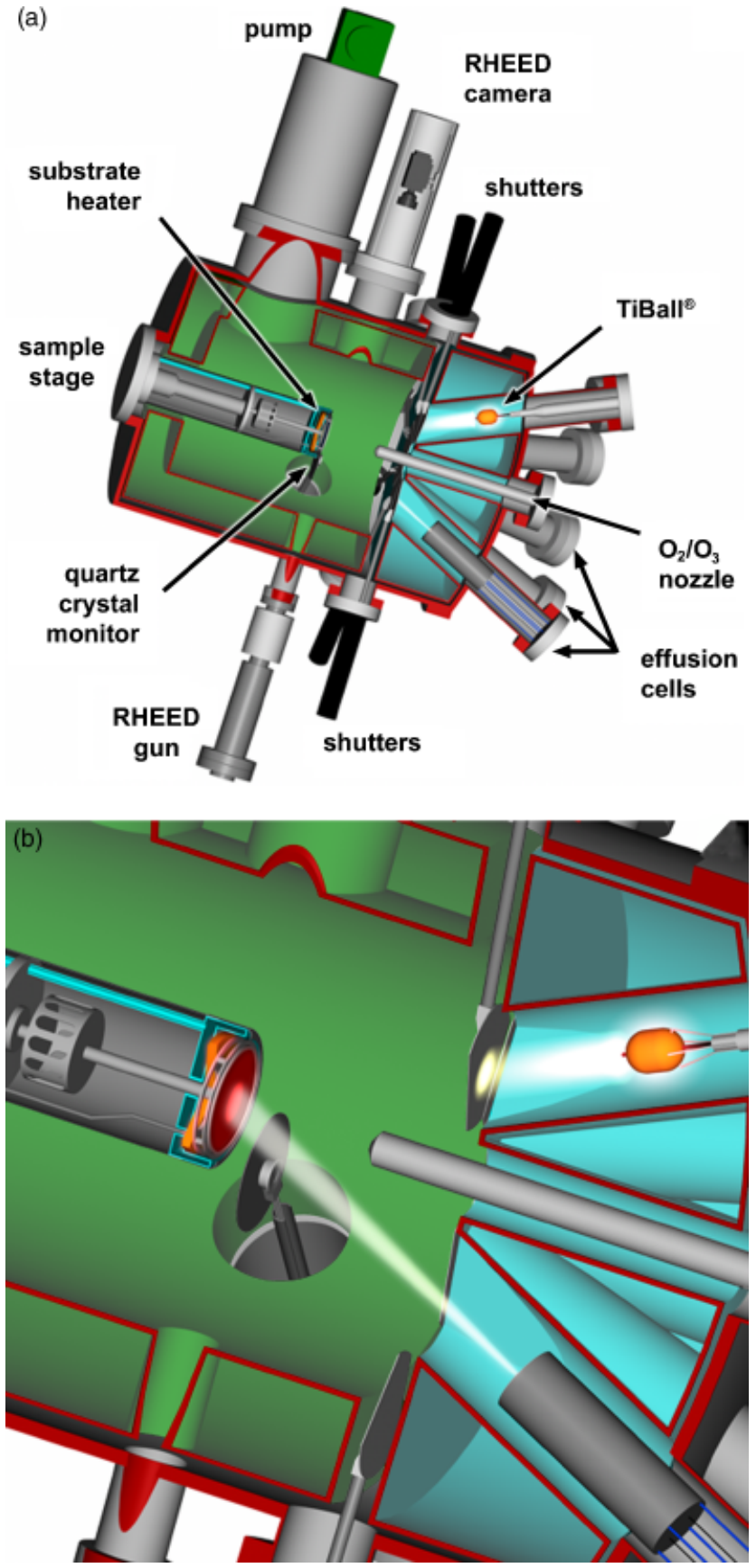

Fig. 8. A schematic diagram of the growth chamber of a molecularbeam epitaxy (MBE) system for the growth of multicomponent oxides. The growth chamber contains molecular beams (emanating from elemental sources), shutters, and ozone distillation and introduction, along with in situ characterization by reflection high-energy electron diffraction (RHEED), real-time spectroscopic ellipsometry (RTSE), mass spectrometry, quartz crystal microbalance $(\mathrm{QCM})$, and atomic absorption spectroscopy (AA). The MBE geometry shown corresponds to a Veeco 930.

cases of incongruent evaporation, where the composition of the evaporant is not the same as its source, the composition of the source changes over time, resulting in a change in the absolute fluxes and relative concentrations of the species emitted from it. This would lead to serious composition-control issues. This problem is avoided by using elemental sources. An additional advantage of elemental sources is the completely independent control of the sequence in which the molecular beams of the elemental constituents are supplied to the substrate. The molecular beams impinge upon the substrate unless they are blocked by shutters. These shutters, which are positioned at the output end of each effusion cell, are controlled by a computer, which enables the elemental fluxes to be supplied to the substrate either at the same time (codeposition) or separately (sequential deposition). Because of the long mean free path inherent to MBE, the shutters do not need to seal tightly. Rather they only need to block the line-of-sight transfer of atoms or molecules from the source to the substrate. The chamber walls are kept cool to impede species that collide with the walls from ever reaching the substrate; ideally only the species in the molecular beams emanating from the sources with open shutters ever reach the substrate.

To oxidize the elemental species reaching the substrate to form the desired functional oxide, a molecular beam of oxidant is used. The tolerable pressure of this oxidant is limited so as not to destroy the long mean free path necessary for MBE. The maximum pressure depends on the MBE geometry, the element to be oxidized, and the oxidant species used, but oxidant pressures less than about $10^{-4}$ Torr are typically required for MBE. ${ }^{76}$ While molecular oxygen has been used for the growth

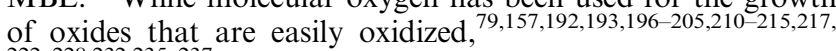
222-228,232,235-237 oxidants with higher activity are needed for the growth of ferroelectrics containing species that are more difficult to oxidize, e.g., bismuth-, lead-, or copper-containing oxides. For this purpose, purified ozone ${ }^{4-7,76,99,110,112,114,117,119,203,206}$ $209,216,218,230,231,234$ or plasma sources ${ }^{194,195,199,200,228,229,233}$ have been successfully used.

Inadequate composition control has been a major problem for previous oxide MBE work, ${ }^{76}$ and the success and improvement of MBE for the controlled growth of multicomponent functional oxides is crucially dependent on accurate composition control. The use of atomic absorption spectroscopy (AA) for oxide MBE composition control has allowed fluxes to be measured with an accuracy of better than $1 \%{ }^{240}$ The MBE system shown in Fig. 8 also contains a retractable quartz crystal microbalance to provide an absolute in situ flux measurement at the position of the wafer (before growth) for calibration of the fluxes before or after growth and calibration of the AA signals. The depositing fluxes of all the sources can be simultaneously monitored during growth by AA. The measured AA signal is fed into the MBE computer control system, which integrates the AA fluxes and closes the appropriate shutters after the desired dose has been delivered to the substrate. In addition, modern oxide MBE systems also contain features found in semiconductor MBE systems: in situ RHEED, mass spectrometry, load-locked wafer introduction, real-time spectroscopic ellipsometry, ${ }^{241}$ substrate temperature measurement systems that utilize the temperature dependence of the bandgap of oxide substrates, ${ }^{230,231,242,243}$ multibeam optical stress sensors (wafer curvature measurements to quantify film strain), ${ }^{244,245}$ time-of-flight ion scattering and recoil spectroscopy, ${ }^{246}$ and even low-energy electron microscopy. ${ }^{246}$

RHEED is widely used in MBE for the in situ characterization of the growing surface. The sensitivity of this grazing angle diffraction technique to surface structure is ideal for monitoring the evolution of growth from initial nucleation to the deposition of each subsequent layer. The formation of intermediate reaction products or impurity phases can be readily monitored and the growth conditions adjusted during growth accordingly.

The multielement deposition control, growth flexibility, and in situ monitoring advantages of MBE are well suited to the growth of multicomponent functional oxides that cannot be produced in single-phase form by bulk techniques, including the customized growth of new metastable materials, and heterostructures containing these phases. Other deposition techniques, in particular PLD, are, from an economic and process simplicity perspective, generally better suited than MBE to the synthesis of heterostructures made up of phases, each of which can be produced by bulk techniques in single-phase form (i.e., where the formation energy of each phase is sufficiently favored over other phases that could accommodate its composition).

\section{Orientation Control}

Except for the most trivial properties (e.g., density), functional properties depend in general on direction. Because of this there 
exist in general optimal orientations for an epitaxial oxide film for any particular application. This might be the ones that align the spontaneous polarization of a ferroelectric material with the direction of the applied electric field from the electrodes that surround it to maximize the switchable polarization. Or it might be orientation that minimize the temperature variation of the resonant frequency of a piezoelectric oscillator. Whatever the application, the ability to control the orientation of the epitaxial film through the choice of substrate, its orientation (see, e.g., Fig. 6), and the growth conditions is a key advantage of epitaxial growth. ${ }^{172,247-253}$ Orientation control is vital to the preparation of samples suitable for establishing the intrinsic properties of materials, especially those that cannot be prepared as bulk single crystals due to their metastability, high melting temperatures, or phase transitions that occur on cooling. When it comes to applications, techniques that can improve the functional properties of oxide films by controlling film texture through epitaxial growth on a grain-by-grain basis (local epitaxy) are also utilized, e.g., ion-beam-assisted deposition $^{254,255}$ and rolling-assisted biaxially textured substrates ${ }^{256,257}$ for the growth of $\mathrm{YBa}_{2} \mathrm{Cu}_{3} \mathrm{O}_{7}$ superconducting cables ${ }^{258}$ as well as $\mathrm{Pb}(\mathrm{Zr}, \mathrm{Ti}) \mathrm{O}_{3}$ in FeRAMs. ${ }^{259}$

\section{Integration of Oxides}

\section{(1) Substrates and Substrate Preparation}

The importance of the quality of the underlying crystalline template, on which an epitaxial film is grown, cannot be overemphasized. For conventional semiconductors (e.g., silicon and GaAs) highly perfect single crystals, chemical mechanical polishing, and chemical etching methods to prepare smooth and damage-free surfaces for epitaxial growth, and detailed knowledge of surface reconstructions all exist, and are a key to the success of semiconductor technology. For the growth of superlattices of functional oxides, tunneling heterostructures, etc., where the intrinsic properties of films with thickness in the nanometer range are desired, the availability of appropriate substrates and methods to prepare smooth and highly perfect surfaces on which epitaxial growth is initiated are also crucial.

For functional oxides with perovskite structures (e.g., $\mathrm{SrTiO}_{3}$, $\mathrm{BiMnO}_{3}, \mathrm{BiFeO}_{3}, \mathrm{~Pb}(\mathrm{Zr}, \mathrm{Ti}) \mathrm{O}_{3}$, and $\left.\mathrm{PbZn}_{1 / 3} \mathrm{Nb}_{2 / 3} \mathrm{O}_{3}-\mathrm{PbTiO}_{3}\right)$, chemically and structurally compatible perovskite substrate materials are needed. Intensive work on high-temperature superconductors stimulated the production of many perovskite single crystals $^{230-269}$ to diameters up to 4 in. as well as spawning a number of new perovskite and perovskite-related substrates. $^{270-273}$ These single-crystal perovskite and perovskiterelated substrates include $\mathrm{YAlO}_{3},{ }^{265} \mathrm{LaSrAlO}_{4},{ }^{270} \mathrm{LaAlO}_{3},{ }^{267,269}$ $\mathrm{LaSrGaO}_{4}{ }^{271} \mathrm{NdGaO}_{3}{ }^{261,266}\left(\mathrm{LaAlO}_{3}\right)_{0.29}-\left(\mathrm{Sr}_{1 / 2} \mathrm{Al}_{1 / 2} \mathrm{TaO}_{3}\right)_{0.71}$ (LSAT), ${ }^{272,274} \mathrm{LaGaO}_{3},{ }^{260} \mathrm{SrTiO}_{3},{ }^{275-278}$ and $\mathrm{KTaO}_{3}{ }^{263}$; many are produced with structural perfection rivaling that of conven- tional semiconductors. The pseudotetragonal or pseudocubic $a$-axis lattice spacings offered by these commercial substrates, together with the corresponding lattice spacings of several functional oxides with perovskite and perovskite-related structures, are shown in Fig. 9. As can be seen in Fig. 9, the lattice constants of the available perovskite substrates tend to be smaller than many of the ferroelectric and multiferroic ${ }^{279}$ perovskites of current interest. This is because most of the commercially available perovskite substrates were developed for high-temperature superconductors, which typically have lattice constants in the 3.8-3.9 range. Rare-earth scandate $\left(\mathrm{REScO}_{3}\right)$ substrates have been recently developed with the larger lattice constants of ferroelectric and multiferroic perovskites in mind. ${ }^{280-284}$

In addition to appropriate substrate single crystals, a method to prepare substrates with a specific chemical termination of the surface is a prerequisite for atomic-layer-controlled thin film growth of epitaxial heterostructures. For example, chemical-mechanically polished (001) $\mathrm{SrTiO}_{3}$ substrates display a mixture of $\mathrm{SrO}$ and $\mathrm{TiO}_{2}$ terminated surfaces. Kawasaki et al. ${ }^{285}$ showed that an $\mathrm{NH}_{4} \mathrm{~F}$-buffered $\mathrm{HF}$ solution with controlled $\mathrm{pH}$ enables etching of the more basic $\mathrm{SrO}$ layer and leaves a completely $\mathrm{TiO}_{2}$ terminated surface on the substrate. ${ }^{285}$ This method of preparing a $\mathrm{TiO}_{2}$-terminated (001) $\mathrm{SrTiO}_{3}$ surface has been further perfected by Koster et al. ${ }^{286}$ SrO-terminated (001) $\mathrm{SrTiO}_{3}$ substrates can also be prepared. ${ }^{287}$ A means to prepare low-defect surfaces with controlled termination has also been developed for $(001)_{p} \mathrm{LaAlO}_{3}{ }^{288,289}$ (110) $\mathrm{NdGaO}_{3}{ }^{289}(001)_{p}$ LSAT, ${ }^{289} \mathrm{KTaO}_{3},{ }^{290}$ and (110) $\mathrm{DyScO}_{3}$ substrates. ${ }^{288}$ Here the $p$ subscript refers to pseudocubic indices.

\section{(2) Epitaxial Oxide Heterostructures}

(A) Structural Quality of Epitaxial Films Versus Single Crystals: An example of the structural perfection possible in functional oxide films is shown in Fig. 10(a) where the rocking curve full-width at half-maximum (FWHM) of a strained $\mathrm{SrTiO}_{3}$ film and typical commercial $\mathrm{SrTiO}_{3}$ single crystals are compared. With rocking curve widths as narrow as 7 arc sec, ${ }^{216,218,291}$ these epitaxial $\mathrm{SrTiO}_{3} / \mathrm{DyScO}_{3}$ films not only have the highest structural quality ever reported in heteroepitaxial films of any oxide grown by any technique, but they even have better structural perfection than $\mathrm{SrTiO}_{3}$ single crystals. ${ }^{277,278,292}$ Similarly, as shown in Fig. 10(b), the growth of $\mathrm{BaTiO}_{3}$ films on $\mathrm{GdScO}_{3}$ substrates has achieved films with narrower rocking curves than $\mathrm{BaTiO}_{3}$ single crystals. ${ }^{291}$ Epitaxial films of $\mathrm{BiFeO}_{3}{ }^{293}$ $\mathrm{BiMnO}_{3},{ }^{294} \mathrm{EuTiO}_{3}, \quad(\mathrm{La}, \mathrm{Sr}) \mathrm{MnO}_{3},{ }^{295}$ and $\mathrm{BaTiO}_{3} / \mathrm{SrTiO}_{3}$ superlattices $^{237}$ all with rocking curve FWHM $\leq 10$ arc sec have been prepared by $\mathrm{MBE}$ on $\mathrm{REScO}_{3}$ substrates. These narrow rocking curves are made possible by the excellent structural perfection of commercially available $\mathrm{REScO}_{3}$ substrates $^{282,284}$; they are grown by the Czochralski method, which is not applicable to either $\mathrm{SrTiO}_{3}$ or $\mathrm{BaTiO}_{3}$. The rocking curve widths of

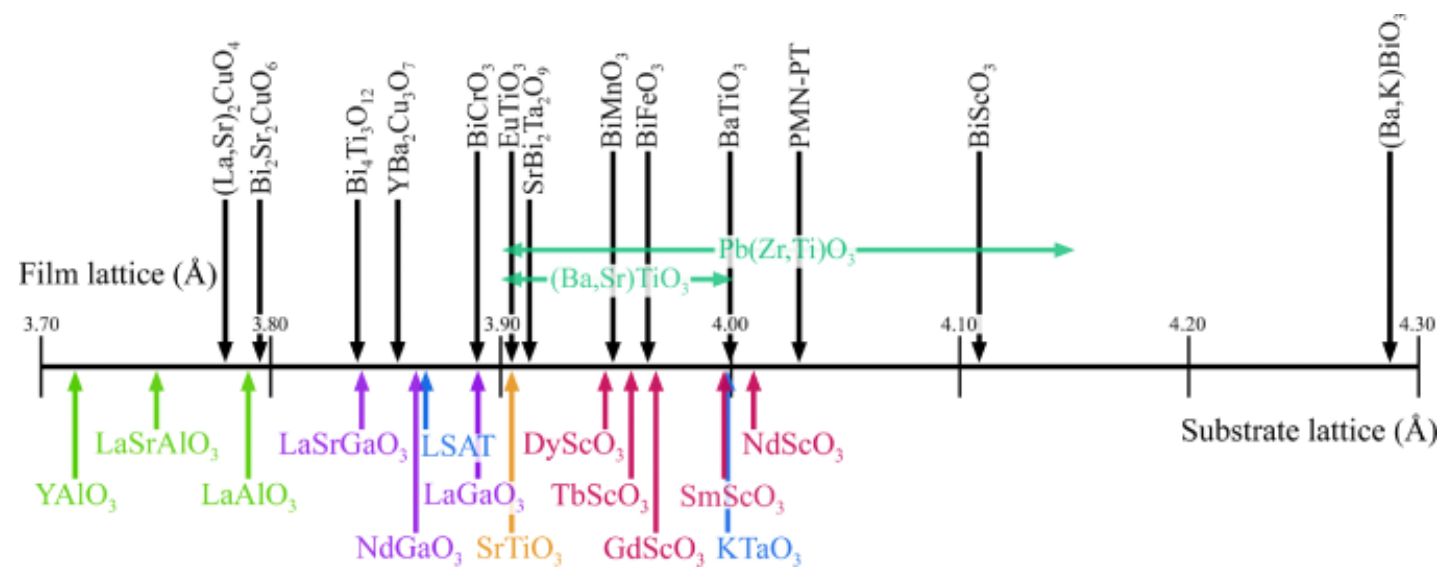

Fig. 9. A number line showing the pseudotetragonal or pseudocubic $a$-axis lattice constants in angstroms of some perovskites and perovskite-related phases of current interest (above the number line) and of some of the perovskite and perovskite-related substrates that are available commercially (below the number line). (Adapted from Schlom et al. ${ }^{345}$ ) 

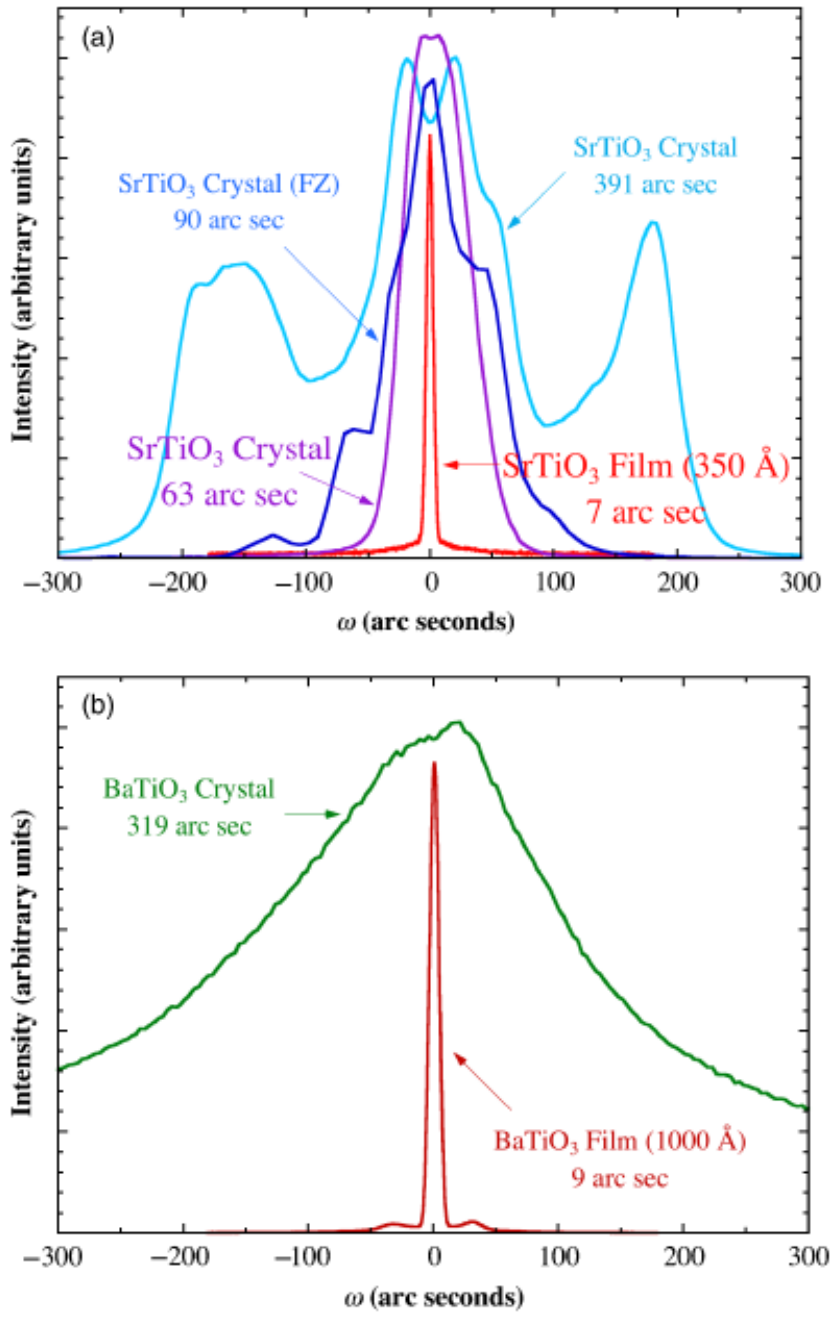

Fig. 10. (a) Rocking curves and full-width at half-maximum (FWHM) of three commercial $\mathrm{SrTiO}_{3}$ single crystals (one grown by floating zone (FZ) and two by flame fusion) showing the variation in structural quality together with an epitaxial 350-A-thick $\mathrm{SrTiO}_{3}$ film grown on a (110) $\mathrm{DyScO}_{3}$ substrate by molecular-beam epitaxy (MBE) at $650^{\circ} \mathrm{C}$ under biaxial tension of $\varepsilon_{\mathrm{s}}=+1.1 \%$. (b) Rocking curves and FWHM of a commercial $\mathrm{BaTiO}_{3}$ single crystal and an epitaxial 1000- $\mathrm{A}$-thick $\mathrm{BaTiO}_{3}$ film grown on a (110) $\mathrm{GdScO}_{3}$ substrate by $\mathrm{MBE}$ at $650^{\circ} \mathrm{C}$ under biaxial compression of $\varepsilon_{s}=-1.0 \%$. (From Schlom et al. ${ }^{345}$ )

these functional oxide films are within instrumental error identical to those of the substrates upon which they are grown.

\section{(3) Epitaxial Integration of Oxides with Semiconductors}

An important technological enabler is the ability to epitaxially integrate functional oxides with conventional semiconductors. Although the structural quality of films of functional oxides grown on semiconductor substrates is far from the quality of these materials grown on appropriate oxide substrates, significant improvements have been made over the last seven decades (and especially in the last two decades) because oxides were first epitaxially integrated with semiconductors. ${ }^{296,297}$ Several routes now exist for the epitaxial integration of functional oxides with semiconductors including (001) Si, ${ }^{196,204,205,210,212-215,225,226,298-306}$ (001) $\mathrm{Ge},{ }^{198,204,307,308}$ (001) GaAs, ${ }^{304,309,310}$ (001) $\mathrm{InP},{ }^{311,312}$ and (0001) GaN..$^{226,313-315}$ Using these routes a multitude of functional oxides, with conducting top and bottom electrodes when desired, have been epitaxially integrated with semiconductor materials. $196,198,204,205,225,226,298,299,301,304,307-309,313,314,316-326$ This capability could play a significant role in future hybrid devices.

Combining functional oxides with existing semiconductor technology greatly enhances the materials properties available for use in microelectronics, optoelectronics, and spintronics, by bringing new functionalities to conventional semiconductor platforms. Epitaxial integration with silicon is particularly important due to it being the backbone of modern semiconductor technology. Unfortunately, direct growth of functional oxides on silicon is frequently accompanied by extensive interdiffusion or chemical reactions that degrade the properties of the oxide, the underlying silicon, or both, and leads to electrically active defects at the semiconductor/oxide interface $\left.\left(D_{\mathrm{it}}\right)\right)^{327-333}$ Such defects at the semiconductor/oxide interface preclude many potential applications, e.g., FeRAMs with a nondestructive readout based on the resistance of the semiconductor channel. ${ }^{334-343}$ That $\mathrm{PbTiO}_{3}, \mathrm{BaTiO}_{3}$, and $\mathrm{SrTiO}_{3}$ are all unstable in direct contact with silicon is evident from the chemical reactions below ${ }^{344,345}$.

$$
\begin{gathered}
3 \mathrm{Si}+\mathrm{PbTiO}_{3} \stackrel{\Delta G_{1000 \mathrm{~K}}^{\circ}}{=} \stackrel{=-79.312 \frac{\mathrm{kJ}}{\mathrm{mol}}}{\longrightarrow} \mathrm{PbSiO}_{3}+\mathrm{TiSi}_{2}, \\
3 \mathrm{Si}+\mathrm{BaTiO}_{3} \stackrel{\Delta G_{1000 \mathrm{~K}}^{\circ}}{\longrightarrow} \stackrel{=-101.802 \frac{\mathrm{kJ}}{\mathrm{mol}}}{\longrightarrow} \mathrm{BaSiO}_{3}+\mathrm{TiSi}_{2},
\end{gathered}
$$

and

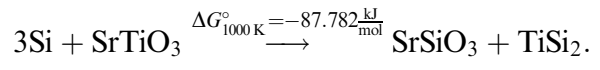

For each of these reactions $\Delta G_{1000 \mathrm{~K}}^{\circ}$ is the free energy change of the system when the reaction between reactants and products, all taken to be in their standard state (the meaning of the superscript), proceeds in the direction indicated at a temperature of $1000 \mathrm{~K} .{ }^{346}$ Note that all of the above reactions are energetically favorable $(\Delta G<0)$. This is true not only at $1000 \mathrm{~K}$ (a typical processing temperature), but at all temperatures between room temperature and the melting point of silicon. Consequently, the focus of a great deal of materials research has been devoted to overcoming this fundamental obstacle through the identification of compatible buffer layers for use between silicon and functional oxides. ${ }^{234,344,347}$ Many factors must be considered in selecting materials for use as buffer layers between silicon and a particular oxide: chemical reactions, interdiffusion, crystal structure, and lattice match are some of the most important. ${ }^{273,304,347,348}$

The importance of avoiding interfacial chemical reactions, i.e., the need for a thermodynamically stable interface between the silicon substrate and the functional oxide or the buffer layer leading to the functional oxide is underscored by the observation that nearly all oxides that have been directly epitaxially integrated with silicon are either thermodynamically stable or possibly thermodynamically stable in contact with silicon. A periodic table depicting which elements have binary oxides that are stable or potentially stable in contact with silicon is shown in Fig. 11. 344,349 Also shown in Fig. 11 are those elements with binary oxides that have been epitaxially grown on silicon. $\mathrm{BaO}$ is the only binary oxide that thermodynamic data show to be unstable in contact with silicon, yet can be grown epitaxially on it at low temperatures (below $\sim 200^{\circ} \mathrm{C}$ ). ${ }^{204,210,306}$ Nonetheless when $\mathrm{BaO} / \mathrm{Si}$ films are heated or when growth is attempted at higher temperatures, reaction between $\mathrm{BaO}$ and silicon is observed as expected. ${ }^{350-353}$

The large difference in thermal expansion coefficient between silicon (which averages $3.8 \times 10^{-6} \mathrm{~K}^{-1}$ between room temperature and $700^{\circ} \mathrm{C}$ ) 354 and oxide ferroelectrics (typically $10 \times 10^{-6}$ $\mathrm{K}^{-1}$ ) remains a significant problem. Upon cooling after growth, the functional oxide films are in a state of biaxial tension, which can lead to cracking in thick films. ${ }^{304,355}$

\section{Customizing Oxides at the Atomic Layer Level}

\section{(1) Metastable Phases}

(A) $\mathrm{BiMnO}_{3}, \mathrm{Ba}_{2} \mathrm{RuO}_{4}, \mathrm{LuScO}_{3}$ : Epitaxial growth can be used to create metastable phases by utilizing lattice misfit strain energies and interfacial energies to favor the 
desired metastable phase over the equilibrium phase (epitaxial stabilization). ${ }^{159,356-358}$ In contrast to bulk synthesis, in epitaxial growth, strain and interfacial energies play a significant role. Specifically, strain energies due to lattice mismatch are often sufficient to shift the energetics of phase stabilities. For sufficiently thin films, the interfacial free energy and strain free energy terms can overcome the volume free energy differences between polymorphs to make a desired metastable form have the lower total free energy (volume+interfacial+strain). $\mathrm{Nu}$ merous examples of epitaxially stabilized phases exist in semiconductor, metal, and alkali halide systems. ${ }^{182,356-359}$ Examples of metastable functional oxides grown by PLD and MBE include $\mathrm{Ba}_{2} \mathrm{RuO}_{4},{ }^{158} \mathrm{BiMnO}_{3},{ }^{160}$ and $\mathrm{LuScO}_{3}{ }^{161}$ In these examples a substrate with a good lattice and structural match to the desired metastable phase is used to provide the interfacial+strain free energy bias that favors it over the equilibrium phase. Some of these metastable phases have been produced in bulk by high-pressure synthesis ${ }^{158,160}$; others are totally new. ${ }^{161}$

$\mathrm{BiMnO}_{3}$ holds the record (Table I) as the material that is believed to be simultaneously ferromagnetic and ferroelectric at the highest temperature ${ }^{28-30}$ on which a conventional polarization-electric field hysteresis loop has been reported. ${ }^{28}$ Although it was the suggestion of possible simultaneous ferromagnetism and ferroelectricity in $\mathrm{BiMnO}_{3}$ that started the recent renaissance of activity in multiferroics, ${ }^{29}$ advances in computers and first principles methods have allowed these authors to perform more accurate calculations from which they conclude that $\mathrm{BiMnO}_{3}$ is not ferroelectric. ${ }^{30}$ At atmospheric pressure $\mathrm{BiMnO}_{3}$ is unstable and phase separates to a mixture of $\mathrm{Bi}_{2} \mathrm{O}_{3}$ and $\mathrm{Bi}_{2} \mathrm{Mn}_{4} \mathrm{O}_{9}{ }^{360}$ In bulk, $\mathrm{BiMnO}_{3}$ is made in powder form at pressures of typically $60000 \mathrm{~atm}$ and a temperature of $1100 \mathrm{~K}$, where it is the stable phase. ${ }^{361-363}$ But to establish the properties of $\mathrm{BiMnO}_{3}$ and especially to determine whether or not it is truly ferroelectric, large single crystals or epitaxial films are desired. Using epitaxial stabilization, $\mathrm{BiMnO}_{3}$ films have been prepared with several orientations. ${ }^{30,160}$ Although the epitaxial films have the same symmetry as $\mathrm{BiMnO}_{3}$ made at high pressure, they are too leaky (so far) for reliable ferroelectric measurements. Nonetheless, second harmonic generation (SHG) measurements made on metastable $\mathrm{BiMnO}_{3}$ films are consistent with it being ferroelectric. ${ }^{30}$

Because of the unusual properties of the superconductor $\mathrm{Sr}_{2} \mathrm{RuO}_{4},{ }^{364}$ ruthenates with closely related structures are of great interest to help pin down the characteristics of $\mathrm{Sr}_{2} \mathrm{RuO}_{4}$ responsible for its unusual superconducting behavior. For example, in light of the observation that hydrostatic pressure reduces the superconducting transition temperature $\left(T_{\mathrm{c}}\right)$ of $\mathrm{Sr}_{2} \mathrm{RuO}_{4},{ }^{365}$ it is desirable to investigate the properties of $\mathrm{Ba}_{2} \mathrm{RuO}_{4}$ in which the larger $\mathrm{Ba}^{2+}$ ion is substituted for $\mathrm{Sr}^{2+}$, expanding the structure. Utilizing such chemical substitutions to induce "chemical pressure" (negative pressure in this case) is common in superconducting research. ${ }^{366}$ The only hitch to its use in this case is that $\mathrm{Ba}_{2} \mathrm{RuO}_{4}$ is not isostructural with $\mathrm{Sr}_{2} \mathrm{RuO}_{4}$ when synthesized at atmospheric pressure. ${ }^{\$ \uparrow}$, ${ }^{267-373} \mathrm{In}$ bulk, $\mathrm{Ba}_{2} \mathrm{RuO}_{4}$ powder isostructural with $\mathrm{Sr}_{2} \mathrm{RuO}_{4}$ has been synthesized using pressures of $65000 \mathrm{~atm}{ }^{371}$ As an alternative to the difficult task of growing extremely pure single crystals at $65000 \mathrm{~atm}$, epitaxial stabilization has been used to prepare the metastable $\mathrm{K}_{2} \mathrm{NiF}_{4}$-type polymorph of $\mathrm{Ba}_{2} \mathrm{RuO}_{4}{ }^{158}$

$\mathrm{LuScO}_{3}$ is another example of a new metastable phase prepared using epitaxial stabilization. ${ }^{161}$ All attempts to prepare it using high-pressure synthesis techniques as a perovskite (isostructural to

\footnotetext{
${ }^{\$ \$}$ Although these authors did not determine the crystal structure of the stable form of $\mathrm{Ba}_{2} \mathrm{RuO}_{4}$ that they synthesized at atmospheric pressure and $1000^{\circ}-1100^{\circ} \mathrm{C}$, they did report the XRD pattern of the $\mathrm{Ba}_{2} \mathrm{RuO}_{4}$ that they made (which is completely different than the $\mathrm{K}_{2} \mathrm{NiF}_{4}$ form reported by Kafalas and Longo ${ }^{367}$ ) and described it as having "low symmetry.",

"There is one report in the literature of the synthesis of $\mathrm{Ba}_{2} \mathrm{RuO}_{4}$ with the $\mathrm{K}_{2} \mathrm{NiF}_{4}$ structure that does not mention the use of high-pressure methods: Prosychev and Shaply$\operatorname{gin}^{370,371}$ and Gadzhiev and Shaplygin. ${ }^{372,373}$ In addition to not stating the synthesis pressure, however, no X-ray or structural data are presented. As Kafalas and Longo ${ }^{367}$ and sure, however, no X-ray or structural data are presented. As Kafalas and Longo ${ }^{367}$ and
Popova et al. $^{368,369}$ both contradict this claim and present X-ray data, their results are taken as evidence that $\mathrm{Ba}_{2} \mathrm{RuO}_{4}$ with the $\mathrm{K}_{2} \mathrm{NiF}_{4}$ structure is metastable at atmospheric (or lower) pressure and synthesis temperatures of $1000^{\circ}-1100^{\circ} \mathrm{C}$, as used in both Popova et al..$^{368,369}$ for
} bulk synthesis and Jia et al. ${ }^{158}$ for epitaxial films.
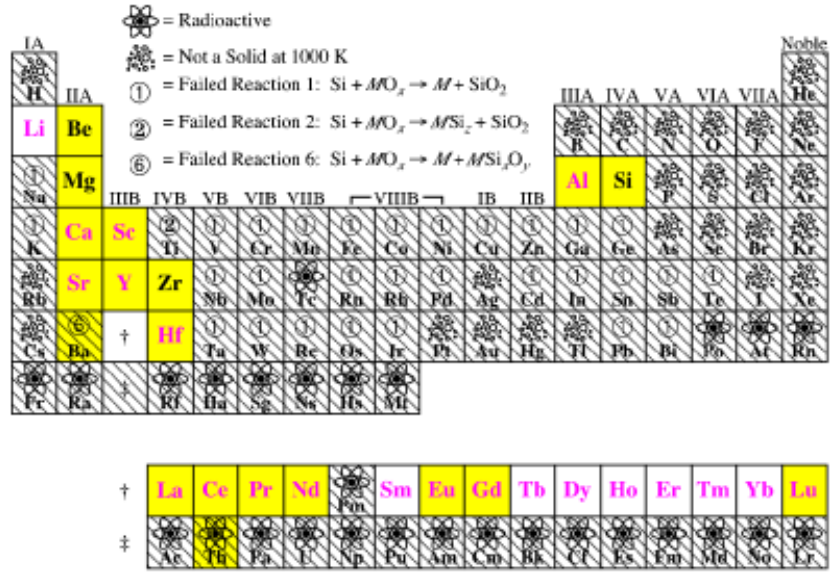

Insufficient Thermodynamic Data to Complete Calculations Experimentally Demonstrated

Fig. 11. Pictorial summary of which elements $M$ have an oxide $\left(M \mathrm{O}_{x}\right)$ that may be thermodynamically stable in contact with silicon at $1000 \mathrm{~K}$. Elements $M$ having no thermodynamically stable or potentially thermodynamically stable oxide $\left(M \mathrm{O}_{x}\right)$ are shaded (hatched), and the reason for their elimination is given. Also shown are the elements $M$ having an oxide $\left(M \mathrm{O}_{x}\right)$ that has been experimentally demonstrated to be stable in direct contact with silicon. Performing the thermodynamic analysis over the full range of temperatures for which relevant thermodynamic data are available (as much as $300-1600 \mathrm{~K}$ ) does not alter the conclusions shown. (Adapted from Schlom and Haeni ${ }^{349}$.)

the available $\mathrm{REScO}_{3}$ substrates), using pressures up to 60000 atm, were unsuccessful. ${ }^{374,375}$ But with an appropriate perovskite substrate, the perovskite polymorph of $\mathrm{LuScO}_{3}$ was readily synthesized by epitaxial stabilization. 61

These are just a few of many success stories in the preparation of metastable functional oxides by epitaxial stabilization. ${ }^{159}$ An obvious approach to prepare the metastable ferroelectric ferromagnet with the highest predicted transition temperature, $\mathrm{FeTiO}_{3}$ with the $\mathrm{LiNbO}_{3}$ structure (see Table I) is epitaxial stabilization. ${ }^{27}$

\section{(2) New Phases}

(A) Ruddlesden-Popper Phases: In addition to preparing new metastable phases, MBE can be used to select a particular phase from among a homologous series of phases with nearly equal formation energies. An example is the creation of high- $n$ Ruddlesden-Popper phases. These layered structures can be created by atomic-layer engineering using MBE. An example is the phase-pure growth of the $n=1-5$ members of the $\mathrm{Sr}_{n+1} \mathrm{Ti}_{n} \mathrm{O}_{3 n+1}$ and $\mathrm{Sr}_{n+1} \mathrm{Ru}_{n} \mathrm{O}_{3 n+1}$ homologous series. ${ }^{77-80}$ The crystal structures of the $n=1-5$ members of this homologous series are shown in Fig. 3.

Complexities of the $\mathrm{SrO}-\mathrm{TiO}_{2}$ phase diagram have frustrated efforts to prepare bulk single crystals of any members of the $\mathrm{Sr}_{n+1} \mathrm{Ti}_{n} \mathrm{O}_{3 n+1}$ series other than the $n=\infty$ end member, $\mathrm{SrTiO}_{3}$. The single-crystal growth of the $n=1$ member of the series, $\mathrm{Sr}_{2} \mathrm{TiO}_{4}$, is complicated (if not prohibited) by a phase transition at $1550^{\circ} \mathrm{C}$ and a peritectic decomposition at $1860^{\circ} \mathrm{C} .^{376}$ The $n=2$ member, $\mathrm{Sr}_{3} \mathrm{Ti}_{2} \mathrm{O}_{7}$, has a peritectoid decomposition at $1580^{\circ} \mathrm{C},{ }^{376}$ which prohibits growth of single crystals of this phase from the melt.

Using reactive MBE the first five members of these RuddlesdenPopper homologous series have been prepared. ${ }^{77-80}$ X-ray diffraction (XRD) (Fig. 12) and high-resolution cross-sectional TEM images (Fig. 13) confirm that these films are epitaxially oriented and contain relatively few intergrowths. Detailed investigations using quantitative HRTEM methods reveal that the films have the expected $n=1-5$ structures. $^{78}$ Among these films, the $n=1-3$ thin films are nearly free of intergrowths, while the $n=4$ and 5 thin films contain noticeably more antiphase boundaries in their perovskite sheets and intergrowth defects. ${ }^{78} \mathrm{The} \mathrm{Sr}_{n+1} \mathrm{Ru}_{n} \mathrm{O}_{3 n+1}$ films contain fewer defects than their $\mathrm{Sr}_{n+1} \mathrm{Ti}_{n} \mathrm{O}_{3 n+1}$ counterparts and even the high- $n \mathrm{Sr}_{n+1} \mathrm{Ru}_{n} \mathrm{O}_{3 n+1}$ films are $>98 \%$ phase pure. ${ }^{80}$ 

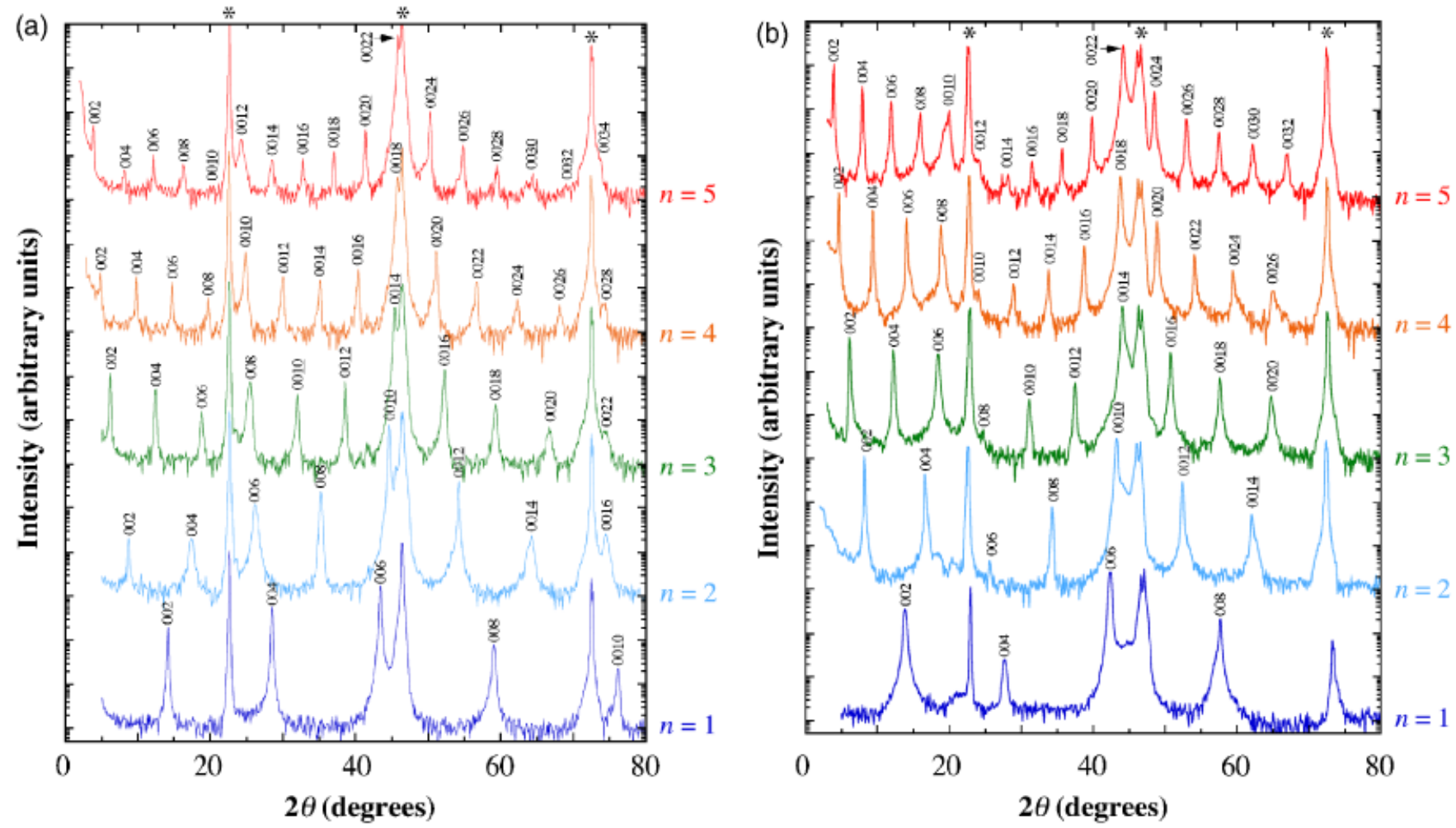

Fig. 12. $\theta-2 \theta \mathrm{X}$-ray diffraction scans of the first five members of the (a) $\mathrm{Sr}_{n+1} \mathrm{Ti}_{n} \mathrm{O}_{3 n+1}$ (reprinted from Haeni et al. ${ }^{77}$ with permission; C $2001 \mathrm{American}$ Institute of Physics) and (b) $\mathrm{Sr}_{n+1} \mathrm{Ru}_{n} \mathrm{O}_{3 n+1}$ Ruddlesden-Popper homologous series (reprinted from Tian et al., ${ }^{80}$ with permission; (C)2007 American Institute of Physics). Substrate peaks are labeled with an $\left(^{*}\right)$ and the plots are offset for clarity.

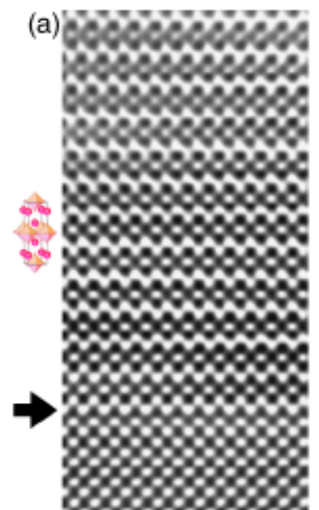

$\mathrm{Sr}_{2} \mathrm{TiO}_{4}$

$(n=1)$

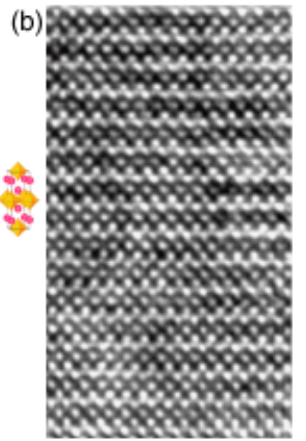

$\mathrm{Sr}_{2} \mathrm{RuO}_{4}$

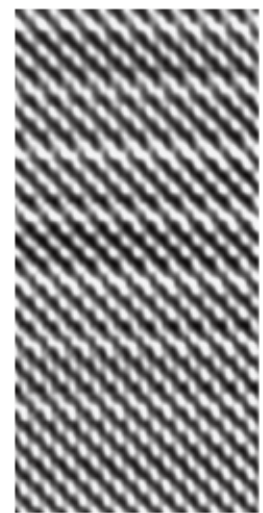

$\mathrm{Sr}_{3} \mathrm{Ti}_{2} \mathrm{O}$

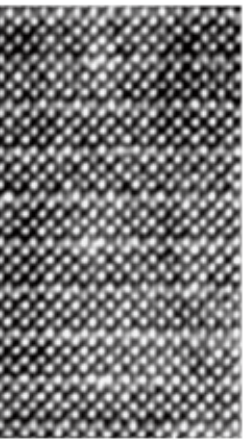

$\mathrm{Sr}_{3} \mathrm{Ru}_{2} \mathrm{O}_{7}$

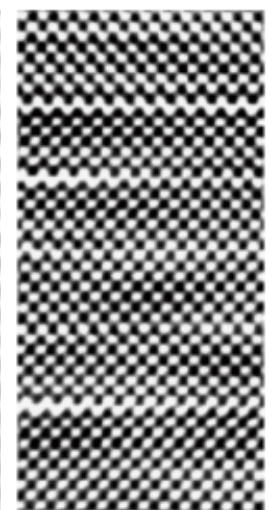

$\mathrm{Sr}_{4} \mathrm{Ti}_{3} \mathrm{O}_{10}$

$(n=3)$

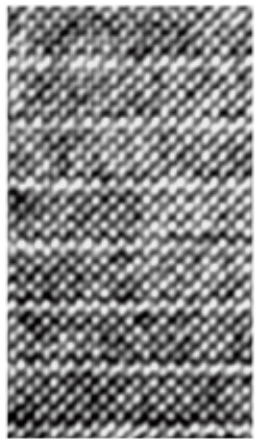

$\mathrm{Sr}_{4} \mathrm{Ru}_{3} \mathrm{O}_{10}$

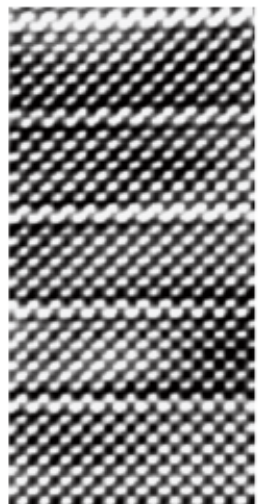

$\mathrm{Sr}_{5} \mathrm{Ti}_{4} \mathrm{O}$

$(n=4)$

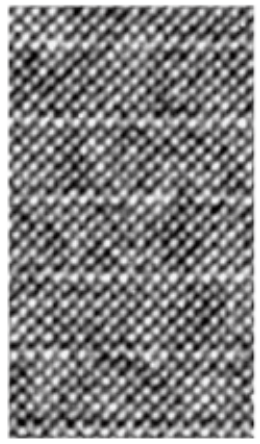

$\mathrm{Sr}_{3} \mathrm{Ru}_{4} \mathrm{O}_{13}$

$(n-4)$

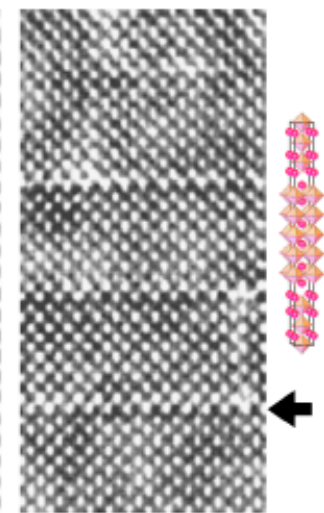

$\mathrm{Sr}_{6} \mathrm{Ti}_{5} \mathrm{O}_{1}$

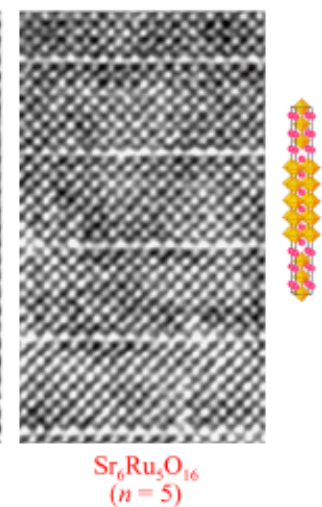

Fig. 13. High-resolution cross-sectional TEM images of the same five members of the (a) $\operatorname{Sr}_{n+1} \mathrm{Ti}_{n} \mathrm{O}_{3 n+1}$ (reprinted from Haeni et al. ${ }^{77}$ with permission; (C)2001 American Institute of Physics) and (b) $\mathrm{Sr}_{n+1} \mathrm{Ru}_{n} \mathrm{O}_{3 n+1}$ Ruddlesden-Popper homologous series shown in Fig. 12 (reprinted from Tian et al., ${ }^{80}$ with permission; (C)2007 American Institute of Physics). The two adjacent white rows in the images correspond to the [100] projections of the rock-salt $\mathrm{SrO}$ layers. Between the double $\mathrm{SrO}$ layers lies the [100] projection of the $\mathrm{SrTiO}_{3}$ and $\mathrm{SrRuO}_{3}$ perovskite sheets. The arrows in (a) indicate the position of the interface between the $\mathrm{Sr}_{n+1} \mathrm{Ti}_{n} \mathrm{O}_{3 n+1}$ films and (100) $\mathrm{SrTiO}_{3}$ substrate on which they were grown. 
The preparation of these materials as epitaxial films has allowed their properties to be explored. The full dielectric constant tensor of the $\mathrm{Sr}_{n+1} \mathrm{Ti}_{n} \mathrm{O}_{3 n+1}$ epitaxial films has been measured ${ }^{377}$ as a function of frequency and temperature and compared with theory. ${ }^{378}$ Preparation of the $n=1-5 \mathrm{Sr}_{n+1} \mathrm{Ru}_{n} \mathrm{O}_{3 n+1}$ Ruddlesden-Popper phases has allowed the effects of dimensionality on the magnetic properties of these phases to be established. It is found that decreasing the dimensionality of this system, i.e., the effect of decreasing $n$ on the magnetic properties of $\mathrm{Sr}_{n+1} \mathrm{Ru}_{n} \mathrm{O}_{3 n+1}$ phases, leads to a systematic reduction in ferromagnetism. ${ }^{80}$ The minimum value of $n$ for ferromagnetism is $n=3\left(\mathrm{Sr}_{4} \mathrm{Ru}_{3} \mathrm{O}_{10}\right)$. This corresponds to the case where at least one $\mathrm{RuO}_{2}$ sheet in the structure is surrounded by $\mathrm{RuO}_{2}$ sheets from above and below (see Fig. 3). For $n=1$ and $2 \mathrm{Sr}_{n+1} \mathrm{Ru}_{n} \mathrm{O}_{3 n+1}$ phases, no $\mathrm{RuO}_{2}$ sheets are surrounded by $\mathrm{RuO}_{2}$ sheets, resulting in the loss of ferromagnetism.

(B) Aurivillius Phases: Just as thin film techniques can be used to prepare and explore the properties of high- $n$ Ruddlesden-Popper phases that cannot be realized by bulk synthesis, they can also be used to prepare high- $n$ Aurivillius phases. An example is the $n=7$ Aurivillius phase $\mathrm{Sr}_{4} \mathrm{Bi}_{4} \mathrm{Ti}_{7} \mathrm{O}_{24}$ whose XRD and cross-sectional TEM are shown in Fig. 14. This film was grown by PLD and is the highest- $n$ Aurivillius phase ever reported. ${ }^{379}$ As the schematic shows, this phase contains seven $\mathrm{SrTiO}_{3}$ perovskite layers between $\mathrm{Bi}_{2} \mathrm{O}_{2}$ sheets.

In addition to increasing the number of perovskite layers between $\mathrm{Bi}_{2} \mathrm{O}_{2}$ layers in Aurivillius phases, different perovskite layers can be inserted between the $\mathrm{Bi}_{2} \mathrm{O}_{2}$ layers to alter the properties of the resulting phase as shown schematically in
Fig. 4. This can be used, for example, as a composite approach on an atomic scale to the fabrication of a magnetic ferroelectric. Many Aurivillius phases are ferroelectric, ${ }^{380}$ e.g., $\mathrm{Bi}_{4} \mathrm{Ti}_{3} \mathrm{O}_{12}$, and one could imagine introducing a ferromagnetic perovskite, e.g., $\mathrm{BiMnO}_{3}$, into $\mathrm{Bi}_{4} \mathrm{Ti}_{3} \mathrm{O}_{12}$ to construct a ferromagnetic ferroelectric. Although in bulk, manganese has been found to have negligible solubility in $\mathrm{Bi}_{4} \mathrm{Ti}_{3} \mathrm{O}_{12}$ itself, ${ }^{381}$ this is not a constraint for thin film growth where the targeted phase is a superlattice composite of $\mathrm{BiMnO}_{3}$ and $\mathrm{Bi}_{4} \mathrm{Ti}_{3} \mathrm{O}_{12}$. A composite approach to fabricating two-phase ferroelectric-magnetic composite heterostructures ${ }^{382-385}$ has been shown to be viable, and refining the scale of the composite down to the atomic scale is a useful goal in terms of both maximizing elastic coupling and exploring the spatial limits of this coupling. At the macroscale, 3-3 bulk composites ${ }^{386}$ have mechanical stability issues and exhibit poor coupling. ${ }^{387}$ At the microscale, tape-cast structures avoid mechanical issues and exhibit stronger coupling, ${ }^{388}$ but granular orientation effects are likely to reduce mechanical coupling efficiency and to complicate analysis of strain within the crystalline lattice. At the nanoscale, thin film structures have been the most effective in producing multiferroic composite behavior. Although a 2-2 composite (stack of films on a substrate) ${ }^{386}$ is convenient for electrical characterization, a nonferroic substrate will clamp the response. ${ }^{389}$ A solution has been to use a ferroic substrate, ${ }^{390}$ but the limited selection of substrate materials can be problematic, as can be domain effects in a noncentrosymmetric substrate crystal. Another solution has been to use a 1-3
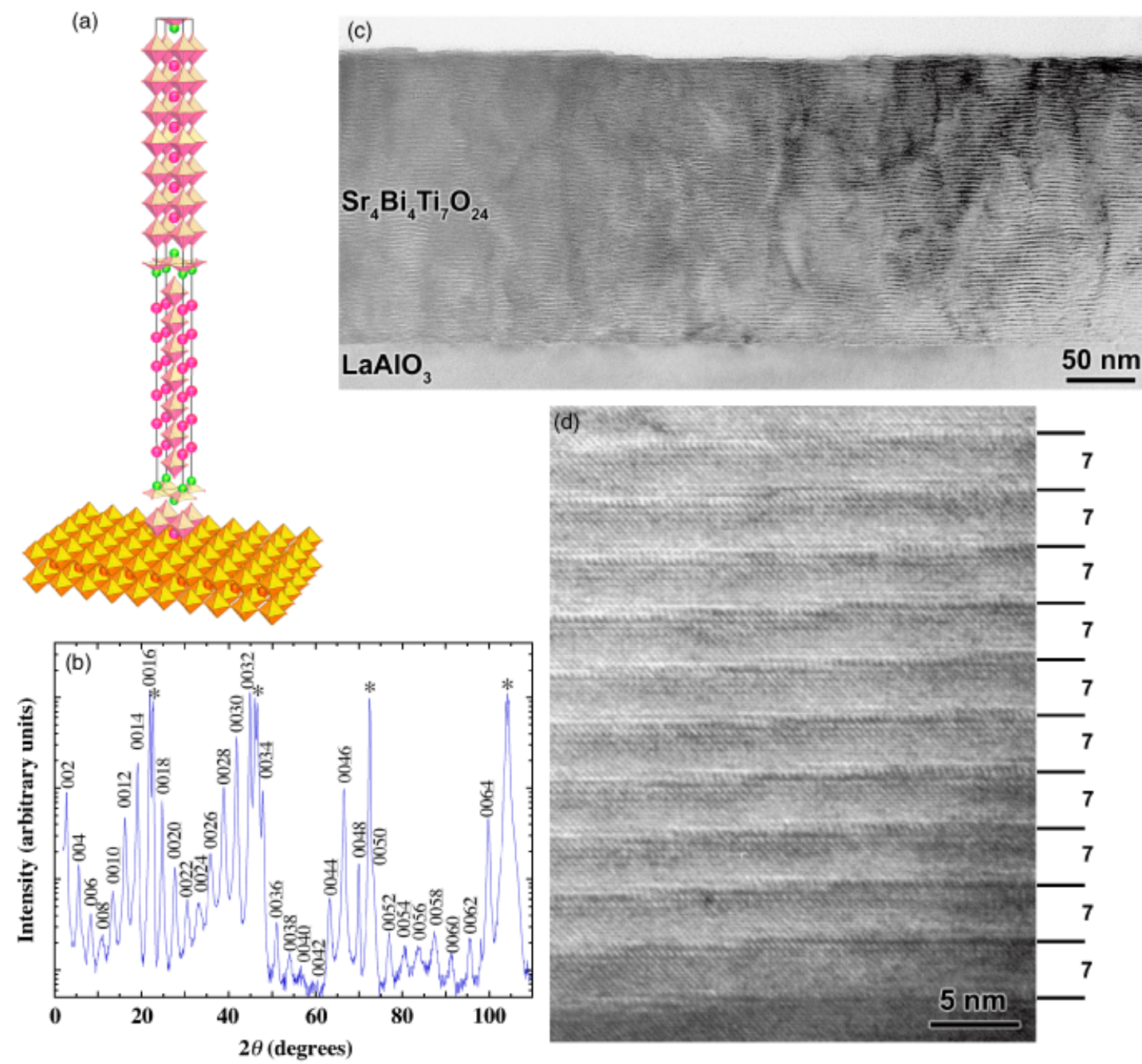
composite system that maximizes out-of-plane mechanical coupling in a film, for example $\mathrm{BaTiO}_{3}-\mathrm{CoFe}_{2} \mathrm{O}_{4}{ }^{391}$ The ultimate level for forming a composite is at the atomic or unit-cell scale. Most physical or phase separation approaches to composites are not feasible at this scale; hence, natural multiferroics, single-phase materials that can incorporate substructures of both types is a noteworthy approach. This composite strategy was recently applied using PLD to the $n=6$ Aurivillius phase $\mathrm{Bi}_{7} \mathrm{Mn}_{3.75} \mathrm{Ti}_{2.25} \mathrm{O}_{21}$.

\section{Thin Film Routes to Enhance the Properties of Oxides}

\section{(1) Epitaxial Strain}

An advantage of using thin films as a platform to explore size effects in ferroelectrics is that they allow huge strains to be applied-strains far larger than where bulk ferroelectrics would crack. ${ }^{392,393}$ These strains can be imparted through differences in lattice parameters and thermal expansion behavior between the film and the underlying substrate or arise from defects formed during film deposition. ${ }^{393-396}$ Fully coherent, epitaxial films have the advantage that high densities of threading dislocations (e.g., the $\sim 10^{11}$ dislocations $/ \mathrm{cm}^{2}$ observed in partially relaxed $\left(\mathrm{Ba}_{x} \mathrm{Sr}_{1-x}\right) \mathrm{TiO}_{3}$ films $)^{397,398}$ are avoided. Strain fields around dislocations locally alter the properties of a film, making its ferroelectric properties inhomogeneous and often degraded. ${ }^{399-401}$ As the film is clamped to the substrate, but free in the out-ofplane direction, the effect of a biaxial strain state on properties can be dramatic.

The effects of biaxial strain and temperature on ferroelectric transitions and domain structures have been theoretically studied for a number of ferroelectrics. ${ }^{291}$ These include $(001)_{p}$ oriented $\mathrm{PbTiO}_{3},{ }^{402-406} \mathrm{BaTiO}_{3},{ }^{203,402,407,408}$ and $\mathrm{Pb}\left(\mathrm{Zr}_{x}\right.$ $\left.\mathrm{Ti}_{1-x}\right) \mathrm{O}_{3},{ }^{409-411}$ where the subscript $p$ refers to the pseudocubic index, and even $(001)_{p} \mathrm{SrTiO}_{3},{ }^{14,412-415}$ which is not normally ferroelectric, but can become ferroelectric when strained. Strain phase diagrams for these thin films, which graphically display the ferroelectric phase transition temperatures and domain structures as a function of strain, have been constructed using thermodynamic analysis and phase-field simulations.

The strain phase diagrams in Figs. 15 and 16, for $(001)_{p}$ $\mathrm{BaTiO}_{3}$ and $(001)_{p} \mathrm{SrTiO}_{3}$, respectively, imply that ferroelectrics can be very sensitive to strain. These predictions imply that a biaxial tensile strain of order $1 \%$ will shift the $T_{\mathrm{C}}$ of $\mathrm{SrTiO}_{3}$, a material that normally is not ferroelectric at any temperature, to the vicinity of room temperature (see Fig. 16). ${ }^{114,291,412-415}$ Comparable shifts in transition temperature, roughly $300 \mathrm{~K}$ per percent biaxial strain, are expected for $\mathrm{BaTiO}_{3}$ (Fig. 15) ${ }^{203,291,402,407,408}$ and $\mathrm{PbTiO}_{3} \cdot{ }^{291,402-406}$ These predictions have been borne out by experiments on strained $\mathrm{SrTiO}_{3}$, ${ }^{14,216,291,416-423} \mathrm{PbTiO}_{3}$, ${ }^{291,424}$ and $\mathrm{BaTiO}_{3}$ films ${ }^{203,291}$; large strain effects of comparable magnitude were observed earlier in $\mathrm{KTaO}_{3} / \mathrm{KNbO}_{3}{ }^{425} \mathrm{SrTiO}_{3} / \mathrm{SrZrO}_{3}$, ${ }^{426}$ and $\mathrm{SrTiO}_{3} /$ $\mathrm{BaZrO}_{3}$ superlattices, ${ }^{427}$ and strained $(\mathrm{Ba}, \mathrm{Sr}) \mathrm{TiO}_{3}$ films. ${ }^{428,429}$

$T_{\mathrm{C}}$ has been determined on strained thin films using several experimental methods. The conventional method of measuring a hysteresis loop is problematic when the electrical leakage current is high, e.g., for extremely thin films where currents due to electron tunneling are high or at elevated temperatures where significant ionic conductivity can occur. It also requires electrodes, which alters the electrical boundary conditions and can impose experimental complications. Two methods that are applicable at high temperatures to extremely thin ferroelectric films have become popular. One method involves measuring the temperature dependence of the out-of-plane lattice parameter of the strained film. A kink in the out-of-plane lattice parameter occurs at $T_{\mathrm{C}}$. Such kinks at $T_{\mathrm{C}}$ have been observed in a number of coherently strained ferroelectric films ${ }^{203,424,425}$ and are expected from theory. ${ }^{203,424,430}$ A second method is to use SHG. Only materials that lack inversion symmetry exhibit an SHG signal. All ferroelectrics must lack inversion symmetry, but there are many materials that lack inversion symmetry and are not
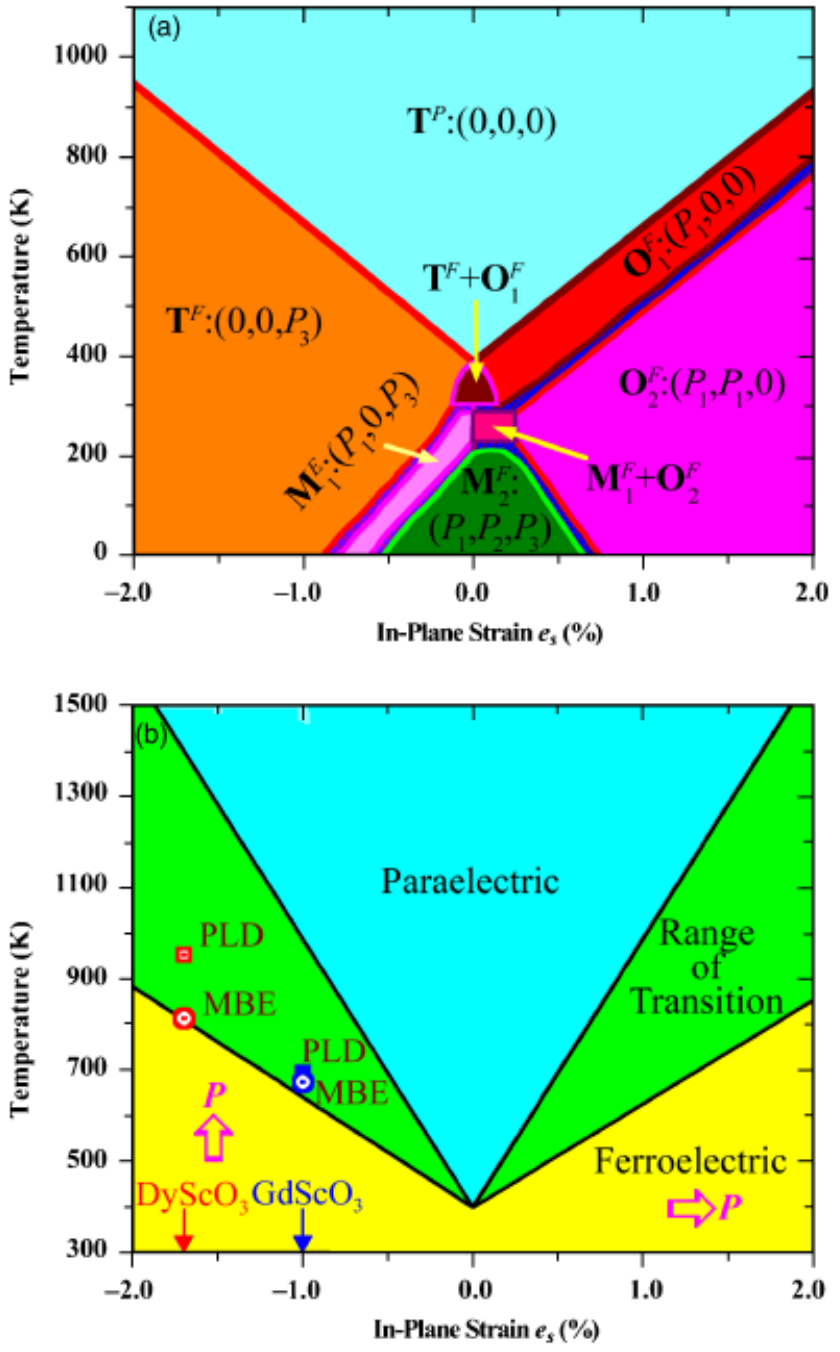

Fig. 15. (a) The strain phase diagram of $(001)_{p}$-oriented $\mathrm{BaTiO}_{3}$ obtained from phase-field simulations. The letters $\mathbf{T}, \mathbf{O}$, and $\mathbf{M}$ used in the phase notations indicate tetragonal, orthorhombic, and monoclinic crystallographic symmetries, respectively, under a constraint. The paraelectric and ferroelectric natures of the phases are revealed by the superscript $P$ and $F$, respectively. $\mathbf{M}_{1}^{F}+\mathbf{O}_{2}^{F}$ implies a mixture of $\mathbf{M}_{1}^{F}$ and $\mathbf{O}_{2}^{F}$ phases. The components of the polarization vector $\boldsymbol{P}$ corresponding to the phases (along the crystallographic directions of pseudocubic $\mathrm{BaTiO}_{3}$ ) are indicated within the parentheses following the phase notation (reprinted from $\mathrm{Li}$ and Chen, ${ }^{408}$ with permission; (C)2006 American Institute of Physics). (b) A simplified strain phase diagram of $\mathrm{BaTiO}_{3}$ showing the error bars of the prediction from thermodynamic analysis as well as the results on commensurately strained $\mathrm{BaTiO}_{3}$ films grown on various substrates (From Choi et al. $^{203}$ Reprinted with permission from AAAS.)

ferroelectric. This makes SHG a necessary, but insufficient probe for ferroelectricity. A better test for ferroelectricity with SHG is to monitor changes in the symmetry of the SHG response that occur when external electric fields are applied; such changes imply the presence and rearrangement of ferroelectric domains. ${ }^{431-435}$

(A) Strained $\mathrm{SrTiO}_{3}:$ Ferroelectricity in strained $\mathrm{SrTiO}_{3}$ films has been inferred from dielectric constant versus temperature measurements, ${ }^{114,216,291,421,422}$ the tunability of the dielectric constant through an applied electric field at temperatures just above $T_{\mathrm{C}}$, ${ }^{14,291} \mathrm{SHG}$ measurements as a function of temperature and applied fields, ${ }^{416,417,419,421}$ transmission IR measurements as a function of temperature showing changes in the soft modes, ${ }^{423}$ piezo-force microscopy measurements as a function of temperature, ${ }^{416}$ time-resolved confocal scanning optical microscopy, ${ }^{114,418}$ electro-optic response measurements, ${ }^{417,420}$ and conventional hysteresis loops as a function of 

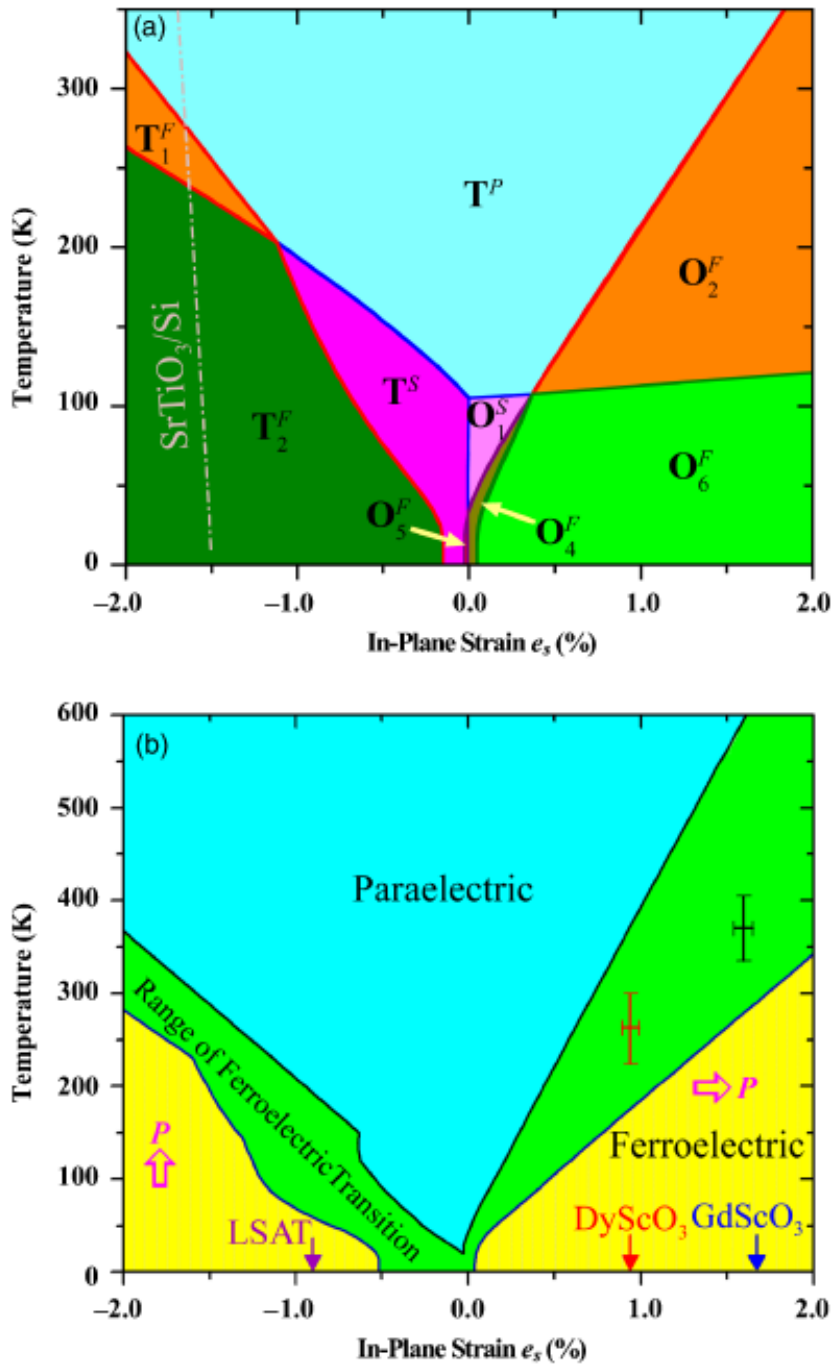

Fig. 16. (a) The strain phase diagram of $(001)_{p}$-oriented $\mathrm{SrTiO}_{3}$ calculated assuming a single-domain state for all structural and ferroelectric phases (adapted from Li et al. ${ }^{415}$ ). Identical nomenclature as Fig. 15 is used to describe the crystallographic symmetry of the phases and order parameters. This diagram has only a minor difference from that presented in Pertsev et al. ${ }^{412,413}$ (b) A simplified strain phase diagram of $\mathrm{SrTiO}_{3}$ showing the error bars of the prediction from thermodynamic analysis as well as the results on commensurately strained $\mathrm{SrTiO}_{3}$ films grown on various substrates. (Adapted from Haeni et al. ${ }^{14}$ )

temperature and orientation..$^{216,421,422}$ The combined experimental evidence from these methods is consistent with the predicted effect of strain on the ferroelectric transition and antiferrodistortive transition of $\mathrm{SrTiO}_{3} \cdot{ }^{114,412-417,419,421}$ With strain, $\mathrm{SrTiO}_{3}$ becomes a multiferroic. ${ }^{416,419,421}$

An overlay of the paraelectric-to-ferroelectric transition temperature found in commensurately strained $\mathrm{SrTiO}_{3}$ films grown on different substrates is shown in Fig. 16(b) together with a simplified version of the prediction of strain on $\mathrm{SrTiO}_{3}$ (Fig. 16(a)) that includes the error bars of the thermodynamic analysis. Thermodynamic analysis utilizes the electrostrictive coefficients and elastic constants of $\mathrm{SrTiO}_{3}$. The strain phase diagram shown in Fig. 16(a) was made using a chosen set of these coefficients from the literature for measurements on $\mathrm{SrTiO}_{3}$ single crystals. If instead of using a chosen set of these property coefficients, the range of reported values of the electrostrictive and elastic coefficients of $\mathrm{SrTiO}_{3}$ single crystals are included in the thermodynamic analysis, the uncertainty of the predicted effect of strain on the ferroelectric transition of $\mathrm{SrTiO}_{3}$ emerges. This range is explicitly shown in Fig. 16(b). As is evident, the observed effect of strain on the ferroelectric transition of $\mathrm{SrTiO}_{3}$ is remarkably consistent with theory.
These strained $\mathrm{SrTiO}_{3}$ films grown on (110) $\mathrm{DyScO}_{3}$ substrates show a tunability of the dielectric constant at room temperature of $82 \%$ at $10 \mathrm{GHz}$ and dielectric constant maxima near 20000 at $500 \mathrm{~Hz}^{114,216,291}$ Strain enables room temperature access to the high and electric-field-tunable dielectric properties of $\mathrm{SrTiO}_{3}, 114,216$ normally seen only at cryogenic temperatures. ${ }^{436,437}$

(B) Strained $\mathrm{BaTiO}_{3}$ : The ferroelectric properties of $\mathrm{BaTiO}_{3}$ thin films have been dramatically enhanced using biaxial compressive strains up to $1.7 \%$ imposed by coherent epitaxial film growth on $\mathrm{REScO}_{3}$ substrates. ${ }^{203}$ In addition to significantly increasing the remanent polarization $\left(P_{\mathrm{r}}\right), T_{\mathrm{C}}$ was increased by nearly $500^{\circ} \mathrm{C} .{ }^{203}$ To establish $T_{\mathrm{C}}$, a combination of techniques was used because of the high temperatures involved and the electrical leakage of the thin $\mathrm{BaTiO}_{3}$ films at high temperatures. The conventional test for ferroelectricity, hysteresis measurements, was used at room temperature to establish ferroelectricity. Then SHG and the temperature dependence of the out-of-plane lattice parameter was measured from the temperature of the hysteresis loops to where kinks were seen in the temperature-dependent XRD and SHG to establish $T_{\mathrm{C}}$. The temperatures seen by both methods were in agreement with each other and with the predictions of thermodynamic analysis (Fig. 15). ${ }^{203,291,402,407,408}$

An overlay of the experimentally observed effect of strain on the ferroelectric transition of commensurately strained $\mathrm{BaTiO}_{3}$ films grown on different substrates is shown in Fig. 15(b). Again the range in the theoretical predictions calculated using the range of relevant property coefficients reported for $\mathrm{BaTiO}_{3}$ single crystals is shown and the agreement is again excellent. The epitaxial $\mathrm{BaTiO}_{3}$ films for Fig. 15(b) were grown by both PLD and MBE. The similarity of the results by these two very different thin film preparation techniques is evidence that the observed strain effects represent the intrinsic effect of biaxial strain on $\mathrm{BaTiO}_{3}$.

The first study of the effect of biaxial strain on the ferroelectric properties of $\mathrm{BaTiO}_{3}$ dates more than 50 years when $\mathrm{P}$. W. Forsbergh built a special fixture to biaxially strain a $\mathrm{BaTiO}_{3}$ single crystal. ${ }^{438}$ His observations of the effect of biaxial strain on $\mathrm{BaTiO}_{3}$ single crystals are qualitatively similar to those observed in biaxially strained films: biaxial strain increases $T_{\mathrm{C}}$. A notable difference, however, is that a $T_{\mathrm{C}}$ enhancement of only $\sim 10 \mathrm{~K}$ was observed for the strained $\mathrm{BaTiO}_{3}$ single crystals before they broke. ${ }^{438}$ A much larger strain effect can be seen in films because they can withstand far greater strains before fracture on account of their thinness, ${ }^{392,393}$ which enables a plane stress condition to be controllably applied.

The resulting ferroelectric properties of strained $\mathrm{BaTiO}_{3}$ films are comparable to those exhibited by unstrained $\mathrm{Pb}\left(\mathrm{Zr}_{x} \mathrm{Ti}_{1-x}\right) \mathrm{O}_{3}$, but in a more environmentally benign composition that is free of lead. These results demonstrate how strain can be used as a route to lead-free ferroelectrics for device applications, e.g., nonvolatile memories and electro-optic devices.

(C) Strained $\mathrm{EuTiO}_{3}$ : Strong coupling between the magnetic and ferroelectric order parameters via a spin-phonon interaction was recently predicted to occur in appropriately strained $\mathrm{EuTiO}_{3}{ }^{439}$ Although unstrained $\mathrm{EuTiO}_{3}$ is paraelectric and antiferromagnetic at low temperatures, first-principle calculations indicate that $(001)_{p} \mathrm{EuTiO}_{3}$ under a biaxial compressive strain of about $1 \%$ is on the verge of a transition to a ferroelectric and ferromagnetic state. For such strained $\mathrm{EuTiO}_{3}$ films, the application of a modest electric field of order $10^{5} \mathrm{~V} / \mathrm{cm}$ is predicted to induce ferromagnetism with a magnetization of 7 $\mu_{\mathrm{B}}$ per europium atom. Similarly, the application of a modest magnetic field of order $1 \mathrm{~T}$ is predicted to induce ferroelectricity with a spontaneous polarization of about $10 \mu \mathrm{C} / \mathrm{cm}^{2}$. 439 The predicted coupling between the magnetic and ferroelectric order parameters in this strain-enabled material is orders of magnitude larger than any known multiferroic and a fantastic opportunity for strain tuning. Recent measurements of strained $\mathrm{EuTiO}_{3}$ films show excellent agreement with theory on the dependence of the soft-mode frequencies on strain, and ferroelectricity at room 
temperature has been observed in commensurately strained $\mathrm{EuTiO}_{3}$ films. ${ }^{423}$

\section{(2) Modulation Doping}

Two-dimensional electron gases (2DEG) have been widely investigated in conventional semiconductors ${ }^{440}$ and more recently in the II-VI semiconducting oxide $\mathrm{ZnO}^{441}$ But functional oxides have properties drastically different than conventional semiconductors. The perovskite $\mathrm{SrTiO}_{3}$, for example, has an electron effective mass $\left(m_{e}^{*}=5 m_{o}\right)^{442,443}$ and dielectric constant $\left(\varepsilon_{\mathrm{r}}=20000 \text { at } 4 \mathrm{~K}\right)^{436}$ orders of magnitude higher than conventional semiconductors and the highest electron mobility $\left(\mu_{n}^{\text {bulk }}=22000 \mathrm{~cm}^{2} / \mathrm{V} \text { s at } 2 \mathrm{~K}\right)^{11}$ of any known oxide. This completely different regime of semiconducting properties, coupled with the occurrence of superconductivity in appropriately electron-doped $\mathrm{SrTiO}_{3},{ }^{444}$ makes the study of the behavior of a $2 \mathrm{DEG}$ in $\mathrm{SrTiO}_{3}$ of great interest. The desire to study a 2DEG in $\mathrm{SrTiO}_{3}$ was recognized long ago, ${ }^{445}$ and was recently achieved experimentally using a $\mathrm{LaAlO}_{3} / \mathrm{SrTiO}_{3}$ heterostructure. ${ }^{10}$

Modulation doping, the dominant technique used to realize 2DEGs in conventional semiconductors, ${ }^{446}$ is not foreign to oxides. Indeed it occurs naturally in layered functional oxides, e.g., oxide superconductors, as "charge reservoir" layers donate their carriers to surrounding $\mathrm{CuO}_{2}$ layers. ${ }^{447}$ In addition to the movement of charge (electronic compensation) relevant for the formation of a 2DEG, another way that an oxide may provide compensating charge is via charged defects (ionic compensation). Hence, to achieve modulation doping in oxides, one must overcome ionic compensation mechanisms. Modulation doping has begun to be applied artificially to oxides, ${ }^{448}$ although information on the band offsets, a critical element of bandgap engineering, is generally lacking for oxide heterojunctions. This process can be engineered through the controlled growth of oxide heterostructures and due to the functional properties of oxides, the formation, study, and exploitation of 2DEGs in them is an area with tremendous potential. Exploration of the behavior of ferroelectric, magnetic, or even spin-polarized 2DEGs is within reach.

\section{(3) Confined Thickness-Finite Size Effects in Superlattices}

Thin film techniques offer powerful ways to assemble new materials, including metastable ones, that cannot be made by other methods. For single layer films, metastable materials may be accessed through epitaxial stabilization. ${ }^{159,357-359}$ In multilayer films the tremendous difference between the diffusion coefficient at the surface of the growing thin film compared with the much lower diffusion coefficient within the bulk of the film, including buried interfaces, makes it possible to create two-phase mixtures of end member phases, even for materials that exhibit are fully miscible with each other in bulk form. This is used in the synthesis of many compound semiconductor device structures, e.g., AlAs/GaAs heterostructures, which are metastable heterostructures because their solid solution has a lower free energy over their entire composition range. ${ }^{449}$ Similarly, heterostructures involving ferroelectrics such as $\mathrm{PbTiO}_{3} / \mathrm{SrTiO}_{3}$ or $\mathrm{BaTiO}_{3} / \mathrm{SrTiO}_{3}$ are metastable; it is energetically favorable for these oxides to dissolve into each other forming $(\mathrm{Pb}, \mathrm{Sr}) \mathrm{TiO}_{3}$ and $(\mathrm{Ba}, \mathrm{Sr}) \mathrm{TiO}_{3}$ solid solutions. ${ }^{450,451}$ Although these superlattices are metastable, cation diffusion constants in oxides are sufficiently small that annealing at $1000^{\circ} \mathrm{C}$ for several hours is typically required before intermixing effects become discernable. ${ }^{79}$ As can be seen in Fig. 17, the interface abruptness and layer thickness control of today's oxide superlattices involving functional oxides ${ }^{79,110,113,117-126,149-157}$ are comparable to what has become commonplace for AlAs/GaAs superlattices grown by $\mathrm{MBE}^{452}$ and MOCVD. ${ }^{453}$

Superlattices consisting of a periodic stacking of thin functional oxide layers have been predicted ${ }^{454} 459$ or reported $^{113,155,235,426,427,460-462}$ to possess many improved physical properties over homogeneous thin films of the same compositions. Among the improved properties are reported enhancements of dielectric constants and remanent polarization in short-period two-component ${ }^{235,460,461}$ and three-component ${ }^{155}$

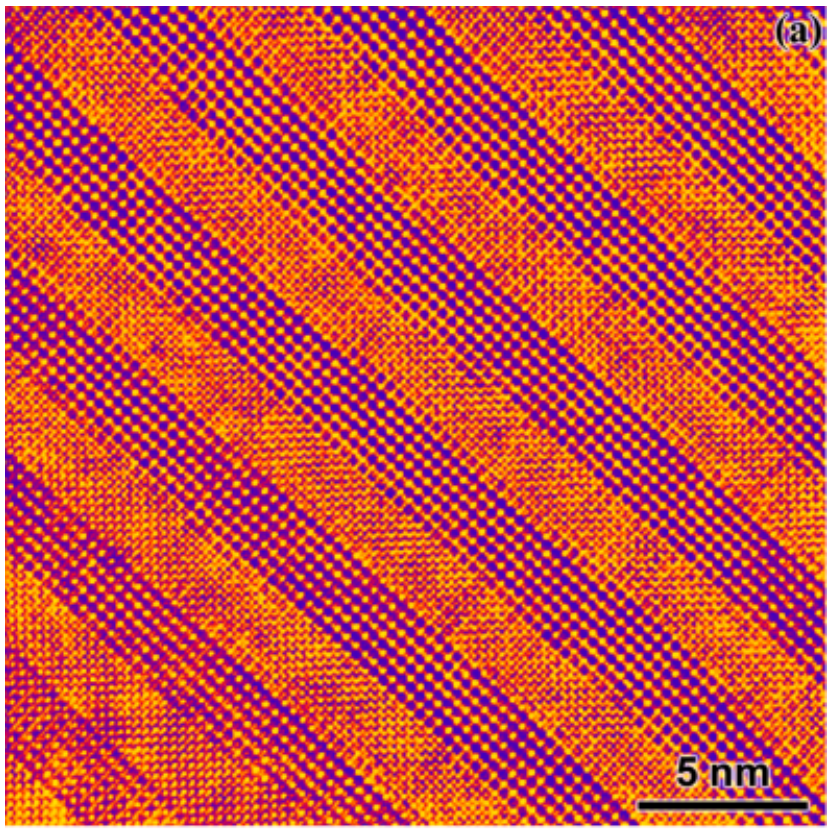

(b)
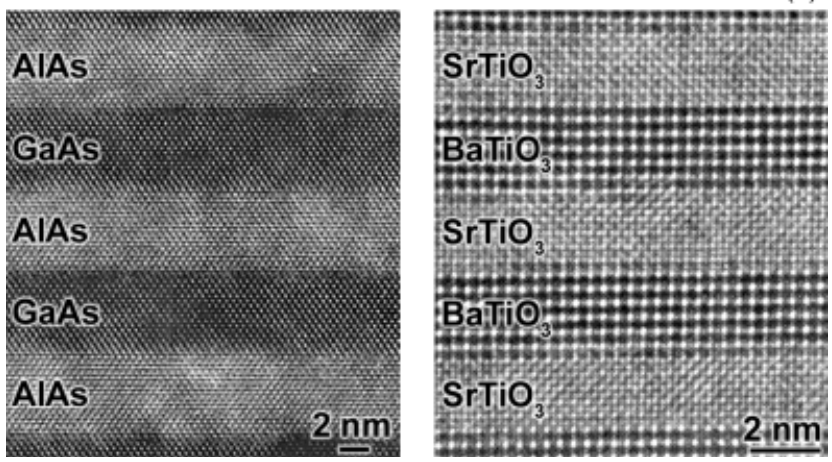

Fig. 17. (a) High-resolution TEM image of a $\mathrm{BaTiO}_{3} / \mathrm{SrTiO}_{3}$ superlattice grown by molecular-beam epitaxy (MBE). (b) A comparison between this same functional oxide superlattice is made with a GaAs/AlAs superlattice (reprinted from Gutakovskii et al., ${ }^{452}$ with permission; (C) 1995 Wiley-VCH). Both superlattices are grown by MBE.

superlattices. While such reports need to be carefully evaluated considering that the movement of space charge in the superlattices can spuriously produce an apparent significant enhancement of dielectric constant, ${ }^{463,464}$ the improved properties could result from the large lattice mismatch leading to huge strains for commensurate epitaxial growth. ${ }^{155,235,460,461}$

Layered heterostructures including superlattices are just one type of epitaxial composite involving functional oxides. Epitaxial heterostructures that make use of phase separation to form connectivities beyond the $2-2$ connectivity ${ }^{386}$ of superlattices are also being explored by thin film techniques. These include 1-3 epitaxial nanocomposites involving pillars of magnetic oxides in a ferroelectric matrix ${ }^{391}$ or pillars of ferroelectric oxides in a magnetic matrix. ${ }^{465}$ These are being explored in ferroelectric systems to enhance the coupling between ferroelectric and magnetic oxides and thus form artificial magneto-electric heterostructures.

Artificially layered superlattices of functional oxides have enormous appeal from both a technological and a fundamental standpoint. With modern deposition techniques the degree of control that can be achieved is astounding and superlattices with essentially perfect interfaces and single-unit-cell constituent layers are well within our grasp. In terms of technology, superlattices of functional oxides with appropriate electrical and mechanical boundary conditions hold the potential of tailoring functional properties precisely for an application; there are some 
indications that under certain circumstances the properties of a superlattice of two or more materials may be far superior to the parent materials from which they have been fabricated.

(A) $\mathrm{BaTiO}_{3} / \mathrm{SrTiO}_{3}$ Superlattices: Crucial to the enlightened (non-Edisonian) synthesis of superior materials is an understanding of how the properties of the resulting superlattice material are related to those of the parent materials used. In superlattices of ferroelectric functional oxides where the in-plane lattice parameter of all the constituents is constrained to that of the underlying substrate, the primary interaction that determines the overall properties of the superlattice seems to be electrostatic, with the principle consideration being the minimization of polarization mismatch between layers, any mismatch giving rise to very high electrostatic energy penalties. ${ }^{456}$ This does not restrict the possibility of strain engineering, as the elastic constraint imposed by the substrate is an important factor in determining the orientation of the polarization in the superlattice layers and thus has a dramatic effect on the properties of the superlattice. Similarly, should a superlattice suffer relaxation due to misfit dislocations, changes in the orientation of the polarization can arise, as seen in the $\mathrm{SrTiO}_{3}$ layers of relaxed $\mathrm{BaTiO}_{3} / \mathrm{SrTiO}_{3}$ superlattices. ${ }^{466-468}$ Beyond the commercial appeal of precisely tailored exceptional materials, these systems also allow an extraordinary opportunity for the exploration of the fundamentals of ferroelectricity. In essence one can produce a system the physics of which is defined by ultra-thin components and interfaces, but with a larger total sample size allowing simple, precise characterization and a detailed exploration of the physics of ferroelectricity in ultra-thin systems.

$(001)_{p} \mathrm{BaTiO}_{3} /(001)_{p} \mathrm{SrTiO}_{3}$ superlattices have also been extensively studied to investigate size effects. In a recent study, ${ }^{157}$ these superlattices were grown on (001) $\mathrm{SrTiO}_{3}$ substrates and the $(001)_{p} \mathrm{BaTiO}_{3}$ layer in the superlattice was varied from 1 to 8 unit cells in thickness, while the $(001)_{p} \mathrm{SrTiO}_{3}$ spacer layer thickness was fixed to be either 4 unit cells or 13 unit cells thick. These superlattices can be denoted by $\left(\mathrm{BaTiO}_{3}\right)_{n} /\left(\mathrm{SrTiO}_{3}\right)_{m}$, where $n$ and $m$ refer to the thickness, in unit cells, of the $(001)_{p} \mathrm{BaTiO}_{3}$ and $(001)_{p} \mathrm{SrTiO}_{3}$ layers, respectively. The reg-

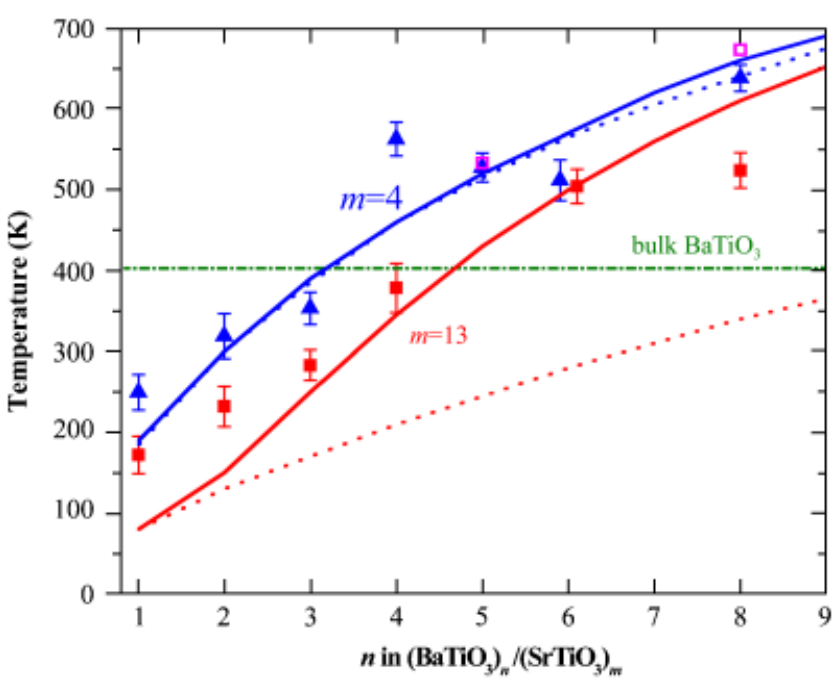

Fig. 19. The dependence of $T_{\mathrm{C}}$ on $n$ and $m$ in $\left(\mathrm{BaTiO}_{3}\right)_{n} /\left(\mathrm{SrTiO}_{3}\right)_{m}$ superlattices. The blue symbols are for $m=4$ and red symbols are for $m=13 . T_{\mathrm{C}}$ was determined by UV Raman (closed symbols) and temperature-dependent X-ray diffraction (open symbols) measurements. A phase-field model with a single-domain assumption yields the dotted curves. The solid lines are from full three-dimensional phase-field calculations. The $T_{\mathrm{C}}$ of bulk unstrained $\mathrm{BaTiO}_{3}$ is also shown (reprinted from Li et al., ${ }^{469}$ with permission; (C)2007 American Institute of Physics).

ularity of these superlattices grown by MBE is demonstrated by the presence and sharpness of all of the superlattice reflections in their XRD patterns. An example is shown in Fig. 18 of the XRD scans of $\left[\left(\mathrm{BaTiO}_{3}\right)_{n} /\left(\mathrm{SrTiO}_{3}\right)_{m}\right]_{p}$ superlattices for (a) $m=4$ and (b) $m=13 \mathrm{SrTiO}_{3}$ layers separating the $\mathrm{BaTiO}_{3}$ layers in the superlattices. ${ }^{237}$ The presence of virtually all satellite peaks in these superlattices attests to their macroscopic structural perfection.
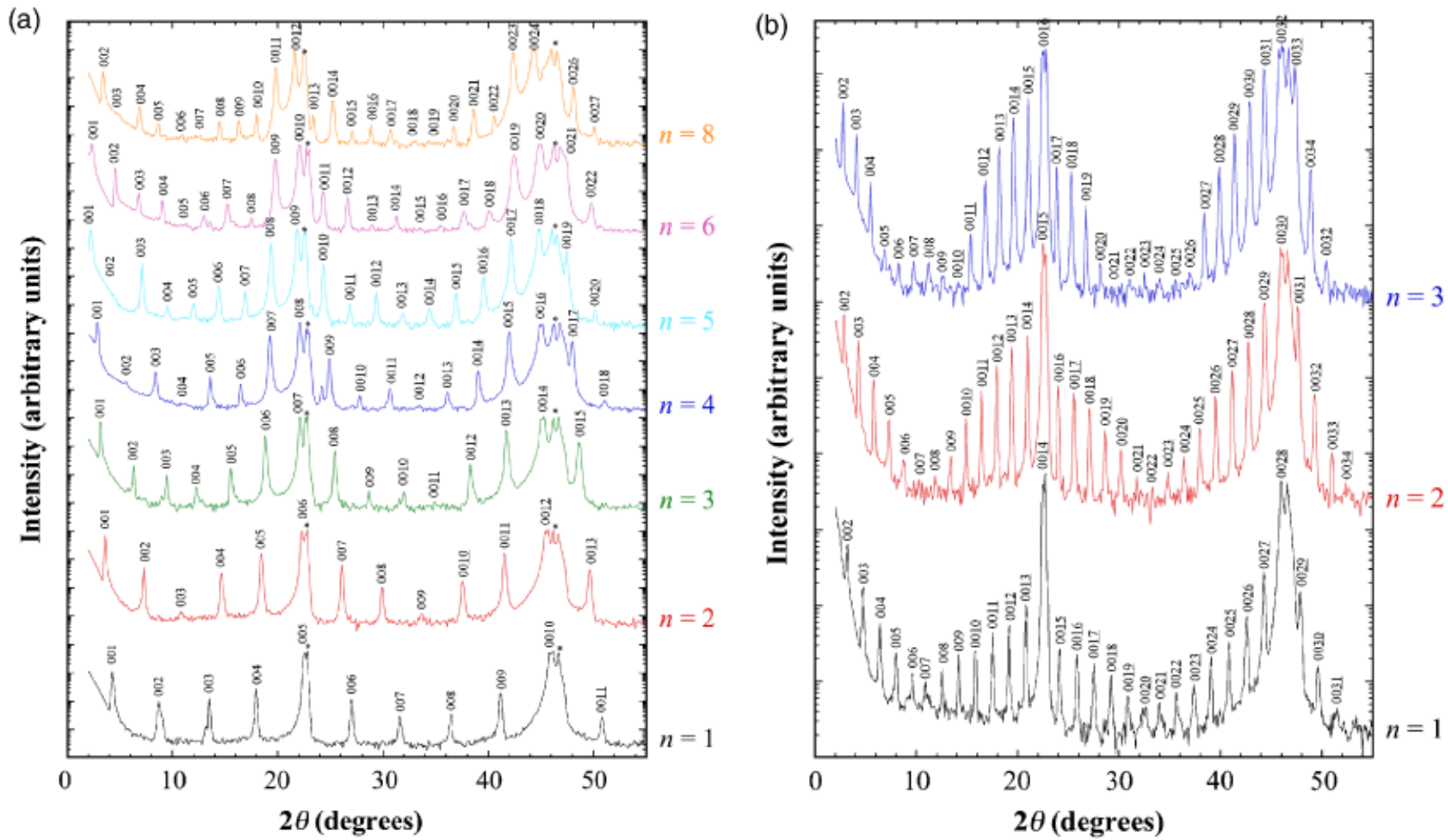

Fig. 18. $\quad \theta-2 \theta \mathrm{X}$-ray diffraction scans of $\left[\left(\mathrm{BaTiO}_{3}\right)_{n} /\left(\mathrm{SrTiO}_{3}\right)_{m}\right]_{p}$ superlattices using $\mathrm{Cu} K_{\alpha}$ radiation for (a) $m=4$ and $n=1,2,3,4,5,6$, and 8 and (b) $m=13$ and $n=1,2$, and 3. Substrate peaks are marked with asterisks $\left(^{*}\right)$. (From Soukiassian et al. ${ }^{237}$ ) 

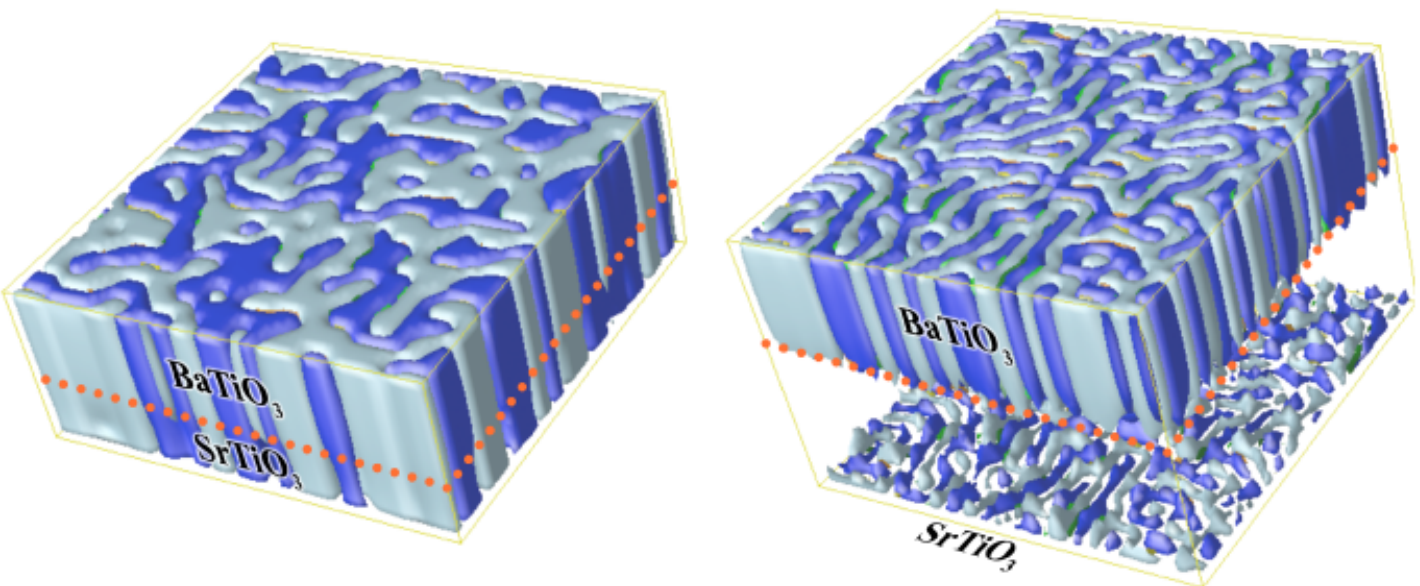

Fig. 20. Calculated multiple domain states of $\left[\left(\mathrm{BaTiO}_{3}\right)_{8} /\left(\mathrm{SrTiO}_{3}\right)_{4}\right]_{p}$ and $\left[\left(\mathrm{BaTiO}_{3}\right)_{8} /\left(\mathrm{SrTiO}_{3}\right)_{13}\right]_{p}$ superlattices. The blue and light-blue colors represent the two types of domains with out-of-plane polarization directions. The interfaces between them are $180^{\circ}$ domain walls. The induced polarization domains are clearly shown in the $\mathrm{SrTiO}_{3}$ layer of the $\left[\left(\mathrm{BaTiO}_{3}\right)_{8} /\left(\mathrm{SrTiO}_{3}\right)_{4}\right]_{p}$ superlattice with polarization values comparable to the $\mathrm{BaTiO}{ }_{3}$ layer. There is only a small induced polarization in the $\mathrm{SrTiO}_{3}$ layer of the $\left[\left(\mathrm{BaTiO}_{3}\right)_{8} /\left(\mathrm{SrTiO}_{3}\right)_{13}\right]_{p}$ superlattice, and hence if we only count regions as domains if their polarization values are above a certain small threshold, there are no observed polarization domains in the $\mathrm{SrTiO}_{3}$ layer for the $\left[\left(\mathrm{BaTiO}_{3}\right)_{8} /\left(\mathrm{SrTiO}_{3}\right)_{13}\right]_{p}$ superlattice.

Characterizing the resulting superlattices by UV Raman made it possible to confirm the prediction that the unstrained $\mathrm{SrTiO}_{3}$ layer in these superlattices is polarized due to the electrostatic effect described above and also enabled the $T_{C}$ of the ferroelectric superlattice to be established. $T_{C}$ is shown as a function of $n$ for $m=4$ and $m=13$ in Fig. 19 together with two different phase-field models of these superlattices. When the phase-field model is limited to a single-domain assumption (dashed lines in Fig. 19), the agreement between theory and experiment is good for $m=4$, but poor for $m=13$. Put another way, the $(001)_{p} \quad \mathrm{BaTiO}_{3} /(001)_{p} \quad \mathrm{SrTiO}_{3}$ superlattices show disagreement with theory when the $\mathrm{BaTiO}_{3}$ layer is thinner than the $\mathrm{SrTiO}_{3}$ layer, just as was seen for $(001)_{p} \mathrm{PbTiO}_{3} /$ $(001)_{p} \mathrm{SrTiO}_{3}$ superlattices. ${ }^{156}$ First principles calculations also operate under a single-domain assumption because of the limited number of atoms in the calculation. When a full three-dimensional phase-field simulation is performed (solid lines in Fig. 19), the agreement between theory and experiment becomes good for both $m=4$ and $m=13$ over the entire range. These calculations indicate that the low-energy configuration is a multiple-domain state, which allows the polarization in the $(001)_{p}$ $\mathrm{SrTiO}_{3}$ layers to drop considerably when the $(001)_{p} \mathrm{BaTiO}_{3}$ layer is thinner than the $(001)_{p} \mathrm{SrTiO}_{3}$ layer, and results in a significant increase of $T_{C}$ compared with the single-domain state. $^{157,469}$ The calculated multiple domain states of [(BaT$\left.\left.\mathrm{iO}_{3}\right)_{8} /\left(\mathrm{SrTiO}_{3}\right)_{4}\right]_{p}$ and $\left[\left(\mathrm{BaTiO}_{3}\right)_{8} /\left(\mathrm{SrTiO}_{3}\right)_{13}\right]_{p}$ superlattices are shown in Fig. 20. It is found that while the $\mathrm{SrTiO}_{3}$ layer in $\left[\left(\mathrm{BaTiO}_{3}\right)_{8} /\left(\mathrm{SrTiO}_{3}\right)_{4}\right]_{p}$ is fully polarized with polarization values that are comparable to the $\mathrm{BaTiO}_{3}$ layer, the polarization in $\mathrm{SrTiO}_{3}$ for the $\left[\left(\mathrm{BaTiO}_{3}\right)_{8} /\left(\mathrm{SrTiO}_{3}\right)_{13}\right]_{p}$ superlattice is much smaller. The $180^{\circ}$ walls between the blue domains and lightblue domains in $\left[\left(\mathrm{BaTiO}_{3}\right)_{8} /\left(\mathrm{SrTiO}_{3}\right)_{4}\right]_{p}$ display continuity from $\mathrm{BaTiO}_{3}$ to $\mathrm{SrTiO}_{3}$. Therefore, a single-domain assumption for the $\left[\left(\mathrm{BaTiO}_{3}\right)_{8} /\left(\mathrm{SrTiO}_{3}\right)_{4}\right]_{p}$ superlattice would be reasonable, whereas the same assumption would lead to a large error in the transition temperature for the $\left[\left(\mathrm{BaTiO}_{3}\right)_{8} /\left(\mathrm{SrTiO}_{3}\right)_{13}\right]_{p}$ superlattice.

\section{Outlook}

The use of thin film techniques for the growth of functional oxides is still in its infancy and many hurdles remain to be overcome for these techniques to develop greater structural control at the atomic layer level, reproducibility, and ultimately precise control of electronic, optical, and spintronic properties. Nonetheless, PLD has become established as an extremely swift and nimble method for rapidly synthesizing epitaxial films and he- terostructures of functional oxides. MBE is the premiere synthesis technique for the synthesis of layered oxides with customized layering control down to the atomic layer level. As the complexity and metastability of desired functional oxides and heterostructures involving functional oxides increases, the need to improve these atomic layer engineering techniques will become all the more important. Accurate composition control is key to the controlled growth of such structures and with improvements in composition control, further improvements in the perfection of the layering control attainable in the growth of functional oxides by MBE is expected.

Traditionally the search for new functional materials involves identifying bulk unstrained phases that exist within composition space. But the available configurational space for functional materials in thin films includes additional degrees of freedom: strain and dimensional confinement. Navigating this vastly increased dimensional space in search of functional materials with improved properties is a daunting task without guidance. Luckily today's multiscale modeling techniques are a tremendous aid in identifying likely locations for improved functional materials. This starts with first-principles methods ${ }^{15,29,157,235,291,416,470-475}$ to elucidate the potential of new functional oxides including microstructures and strain states that are metastable. Continuum techniques may then be used to extend first-principles predictions to multidomain samples, finite temperatures, and include the dynamics of domain switching. ${ }^{14,157,203,235,291}$, $402,405,406,408,412,413,415,416,471$ The resulting calculated phase diagrams including the effect of large strains are rich and depict how strain can greatly extend the range of functional behavior, performance, and utility beyond bulk compounds. ${ }^{114,203,291,402,412,413,470,471,476}$ These modern theoretical methods can target specific compositions, strains, and dimensional confinement for improved functionality and have enjoyed considerable success, e.g., in the fields of ferroelectrics and multiferroics, for predicting the properties of new materials. Many of these new functional oxides are metastable and others attain their improved functionality via strain (strain-enabled). We firmly believe that a theory-driven intelligent approach is imperative for efficiently finding novel or greatly enhanced functional properties in oxides.

\section{Acknowledgments}

We gratefully acknowledge our colleagues and collaborators for sharing their insights and helping us to prepare, explore, and better understand the exciting area of functional oxide thin films. We especially thank C. Adamo, O. Auciello, M. D. Biegalski, D. H. A. Blank, I. Bozovic, C. D. Brandle, A. Bruchhausen, A. Cantarero, W. Chang, Y. B. Chen, K. J. Choi, S. Choudhury, H.-M. Christen, B. 
Craigo, L. E. Cross, J. A. Eastman, J. N. Eckstein, C. B. Eom, A. Fainstein, C. J. Fennie, D. D. Fong, V. J. Fratello, P. H. Fuoss, V. Gopalan, J. H. Haeni, M. E. Hawley, T. Heeg, J. F. Ihlefeld, P. Irvin, Q. X. Jia, Y. Jia, J.C. Jiang, S. Kamba, R. S. Katiyar, X. Ke, D. M. Kim, S. W. Kirchoefer, H. Kohlstedt, A. Kumar, N. D. Lanzillotti-Kimura, J. H. Lee, J. Lettieri, J. Levy, Y. L. Li, F. Lichtenberg, Y. Liu, H. Z. Ma, J. Mannhart, L. Maritato, R. A. McKee, R. E. Newnham, K. M. Rabe, R. Ramesh, P. Reiche, J. Rodriguez-Contreras, P. Schiffer, J. Schubert, A. Sharan, V. Sherman, A. Soukiassian, N. A. Spaldin, G. B. Stephenson, S. K. Streiffer, H. P. Sun, A. K. Tagantsev, D. A. Tenne, C. D. Theis, C. Thompson, W. Tian, J.-M. Triscone, S. Trolier-McKinstry, R. Uecker, V. Vaithyanathan, A. Vasudevarao, F. J. Walker, M. Warusawithana, P. P. Wu, A. J. Ven Graitis, and X. X. Xi.

\section{References}

${ }^{1}$ P. A. Salvador, A.-M. Haghiri-Gosnet, B. Mercey, M. Hervieu, and B. Raveau, "Growth and Magnetoresistive Properties of $\left(\mathrm{LaMnO}_{3}\right)_{m}\left(\mathrm{SrMnO}_{3}\right)_{n}$ Superlattices," Appl. Phys. Lett., 75 [17] 2638-40 (1999).

${ }^{2}$ T. Koida, M. Lippmaa, T. Fukumura, K. Itaka, Y. Matsumoto, M. Kawasaki, and H. Koinuma, "Effect of $A$-Site Cation Ordering on the Magnetoelectric Properties in $\left[\left(\mathrm{LaMnO}_{3}\right)_{m} /\left(\mathrm{SrMnO}_{3}\right)_{m}\right]_{n}$ Artificial Superlattices," Phys. Rev. B, 66 [14] 144418 (2002)

${ }^{3}$ H. Yamada, M. Kawasaki, T. Lottermoser, T. Arima, and Y. Tokura, "LaM$\mathrm{nO}_{3} / \mathrm{SrMnO}_{3}$ Interfaces with Coupled Charge-Spin-Orbital Modulation," Appl. Phys. Lett., 89 [5] 052506 (2006).

${ }^{4}$ A. Bhattacharya, X. Zhai, M. Warusawithana, J. N. Eckstein, and S. D. Bader, "Signatures of Enhanced Ordering Temperatures in Digital Superlattices of (LaM$\left.\mathrm{nO}_{3}\right)_{m} /\left(\mathrm{SrMnO}_{3}\right)_{2 m}, "$ Appl. Phys. Lett., 90 [22] 222503 (2007).

${ }^{5}$ S. J. May, A. B. Shah, S. G. E. te Velthuis, M. R. Fitzsimmons, J. M. Zuo, X Zhai, J. N. Eckstein, S. D. Bader, and A. Bhattacharya, "Magnetically Asymmetric Interfaces in a $\mathrm{LaMnO}_{3} / \mathrm{SrMnO}_{3}$ Superlattice due to Structural Asymmetries," Phys. Rev. B, 77 [17] 174409 (2008).

${ }^{6}$ A. Bhattacharya, S. J. May, S. G. E. te Velthuis, M. Warusawithana, X. Zhai, B. Jiang, J.-M. Zuo, M. R. Fitzsimmons, S. D. Bader, and J. N. Eckstein, "Metal-Insulator Transition and Its Relation to Magnetic Structure in (LaM$\left.\mathrm{nO}_{3}\right)_{2 n} /\left(\mathrm{SrMnO}_{3}\right)_{n}$ Superlattices," Phys. Rev. Lett., 100 [25] 257203 (2008)

${ }^{7}$ C. Adamo, X. Ke, P. Schiffer, A. Soukiassian, M. Warusawithana, L. Maritato, and D. G. Schlom, "Electrical and Magnetic Properties of $\left(\mathrm{SrMnO}_{3}\right)_{n}$ $\left(\mathrm{LaMnO}_{3}\right)_{2 n}$ Superlattices," Appl. Phys. Lett., 92 [11] 112508 (2008)

${ }^{8}$ A. Ohtomo and H. Y. Hwang, "A High-Mobility Electron Gas at the $\mathrm{LaAlO}_{3}$ $\mathrm{SrTiO}_{3}$ Heterointerface," Nature, 427 [6973] 423-6 (2004)

${ }^{9}$ A. Brinkman, M. Huijben, M. van Zalk, J. Huijben, U. Zeitler, J. C. Maan, W. G. van der Wiel, G. Rijnders, D. H. A. Blank, and H. Hilgenkamp, "Magnetic Effects at the Interface Between Non-Magnetic Oxides," Nat. Mater., 6 [7] 493-6 (2007).

${ }^{10}$ N. Reyren, S. Thiel, A. D. Caviglia, L. Fitting Kourkoutis, G. Hammerl, C. Richter, C. W. Schneider, T. Kopp, A.-S. Rüetschi, D. Jaccard, M. Gabay, D. A. Muller, J.-M. Triscone, and J. Mannhart, "Superconducting Interfaces Between Insulating Oxides," Science, 317 [5842] 1196-9 (2007).

${ }^{11}$ O. N. Tufte and P. W. Chapman, "Electron Mobility in Semiconducting Strontium Titanate," Phys. Rev., 155 [3] 796-802 (1967).

${ }^{12}$ G. Petrich, S. von Molnár, and T. Penney, "Exchange-Induced Autoionization in Eu-Rich EuO," Phys. Rev. Lett., 26 [15] 885-8 (1971).

${ }^{13}$ A. Schilling, M. Cantoni, J. D. Guo, and H. R. Ott, "Superconductivity Above $130 \mathrm{~K}$ in the $\mathrm{Hg}-\mathrm{Ba}-\mathrm{Ca}-\mathrm{Cu}-\mathrm{O}$ System," Nature, 363 [6424] 56-8 (1993).

${ }^{14}$ I. Vrejoiu, G. Le Rhun, L. Pintilie, D. Hesse, M. Alexe, and U. Gösele, "Intrinsic Ferroelectric Properties of Strained Tetragonal $\mathrm{PbZr}_{0.2} \mathrm{Ti}_{0.8} \mathrm{O}_{3}$ Obtained on Layer-by-Layer Grown, Defect-Free Single-Crystalline Films," Adv. Mater., 18 [13] 1657-61 (2006).

${ }^{15}$ J. Wang, J. B. Neaton, H. Zheng, V. Nagarajan, S. B. Ogale, B. Liu, D. Viehland, V. Vaithyanathan, D. G. Schlom, U. V. Waghmare, N. A. Spaldin, K. M. Rabe, M. Wuttig, and R. Ramesh, "Epitaxial $\mathrm{BiFeO}_{3}$ Multiferroic Thin Film Heterostructures," Science, 299 [5613] 1719-22 (2003).

${ }^{16}$ J. F. Li, J. Wang, M. Wuttig, R. Ramesh, N. Wang, B. Ruette, A. P. Pyatakov, A. K. Zvezdin, and D. Viehland, "Dramatically Enhanced Polarization in (001), (101), and (111) $\mathrm{BiFeO}_{3}$ Thin Films due to Epitiaxial-Induced Transitions," Appl. Phys. Lett., 84 [25] 5261-3 (2004).

${ }^{17}$ R. R. Das, D. M. Kim, S. H. Baek, C. B. Eom, F. Zavaliche, S. Y. Yang, R Ramesh, Y. B. Chen, X. Q. Pan, X. Ke, M. S. Rzchowski, and S. K. Streiffer, "Synthesis and Ferroelectric Properties of Epitaxial $\mathrm{BiFeO}_{3}$ Thin Films Grown by Sputtering," Appl. Phys. Lett., 88 [24] 242904 (2006).

${ }^{18}$ J. Dho, X. Qi, H. Kim, J. L. MacManus-Driscoll, and M. G. Blamire, "Large Electric Polarization and Exchange Bias in Multiferroic $\mathrm{BiFeO}_{3}, "$ Adv. Mater., 18 [11] 1445-8 (2006).

${ }^{19}$ S. E. Park and T. R. Shrout, "Ultrahigh Strain and Piezoelectric Behavior in Relaxor Based Ferroelectric Single Crystals," J. Appl. Phys., 82 [4] 1804-11 (1997).

${ }^{20}$ B. T. Matthias, R. M. Bozorth, and J. H. Van Fleck, "Ferromagnetic Interaction in EuO," Phys. Rev. Lett., 7 [5] 160-1 (1961).

${ }^{21}$ A. Maignan, C. Simon, V. Caignaert, and B. Raveau, "Giant Magnetoresistance Ratios Superior to $10^{11}$ in Manganese Perovskites," Solid State Commun., 96 [9] 623-5 (1995).

${ }^{22}$ R. M. Bozorth, E. F. Tilden, and A. J. Williams, "Anisotropy and Magnetostriction of Some Ferrites," Phys. Rev., 99 [6] 1788-98 (1955).

${ }^{23}$ K. Y. Ahn and M. W. Shafer, "Relationship Between Stoichiometry and Properties of EuO Films," J. Appl. Phys., 41 [3] 1260-2 (1970).

${ }^{24}$ R. J. Soulen Jr., J. M. Byers, M. S. Osofsky, B. Nadgorny, T. Ambrose, S. F Cheng, P. R. Broussard, C. T. Tanaka, J. Nowak, J. S. Moodera, A. Barry, and J. M. D. Coey, "Measuring the Spin Polarization of a Metal with a Superconducting Point Contact," Science, 282 [5386] 85-8 (1998).
${ }^{25}$ A. Anguelouch, A. Gupta, G. Xiao, G. X. Miao, D. W. Abraham, S. Ingvarsson, Y. Ji, and C. L. Chien, "Properties of Epitaxial Chromium Dioxide Films Grown by Chemical Vapor Deposition Using a Liquid Precursor," J. Appl. Phys., 91 [10] 7140-2 (2002).

${ }^{26}$ N. Ikeda, H. Ohsumi, K. Ohwada, K. Ishii, T. Inami, K. Kakurai, Y. Mu rakami, K. Yoshii, S. Mori, Y. Horibe, and H. Kito, "Ferroelectricity from Iron Valence Ordering in the Charge-Frustrated System $\mathrm{LuFe}_{2} \mathrm{O}_{4}, "$ Nature, 436 [4039] 1136-8 (2005).

${ }^{27}$ C. J. Fennie, "Ferroelectrically Induced Weak Ferromagnetism by Design," Phys. Rev. Lett., 100 [16] 167203 (2008).

${ }^{28}$ A. Moreira dos Santos, S. Parashar, A. R. Raju, Y. S. Zhao, A. K. Cheetham, and C. N. R. Rao, "Evidence for the Likely Occurrence of Magnetoferroelectricity in the Simple Perovskite, $\mathrm{BiMnO}_{3}$," Solid State Commun., 122 [1-2] $49-52$ (2002). ${ }^{29}$ N. A. Hill and K. M. Rabe, "First-Principles Investigation of Ferromagnetism and Ferroelectricity in Bismuth Manganite," Phys. Rev. B, 59 [13] 8759-69 (1999).

${ }^{30}$ A. Sharan, J. Lettieri, Y. Jia, W. Tian, X. Q. Pan, D. G. Schlom, and V. Gopalan, "Bismuth Manganite: A Multiferroic with a Large Nonlinear Optical Response," Phys. Rev. B, 69 [21] 214109 (2004).

${ }^{31}$ P. Baettig, R. Seshadri, and N. A. Spaldin, "Anti-Polarity in Ideal $\mathrm{BiMnO}_{3}$," J. Am. Chem. Soc., 129 [32] 9854-5 (2007).

${ }^{32}$ R. D. Shannon, "Revised Effective Ionic Radii and Systematic Studies of Interatomic Distances in Halides and Chalcogenides," Acta Cryst. A, 32 [5] 751-67 (1976).

${ }^{33}$ K.-H. Hellwege and A. M. Hellwege, Landolt-Börnstein: Numerical Data and Functional Relationships in Science and Technology, Group III, Vol. 12a, pp. 126206. Springer-Verlag, Berlin, 1978.

${ }^{34}$ D. Balz and K. Plieth, "Die Struktur des Kaliumnickelfluorids, $\mathrm{K}_{2} \mathrm{NiF}_{4}$," Z. Elektrochem., 59 [6] 545-51 (1955)

${ }^{35}$ S. N. Ruddlesden and P. Popper, "New Compounds of the $\mathrm{K}_{2} \mathrm{NiF}_{4}$ Type," Acta Cryst., 10 [8] 538-9 (1957).

${ }^{36} \mathrm{~S}$. N. Ruddlesden and P. Popper, "The Compound $\mathrm{Sr}_{3} \mathrm{Ti}_{2} \mathrm{O}_{7}$ and Its Structure," Acta Cryst., 11 [1] 54-5 (1958).

${ }^{37}$ Y. Maeno, H. Hashimoto, K. Yoshida, S. Nishizaki, T. Fujita, J. G. Bednorz, and F. Lichtenberg, "Superconductivity in a Layered Perovskite without Copper," Nature, 372 [6506] 532-4 (1994).

${ }^{38}$ A. Callaghan, C. W. Moeller, and R. Ward, "Magnetic Interactions in Ternary Ruthenium Oxides," Inorg. Chem., 5 [9] 1572-6 (1966).

${ }^{39}$ O. Auciello, J. F. Scott, and R. Ramesh, "The Physics of Ferroelectric Memories," Phys. Today, 51 [7] 22-7 (1998).

${ }^{40}$ J. F. Scott, “Applications of Modern Ferroelectrics," Science, 315 [5814] 954 9 (2007).

${ }^{41}$ M. A. Zurbuchen, R. S. Freitas, M. J. Wilson, P. Schiffer, M. Roeckerath, J. Schubert, M. D. Biegalski, G. H. Mehta, D. J. Comstock, J. H. Lee, Y. Jia, and D G. Schlom, "Synthesis and Characterization of an $n=6$ Aurivillius Phase Incorporating Magnetically Active Manganese, $\mathrm{Bi}_{7}(\mathrm{Mn}, \mathrm{Ti})_{6} \mathrm{O}_{21}$, , Appl. Phys. Lett., 91 [3] 033113 (2007).

${ }^{42}$ B. G. Hyde and S. Andersson, Inorganic Crystal Structures. Wiley-Interscience, New York, 1989.

${ }^{43}$ C. N. R. Rao and B. Raveau, Transition Metal Oxides: Structure, Properties, and Synthesis of Ceramic Oxides, 2nd edition, pp. 61-226. Wiley-VCH, New York, 1998.

${ }^{44}$ D. R. Veblen, "Polysomatism and Polysomatic Series: A Review and Applications," Am. Mineral., 76 [5-6] 801-26 (1991)

${ }^{45}$ R. J. D. Tilley, "An Electron Microscope Study of Perovskite-Related Oxides in the Sr-Ti-O System," J. Solid State Chem., 21 [4] 293-301 (1977).

${ }^{46}$ J. L. Hutchison, J. S. Anderson, and C. N. R. Rao, "Electron Microscopy of Ferroelectric Bismuth Oxides Containing Perovskite Layers," Proc. R. Soc. London, Ser. A, 355 [1682] 301-12 (1977).

${ }^{47}$ J. Drennan, C. P. Tavares, and B. C. H. Steele, "An Electron Microscope Investigation of Phases in the System La-Ni-O," Mater. Res. Bull., 17 [5] 621-6 (1982).

${ }^{48}$ J. Gopalakrishnan, A. Ramanan, C. N. R. Rao, D. A. Jefferson, and D. J. Smith, "A Homologous Series of Recurrent Intergrowth Structures of the Type $\mathrm{Bi}_{4} A_{m+n-2} B_{m+n} \mathrm{O}_{3(m+n)+6}$ Formed by Oxides of the Aurivillius Family," J. Solid State Chem., 55 [1] 101-5 (1984).

${ }^{49}$ D. A. Jefferson, M. K. Uppal, C. N. R. Rao, and D. J. Smith, "Elastic Strain at the Solid-Solid Interface in Intergrowth Structures: A Novel Example of Partial Structure Refinement by HREM," Mater. Res. Bull., 19 [11] 1403-9 (1984).

${ }^{50}$ C. N. R. Rao and J. M. Thomas, "Intergrowth Structures: The Chemistry of Solid-Solid Interfaces," Acc. Chem. Res., 18, 113-9 (1985).

${ }^{51}$ R. A. Mohan Ram, L. Ganapathi, P. Ganguly, and C. N. R. Rao, "Evolution of Three-Dimensional Character across the $\mathrm{La}_{n+1} \mathrm{Ni}_{n} \mathrm{O}_{3 n+1}$ Homologous Series with Increase in $n$," J. Solid State Chem., 63 [2] 139-47 (1986).

${ }^{52}$ J. M. Tarascon, W. R. McKinnon, P. Barboux, D. M. Hwang, B. G. Bagley, L. H. Greene, G. W. Hull, Y. LePage, N. Stoffel, and M. Giroud, "Preparation, Structure, and Properties of the Superconducting Compound Series $\mathrm{Bi}_{2} \mathrm{Sr}_{2}$ $\mathrm{Ca}_{n-1} \mathrm{Cu}_{n} \mathrm{O}_{y}$ with $n=1,2$, and 3," Phys. Rev. B, 38 [13] 8885-92 (1988).

${ }^{53}$ B. Raveau, C. Michel, and M. Hervieu, "Crystal Chemistry of Superconductive Bismuth and Thallium Cuprates"; pp. 151-7 in Advances in Superconductivity: Proceedings of the 1st International Symposium on Superconductivity (ISS '88), Edited by K. Kitazawa, and T. Ishiguro. Springer-Verlag, Tokyo, 1989.

${ }^{54}$ W. T. Fu, H. W. Zandbergen, Q. Xu, J. M. van Ruitenbeek, L. J. de Jongh, and G. van Tendeloo, "Structural and Transport Properties of the Triple-Layer Compounds $\mathrm{Ba}_{4}\left(\mathrm{~Pb}_{1-x} \mathrm{Bi}_{x}\right)_{3} \mathrm{O}_{10}(0 \leq x<0.3)$," Solid State Commun., 70 [12] 1117 21 (1989).

${ }^{55} \mathrm{O}$. Eibl, "Crystal Defects in $\mathrm{Bi}_{2} \mathrm{Sr}_{2} \mathrm{Ca}_{n-1} \mathrm{Cu}_{n} \mathrm{O}_{4+2 n+\delta}$ Ceramics," Physica $C$, 168 [1-2] 249-56 (1990).

${ }^{56}$ R. Ramesh, S. Jin, and P. Marsh, "Superconductor Defect Structure," Nature, 346, 420 (1990). 
${ }^{57}$ A. Nozaki, H. Yoshikawa, T. Wada, H. Yamauchi, and S. Tanaka, "Layered Perovskite Compounds $\mathrm{Sr}_{n+1} \mathrm{~V}_{n} \mathrm{O}_{3 n+1}(n=1,2,3$, and $\infty)$," Phys. Rev. B, 43 [1] 181-5 (1991)

${ }^{58}$ M. A. Señaris-Rodriguez, A. M. Chippindale, A. Várez, E. Morán, and M. A. Alario-Franco, "A Novel '126' Phase of the Family of $\mathrm{Y}_{2} \mathrm{Ba}_{4} \mathrm{Cu}_{6+n} \mathrm{O}_{14+n}$ High-Temperature Superconducting Materials," Physica C, 172 [5-6] 477-80 (1991)

${ }^{59}$ R. J. Cava, T. Siegrist, B. Hessen, J. J. Krajewski, W. F. Peck Jr., B. Batlogg, H. Takagi, J. V. Waszczak, L. F. Schneemeyer, and H. W. Zandbergen, "A New Homologous Series of Lanthanum Copper Oxides," J. Solid State Chem., 94 [1] 170-84 (1991).

${ }^{60} \mathrm{~K}$. Hawkins and T. J. White, "Defect Structure and Chemistry of $\left(\mathrm{Ca}_{x} \mathrm{Sr}_{1-x}\right)_{n+1} \mathrm{Ti}_{n} \mathrm{O}_{3 n+1}$ Layer Perovskites," Philos. Trans. R. Soc. London, Ser. $A, 336$ [1644] 541-69 (1991).

${ }^{61}$ T. Williams, F. Lichtenberg, A. Reller, and G. Bednorz, "New Layered Perovskites in the $\mathrm{Sr}-\mathrm{Ru}-\mathrm{O}$ System: A Transmission Electron Microscope Study," Mater. Res. Bull., 26 [8] 763-70 (1991).

${ }^{62}$ M. Čeh, V. KraŠevec, and D. Kolar, "A Transmission Electron Microscope Study of SrO-Doped $\mathrm{CaTiO}_{3}$," J. Solid State Chem., 103 [1] 263-8 (1993).

${ }^{63}$ S. Adachi, H. Yamauchi, S. Tanaka, and N. Môri, "New Superconducting Cuprates in the $\mathrm{Sr}-\mathrm{Ca}-\mathrm{Cu}-\mathrm{O}$ System," Physica C, 212 [1-2] 164-8 (1993).

${ }^{64}$ Z. Hiroi, M. Takano, M. Azuma, and Y. Takeda, "A New Family of Copper Oxide Superconductors $\mathrm{Sr}_{n+1} \mathrm{Cu}_{n} \mathrm{O}_{2 n+1+\delta}$ Stabilized at High Pressure," Nature, 364 [6435] 315-7 (1993).

${ }^{65}$ X.-J. Wu, S. Adachi, C.-Q. Jin, H. Yamauchi, and S. Tanaka, "Novel Homologous Series of Superconducting Copper Oxides, Cu-12(n-1)n," Physica C, 223 [3-4] 243-8 (1994).

${ }^{66}$ P. Laffez, G. Van Tendeloo, R. Seshadri, M. Hervieu, C. Martin, A. Maignan, and B. Raveau, "Microstructural and Physical Properties of Layered Manganites Oxides Related to the Magnetoresistive Perovskites," J. Appl. Phys., 80 [10] 5850-6 (1996).

${ }^{67}$ M. A. McCoy, R. W. Grimes, and W. E. Lee, "Phase Stability and Interfacial Structures in the $\mathrm{SrO}-\mathrm{SrTiO}_{3}$ System," Philos. Mag. A, 75 [3] 833-46 (1997).

${ }^{68}$ R. Seshadri, M. Hervieu, C. Martin, A. Maignan, B. Domenges, B. Raveau, and A. N. Fitch, "Study of the Layered Magnetoresistive Perovskite $\mathrm{La}_{1.2} \mathrm{Sr}_{1.8} \mathrm{Mn}_{2} \mathrm{O}_{7}$ by High-Resolution Electron Microscopy and Synchrotron XRay Powder Diffraction," Chem. Mater., 9 [8] 1778-87 (1997).

${ }^{69}$ S. D. Bader, R. M. Osgoood III, D. J. Miller, J. F. Mitchell, and J. S. Jiang, "Role of Intergrowths in the Properties of Naturally Layered Manganite Single Crystals," J. Appl. Phys., 83 [11] 6385-9 (1998).

${ }^{70}$ J. Sloan, P. D. Battle, M. A. Green, M. J. Rosseinsky, and J. F. Vente, "A HRTEM Study of the Ruddlesden-Popper Compositions $\mathrm{Sr}_{2} L n \mathrm{Mn}_{2} \mathrm{O}_{7}(L n=\mathrm{Y}$ La, Nd, Eu, Ho)," J. Solid State Chem., 138 [1] 135-40 (1998).

${ }^{71} \mathrm{~K}$. Szot and W. Speier, "Surfaces of Reduced and Oxidized $\mathrm{SrTiO}_{3}$ from Atomic Force Microscopy," Phys. Rev. B, 60 [8] 5909-26 (1999).

${ }^{72}$ G. Trolliard, N. Ténèze, P. Boullay, and D. Mercurio, "TEM Study of CationDeficient-Perovskite Related $A_{n} B_{n-1} \mathrm{O}_{3 n}$ Compounds: The Twin-Shift Option," $J$ Solid State Chem., 177 [4-5] 1188-96 (2004).

${ }^{73}$ K. R. Udayakumar and A. N. Cormack, "Structural Aspects of Phase Equilibria in the Strontium-Titanium-Oxygen System," J. Am. Ceram. Soc., 71, C-469 71 (1988).

${ }^{74}$ K. R. Udayakumar and A. N. Cormack, "Non-Stoichiometry in Alkaline Earth Excess Alkaline Earth Titanates," J. Phys. Chem. Solids, 50 [1] 55-60 (1989).

${ }^{75}$ Y. Tokura, "Correlated-Electron Physics in Transition-Metal Oxides," Phys. Today, 56 [7] 50-5 (2003).

${ }^{76}$ D. G. Schlom and J. S. Harris Jr., "MBE Growth of High $T_{\mathrm{c}}$ Superconductors"; pp. 505-622 in Molecular Beam Epitaxy: Applications to Key Materials, Edited by R. F. C. Farrow. Park Ridge, Noyes, 1995.

${ }^{77}$ J. H. Haeni, C. D. Theis, D. G. Schlom, W. Tian, X. Q. Pan, H. Chang, I. Takeuchi, and X.-D. Xiang, "Epitaxial Growth of the First Five Members of the $\mathrm{Sr}_{n+1} \mathrm{Ti}_{n} \mathrm{O}_{3 n+1}$ Ruddlesden-Popper Homologous Series," Appl. Phys. Lett., 78 [21] 3292-4 (2001).

${ }^{78}$ W. Tian, X. Q. Pan, J. H. Haeni, and D. G. Schlom, "Transmission Electron Microscopy Study of $n=1-5 \mathrm{Sr}_{n+1} \mathrm{Ti}_{n} \mathrm{O}_{3 n+1}$ Epitaxial Thin Films," J. Mater. Res., 16 [7] 2013-26 (2001).

${ }^{79}$ D. G. Schlom, J. H. Haeni, J. Lettieri, C. D. Theis, W. Tian, J. C. Jiang, and X. Q. Pan, "Oxide Nano-Engineering Using MBE," Mater. Sci. Eng. B, 87 [3] 282-91 (2001)

${ }^{80}$ W. Tian, J. H. Haeni, D. G. Schlom, E. Hutchinson, B. L. Sheu, M. M. Rosario, P. Schiffer, Y. Liu, M. A. Zurbuchen, and X. Q. Pan, "Epitaxial Growth and Magnetic Properties of the First Five Members of the Layered $\operatorname{Sr}_{n+1} \mathrm{Ru}_{n} \mathrm{O}_{3 n+1}$ Oxide Series," Appl. Phys. Lett., 90 [2] 022507 (2007).

${ }^{81}$ J. G. Bednorz and K. A. Müller, "Possible High $T_{\mathrm{c}}$ Superconductivity in the Ba-La-Cu-O System," Z. Phys. B, 64 [2] 189-93 (1986).

${ }^{82}$ J. G. Bednorz, M. Takashige, and K. A. Müller, "Susceptibility Measurements Support High- $T_{\mathrm{c}}$ Superconductivity in the Ba-La-Cu-O System," Europhys. Lett., 3 [3] 379-85 (1987).

${ }^{83}$ D. Dijkkamp, T. Venkatesan, X. D. Wu, S. A. Shaheen, N. Jisrawi, Y. H. Min-Lee, W. L. McLean, and M. Croft, "Preparation of Y-Ba-Cu Oxide Superconductor Thin Films using Pulsed Laser Evaporation from High $T_{\mathrm{c}}$ Bulk Material," Appl. Phys. Lett., 51 [8] 619-21 (1987).

${ }^{84}$ X. D. Wu, A. Inam, T. Venkatesan, C. C. Chang, E. W. Chase, P. Barboux, J. M. Tarascon, and B. Wilkens, "Low-Temperature Preparation of High $T_{\mathrm{c}}$ Superconducting Thin Films," Appl. Phys. Lett., 52 [9] 754-6 (1988).

${ }^{85}$ R. Ramesh, K. Luther, B. Wilkens, D. L. Hart, E. Wang, J. M. Tarascon, A Inam, X. D. Wu, and T. Venkatesan, "Epitaxial Growth of Ferroelectric Bismuth Titanate Thin Films by Pulsed Laser Deposition," Appl. Phys. Lett., 57 [15] 1505-7 (1990).

${ }^{86}$ D. B. Chrisey, and G. K. Hubler (ed), Pulsed Laser Deposition of Thin Films. Wiley, New York, 1994.
${ }^{87}$ T. Frey, C. C. Chi, C. C. Tsuei, T. Shaw, and F. Bozso, "Effect of Atomic Oxygen on the Initial Growth Mode in Thin Epitaxial Cuprate Films," Phys. Rev. $B, 49$ [5] 3483-91 (1994).

${ }^{88}$ G. Koster, G. J. H. M. Rijnders, D. H. A. Blank, and H. Rogalla, "Imposed Layer-by-Layer Growth by Pulsed Laser Interval Deposition," Appl. Phys. Lett., 74 [24] 3729-31 (1999)

${ }^{89}$ U. Poppe, J. Schubert, R. R. Arons, W. Evers, C. H. Freiburg, W. Reichert, K. Schmidt, W. Sybertz, and K. Urban, "Direct Production of Crystalline Superconducting Thin Films of $\mathrm{YBa}_{2} \mathrm{Cu}_{3} \mathrm{O}_{7}$ by High-Pressure Oxygen Sputtering," Solid State Commun., 66 [6] 661-5 (1988).

${ }^{90}$ H. C. Li, G. Linker, F. Ratzel, R. Smithey, and J. Geerk, "In Situ Preparation of $\mathrm{Y}-\mathrm{Ba}-\mathrm{Cu}-\mathrm{O}$ Superconducting Thin Films by Magnetron Sputtering," Appl. Phys. Lett., 52 [13] 1098-100 (1988).

${ }_{91}$ B. Pachaly, R. Bruchhaus, D. Pitzer, H. Huber, W. Wersing, and F. Koch, "Pyroelectric Properties of Lead Titanate Thin Films deposited on PtCoated Si Wafers by Multi-Target Sputtering," Integr. Ferroelectrics, 5 [4] 333-8 (1994).

${ }^{92}$ P. Muralt, T. Maeder, L. Sagalowicz, S. Hiboux, S. Scalese, D. Naumovic, R. G. Agostino, N. Xanthopoulos, H. J. Mathieu, L. Patthey, and E. L. Bullock, "Texture Control of $\mathrm{PbTiO}_{3}$ and $\mathrm{Pb}(\mathrm{Zr}, \mathrm{Ti}) \mathrm{O}_{3}$ Thin Films with $\mathrm{TiO}_{2}$ Seeding," $J$. Appl. Phys., 83 [7] 3835-41 (1998).

${ }^{93}$ T. Maeder, P. Muralt, and L. Sagalowicz, "Growth of (111)-Oriented PZT on $\mathrm{RuO}_{2}(100) / \mathrm{Pt}(111)$ Electrodes by In-Situ Sputtering," Thin Solid Films, 345 [2] 300-6 (1999).

${ }^{94}$ N. K. Pervez, P. J. Hansen, and R. A. York, "High Tunability Barium Strontium Titanate Thin Films for RF Circuit Applications," Appl. Phys. Lett., 85 [19] 4451-3 (2004).

${ }^{95}$ H. Koinuma, M. Kawasaki, M. Funabashi, T. Hasegawa, K. Kishio, K. Kitazawa, K. Fueki, and S. Nagata, "Preparation of Superconducting Thin Films of $\left(\mathrm{La}_{1-x} \mathrm{Sr}_{x}\right)_{y} \mathrm{CuO}_{4-\delta}$ by Sputtering," J. Appl. Phys., 62 [4] 1524-6 (1987).

${ }^{96}$ R. L. Sandstrom, W. J. Gallagher, T. R. Dinger, R. H. Koch, R. B. Laibowitz, A. W. Kleinsasser, R. J. Gambino, B. Bumble, and M. F. Chisholm, "Reliable Single-Target Sputtering Process for High-Temperature Superconducting Films and Devices," Appl. Phys. Lett., 53 [5] 444-6 (1988).

${ }^{97}$ X. X. Xi, G. Linker, O. Meyer, E. Nold, B. Obst, F. Ratzel, R. Smithey, B. Strehlau, F. Weschenfelder, and J. Geerk, "Superconducting and Structural Properties of YBaCuO Thin Films Deposited by Inverted Cylindrical Magnetron Sputtering," Z. Phys. B, 74 [1] 13-9 (1989).

${ }^{98}$ C. B. Eom, J. Z. Sun, K. Yamamoto, A. F. Marshall, K. E. Luther, T. H. Geballe, and S. S. Laderman, "In Situ Grown $\mathrm{YBa}_{2} \mathrm{Cu}_{3} \mathrm{O}_{7-d}$ Thin Films from Single-Target Magnetron Sputtering," Appl. Phys. Lett., 55 [6] 595-7 (1989).

${ }^{99}$ C. B. Eom, R. B. Van Dover, J. M. Phillips, D. J. Werder, J. H. Marshall, C. H. Chen, R. J. Cava, R. M. Fleming, and D. K. Fork, "Fabrication and Properties of Epitaxial Ferroelectric Heterostructures with $\left(\mathrm{SrRuO}_{3}\right)$ Isotropic Metallic Oxide Electrodes," Appl. Phys. Lett., 63 [18] 2570-2 (1993).

${ }^{100}$ C. H. Ahn, J.-M. Triscone, N. Archibald, M. Decroux, R. H. Hammond, T. H. Geballe, O. Fischer, and M. R. Beasley, "Ferroelectric Field Effect in Epitaxial Thin Film Oxide $\mathrm{SrCuO}_{2} / \mathrm{Pb}\left(\mathrm{Zr}_{0.52} \mathrm{Ti}_{0.48}\right) \mathrm{O}_{3}$ Heterostructures," Science, 269 [5222] 373-6 (1995).

${ }^{101}$ J.-M. Triscone, L. Frauchiger, M. Decroux, L. Mieville, O. Fischer, C. Beeli, P. Stadelmann, and G.-A. Racine, "Growth and Structural Properties of Epitaxial $\mathrm{Pb}\left(\mathrm{Zr}_{x} \mathrm{Ti}_{1-x}\right) \mathrm{O}_{3}$ Films and $\mathrm{Pb}\left(\mathrm{Zr}_{x} \mathrm{Ti}_{1-x}\right) \mathrm{O}_{3}$-Cuprate Heterostructures," J. Appl. Phys., 79 [8] 4298-305 (1996).

${ }^{102}$ S. D. Bu, M. K. Lee, C. B. Eom, W. Tian, X. Q. Pan, S. K. Streiffer, and J. J. Krajewski, "Perovskite Phase Stabilization in Epitaxial $\mathrm{Pb}\left(\mathrm{Mg}_{1 / 3} \mathrm{Nb}_{2 / 3}\right) \mathrm{O}_{3}$ $\mathrm{PbTiO}_{3}$ Films by Deposition onto Vicinal (001) $\mathrm{SrTiO}_{3}$ Substrates," Appl. Phys. Lett., 79 [21] 3482-4 (2001).

${ }^{103}$ D. K. Lathrop, S. E. Russek, and R. A. Buhrman, "Production of $\mathrm{YBa}_{2} \mathrm{Cu}_{3} \mathrm{O}_{7-y}$ Superconducting Thin Films in Situ by High-Pressure Reactive Evaporation and Rapid Thermal Annealing," Appl. Phys. Lett., 51 [19] 1554-6 (1987).

${ }^{104}$ T. Terashima, K. Iijima, K. Yamamoto, Y. Bando, and H. Mazaki, "SingleCrystal $\mathrm{YBa}_{2} \mathrm{Cu}_{3} \mathrm{O}_{7-x}$ Thin Films by Activated Reactive Evaporation," Jpn. J. Appl. Phys., Part 2, 27 [1] L91-3 (1988).

${ }^{05}$ P. Berberich, B. Utz, W. Prusseit, and H. Kinder, "Homogeneous High Quality $\mathrm{YBa}_{2} \mathrm{Cu}_{3} \mathrm{O}_{7}$ Films on $3^{\prime \prime}$ and 4" Substrates," Physica C, 219 [3-4] 497-504 (1994).

${ }^{106}$ D. G. Schlom, J. N. Eckstein, E. S. Hellman, C. Webb, F. Turner, J. S. Harris Jr., M. R. Beasley, and T. H. Geballe, "Molecular Beam Epitaxy of Layered DyBa-Cu-O Compounds"; pp. 197-200 in Extended Abstracts, High-Temperature Superconductors II, Edited by D. W. Capone II, W. H. Butler, B. Batlogg, and C. W. Chu. Materials Research Society, Pittsburgh, 1988.

${ }^{107}$ R. J. Spah, H. F. Hess, H. L. Stormer, A. E. White, and K. T. Short, "Parameters for in Situ Growth of High $T_{\mathrm{c}}$ Superconducting Thin Films Using an Oxygen Plasma Source," Appl. Phys. Lett., 53 [5] 441-3 (1988).

${ }^{108}$ D. G. Schlom, J. N. Eckstein, E. S. Hellman, S. K. Streiffer, J. S. Harris Jr., M. R. Beasley, J. C. Bravman, T. H. Geballe, C. Webb, K. E. von Dessonneck, and F. Turner, "Molecular Beam Epitaxy of Layered Dy-Ba-Cu-O Compounds," Appl. Phys. Lett., 53 [17] 1660-2 (1988).

${ }^{109}$ J. Kwo, M. Hong, D. J. Trevor, R. M. Fleming, A. E. White, R. C. Farrow, A. R. Kortan, and K. T. Short, "In Situ Epitaxial Growth of $\mathrm{Y}_{1} \mathrm{Ba}_{2} \mathrm{Cu}_{3} \mathrm{O}_{7-x}$ Films by Molecular Beam Epitaxy with an Activated Oxygen Source," Appl. Phys. Lett., 53 [26] 2683-5 (1988).

${ }^{110} \mathrm{~J}$. Eckstein and I. Bozovic, "High-Temperature Superconducting Multilayers and Heterostructures Grown by Atomic Layer-By-Layer Molecular Beam Epitaxy," Annu. Rev. Mater. Sci., 25, 679-709 (1995).

${ }^{111}$ I. Bozovic and D. G. Schlom, "Superconducting Thin Films: Materials, Preparation, and Properties"; pp. 8955-64 in The Encyclopedia of Materials: Science and Technology. Edited by K. H. J. Buschow, R. Cahn, M. C. Flemings, B. 
Ilschner, E. J. Kramer, S. Mahajan, and P. Veyssiere. Pergamon, Amsterdam, 2001.

${ }^{112}$ C. D. Theis, J. Yeh, D. G. Schlom, M. E. Hawley, and G. W. Brown, "Adsorption-Controlled Growth of $\mathrm{PbTiO}_{3}$ by Reactive Molecular Beam Epitaxy," Thin Solid Films 325 [1-2] 107-14 (1998).

${ }^{113}$ M. R. Warusawithana, E. V. Colla, J. N. Eckstein, with M. B. Weissman, "Artificial Dielectric Superlattices with Broken Inversion Symmetry," Phys. Rev. Lett., 90 [3] 036802 (2003).

${ }^{114}$ J. H. Haeni, P. Irvin, W. Chang, R. Uecker, P. Reiche, Y. L. Li, S. Choudhury, W. Tian, M. E. Hawley, B. Craigo, A. K. Tagantsev, X. Q. Pan, S. K. Streiffer, L. Q. Chen, S. W. Kirchoefer, J. Levy, and D. G. Schlom, "RoomTemperature Ferroelectricity in Strained $\mathrm{SrTiO}_{3}$, , Nature, 430 [7001] 758-61 (2004)

${ }^{115}$ T. Terashima, K. Shimura, Y. Bando, Y. Matsuda, A. Fujiyama, and S. Komiyama, "Superconductivity of One-Unit-Cell Thick $\mathrm{YBa}_{2} \mathrm{Cu}_{3} \mathrm{O}_{7}$ Thin Film," Phys. Rev. Lett., 67 [10] 1362-5 (1991)

${ }^{116}$ A. Roelofs, T. Schneller, K. Szot, and R. Waser, "Piezoresponse Force Microscopy of Lead Titanate Nanograins Possibly Reaching the Limit of Ferroelectricity," Appl. Phys. Lett., 81 [27] 5231-3 (2002).

${ }^{117}$ I. Bozovic, G. Logvenov, M. A. J. Verhoeven, P. Caputo, E. Goldobin, and T. H. Geballe, "No Mixing of Superconductivity and Antiferromagnetism in a High-Temperature Superconductor," Nature, 422 [6934] 873-5 (2003).

${ }_{118}^{18}$ J.-M. Triscone, M. G. Karkut, L. Antognazza, O. Brunner, and Ø. Fischer, "Y-Ba-Cu-O/Dy-Ba-Cu-O Superlattices: A First Step Towards the Artificial Construction of High- $T_{\mathrm{c}}$ Superconductors," Phys. Rev. Lett., 63 [9] 1016-9 (1989).

${ }^{9}$ D. G. Schlom, J. N. Eckstein, I. Bozovic, Z. J. Chen, A. F. Marshall, K. E. von Dessonneck, and J. S. Harris Jr., "Molecular Beam Epitaxy-A Path to Novel High $T_{\mathrm{c}}$ Superconductors?"; pp. 234-47 in Growth of Semiconductor Structures and High- $T_{c}$ Thin Films on Semiconductors, edited by A. Madhukar, SPIE, Vol. 1285. SPIE, Bellingham, 1990.

${ }^{120}$ D. H. Lowndes, D. P. Norton, and J. D. Budai, "Superconductivity in Nonsymmetric Epitaxial $\mathrm{YBa}_{2} \mathrm{Cu}_{3} \mathrm{O}_{7-x} / \mathrm{PrBa}_{2} \mathrm{Cu}_{3} \mathrm{O}_{7-x} \quad$ Superlattices: The Superconducting Behavior of $\mathrm{Cu}-\mathrm{O}$ Bilayers," Phys. Rev. Lett., 65 [9] 1160-3 (1990).

${ }^{121}$ S. J. Pennycook, M. F. Chisholm, D. E. Jesson, D. P. Norton, D. H. Lowndes, R. Feenstra, H. R. Kerchner, and J. O. Thomson, "Interdiffusion, Growth Mechanisms, and Critical Currents in $\mathrm{YBa}_{2} \mathrm{Cu}_{3} \mathrm{O}_{7-x} / \mathrm{PrBa}_{2} \mathrm{Cu}_{3} \mathrm{O}_{7-x}$ Superlattices," Phys. Rev. Lett., 67 [6] 765-8 (1991).

${ }^{122}$ K. Kamigaki, T. Terashima, K. Shimura, Y. Bando, and H. Terauchi, "Unit Cell-by-Unit Cell Grown $\left(\mathrm{YBa}_{2} \mathrm{Cu}_{3} \mathrm{O}_{7-\delta}\right)_{1} /\left(\mathrm{PrBa}_{2} \mathrm{Cu}_{3} \mathrm{O}_{7-\delta}\right)_{1}$ Superlattice," Phy sica C, 183 [4-6] 252-6 (1991).

${ }^{123}$ H. Tabata, T. Kawai, and S. Kawai, "Crystal Structure and Superconductivity of $(\mathrm{La}, \mathrm{Sr})_{2} \mathrm{CuO}_{4} / \mathrm{Sm}_{2} \mathrm{CuO}_{4}$ Superlattices Prepared by Excimer Laser Deposition," Appl. Phys. Lett., 58 [13] 1443-5 (1991).

${ }^{124}$ I. Bozovic and J. N. Eckstein, "Superconducting Superlattices"; pp. 99-207 in Physical Properties of High Temperature Superconductors V, Edited by D. M. Ginsberg. World Scientific, Singapore, 1996.

${ }^{125} \mathrm{~J}-\mathrm{M}$. Triscone and $\varnothing$. Fischer, "Superlattices of High-Temperature Superconductors: Synthetically Modulated Structures, Critical Temperatures and Vortex Dynamics," Rep. Prog. Phys., 60 [12] 1673-721 (1997).

${ }^{126}$ G. Koster, K. Verbist, G. Rijnders, H. Rogalla, G. van Tendeloo, and D. H. A. Blank, "Structure and Properties of $(\mathrm{Sr}, \mathrm{Ca}) \mathrm{CuO}_{2}-\mathrm{BaCuO}_{2}$ Superlattices Grown by Pulsed Laser Interval Deposition," Physica $C, 353$ [3-4] 167-83 (2001).

${ }^{127}$ H. Yamamoto, M. Naito, and H. Sato, "New Superconducting Cuprate Prepared by Low-Temperature Thin-Film Synthesis in a $\mathrm{Ba}-\mathrm{Cu}-\mathrm{O}$ System," Jpn. J. Appl. Phys., Part 2, 36 [3B] L341-4 (1997).

${ }^{128}$ B. S. Kwak, E. P. Boyd, and A. Erbil, "Metalorganic Chemical Vapor Deposition of $\mathrm{PbTiO}_{3}$ Thin Films," Appl. Phys. Lett., 53 [18] 1702-4 (1988).

${ }^{129}$ M. Okada, S. Takai, M. Amemiya, and K. Tominaga, "Preparation of $c$ Axis-Oriented $\mathrm{PbTiO}_{3}$ Thin Films by MOCVD Under Reduced Pressure," Jpn. J. Appl. Phys., Part 1, 28 [6] 1030-4 (1989).

${ }^{130}$ M. de Keijser, G. J. M. Dormans, J. F. M. Cillessen, D. M. de Leeuw, and H. W. Zandbergen, "Epitaxial $\mathrm{PbTiO}_{3}$ Thin Films Grown by Organometallic Chemical Vapor Deposition," Appl. Phys. Lett., 58 [23] 2636-8 (1991).

${ }^{131} \mathrm{~K}$. Fujii, H. Zama, and S. Oda, "Preparation of $\mathrm{YBa}_{2} \mathrm{Cu}_{3} \mathrm{O}_{x}$ Thin Films by Layer-by-Layer Metalorganic Chemical Vapor Deposition," Jpn. J. Appl. Phys. Part 2, 31 [6B] L787-9 (1992).

${ }^{132}$ G. R. Bai, H. L. M. Chang, H. K. Kim, C. M. Foster, and D. J. Lam, "Epitaxy-Induced Phase of Near-Stoichiometry $\mathrm{PbTiO}_{3}$ Films Prepared by Metalorganic Chemical Vapor Deposition," Appl. Phys. Lett., 61 [4] 408-10 (1992).

${ }^{133}$ G. J. M. Dormans, P. J. van Veldhoven, and M. de Keijser, "CompositionControlled Growth of $\mathrm{PbTiO}_{3}$ on $\mathrm{SrTiO}_{3}$ by Organometallic Chemical Vapour Deposition," J. Cryst. Growth, 123 [3-4] 537-44 (1992).

${ }^{34}$ Z. Li, C. M. Foster, D. Guo, H. Zhang, G. R. Bai, P. M. Baldo, and L. E. Rehn, "Growth of High Quality Single-Domain Single-Crystal Films of $\mathrm{PbTiO}_{3}$," Appl. Phys. Lett., 65 [9] 1106-8 (1994).

${ }^{135}$ M. de Keijser and G. J. M. Dormans, "Modelling of Organometallic Chemical Vapour Deposition of Lead Titanate," J. Cryst. Growth, 149 [3-4] 215-28 (1995)

${ }^{136}$ M. de Keijser and G. J. M. Dormans, "Chemical Vapor Deposition of Electroceramic Thin Films," MRS Bull., 21 [6] 37-43 (1996).

${ }^{137}$ C. M. Foster, "Chemical Vapor Deposition of Ferroelectric Thin Films;" pp. 167-97 in Thin Film Ferroelectric Materials and Devices, Edited by R. Ramesh. Kluwer, Boston, 1997.

${ }^{138}$ G.-R. Bai, I.-F. Tsu, A. Wang, C. M. Foster, C. E. Murray, and V. P. Dravid, "In Situ Growth of Highly Oriented $\mathrm{Pb}\left(\mathrm{Zr}_{0.5} \mathrm{Ti}_{0.5}\right) \mathrm{O}_{3}$ Thin Films by Low-Temperature Metal-Organic Chemical Vapor Deposition," Appl. Phys. Lett., 72 [13] 1572-4 (1998).
${ }^{139}$ J. F. Roeder, T. H. Baum, S. M. Bilodeau, G. T. Stauf, C. Ragaglia, M. W. Russell, and P. C. Van Buskirk, "Liquid-Delivery MOCVD: Chemical and Process Perspectives on Ferroelectric Thin Film Growth," Adv. Mater. Opt. Electron., 10 [3-5] 145-54 (2000).

${ }^{140}$ M. V. Ramana Murty, S. K. Streiffer, G. B. Stephenson, J. A. Eastman, G.-R. Bai, A. Munkholm, O. Auciello, and C. Thompson, "In Situ X-Ray Scattering Study of $\mathrm{PbTiO}_{3}$ Chemical-Vapor Deposition," Appl. Phys. Lett., 80 [10] 1809-11 (2002).

${ }^{141}$ K. Saito, I. Yamaji, T. Akai, M. Mitsuya, and H. Funakubo, "Quantitative Effects of Preferred Orientation and Impurity Phases on Ferroelectric Properties of $\mathrm{SrBi}_{2}\left(\mathrm{Ta}_{1-x} \mathrm{Nb}_{x}\right)_{2} \mathrm{O}_{9}$ Thin Films Measured by X-ray Diffraction Reciprocal Space Mapping," Jpn. J. Appl. Phys., Part 1, 42 [2A] 539-43 (2003).

${ }^{142}$ A. Nagai, H. Morioka, G. Asano, H. Funakubo, and A. Saiki, "Preparing $\mathrm{Pb}(\mathrm{Zr}, \mathrm{Ti}) \mathrm{O}_{3}$ Films Less than $100 \mathrm{~nm}$ Thick by Low-Temperature Metalorganic Chemical Vapor Deposition," Appl. Phys. Lett., 86 [14] 142906 (2005).

${ }^{143}$ Y. K. Kim, H. Morioka, R. Ueno, S. Yokoyama, and H. Funakubo, "Comparison of Electrical Properties of $(100) /(001)$-Oriented Epitaxial $\mathrm{Pb}\left(\mathrm{Zr}_{0.35}, \mathrm{Ti}_{0.65}\right) \mathrm{O}_{3}$ Thin Films with the same (001) Domain Fraction Grown on (100)Si and (100)SrTiO ${ }_{3}$ Substrates," Appl. Phys. Lett., 86 [21] 212905 (2005).

${ }^{144} \mathrm{~J}$. Fukushima, K. Kodaira, and T. Matsushita, "Preparation of Ferroelectric PZT Films by Thermal Decomposition of Organometallic Compounds," J. Mater. Sci., 19 [2] 595-8 (1984).

${ }^{145}$ K. D. Budd, S. K. Dey, and D. A. Payne, "Sol-Gel Processing of $\mathrm{PbTiO}_{3}$, $\mathrm{PbZrO}_{3}, \mathrm{PZT}$, and PLZT Thin Films," Br. Ceram. Proc., 36, 107-21 (1985).

${ }^{146}$ R. W. Schwartz, "Chemical Solution Deposition of Perovskite Thin Films,' Chem. Mater., 9 [11] 2325-40 (1997).

${ }^{147}$ A. I. Kingon and S. Srinivasan, "Lead Zirconate Titanate Thin Films Directly on Copper Electrodes for Ferroelectric, Dielectric and Piezoelectric Applications," Nat. Mater., 4 [3] 233-7 (2005).

${ }^{148}$ M. D. Losego, L. H. Jimison, J. F. Ihlefeld, and J.-P. Maria, "Ferroelectric Response from Lead Zirconate Titanate Thin Films Prepared Directly on LowResistivity Copper Substrates," Appl. Phys. Lett., 86 [17] 172906 (2005).

${ }^{149} \mathrm{~K}$. Iijima, T. Terashima, Y. Bando, K. Kamigaki, and H. Terauchi, "Atomic Layer Growth of Oxide Thin Films with Perovskite-Type Structure by Reactive Evaporation," J. Appl. Phys., 72 [7] 2840-5 (1992).

${ }^{150}$ H.-M. Christen, L. A. Boatner, J. D. Budai, M. F. Chisholm, L. A. Géa, P. J. Marrero, and D. P. Norton, "The Growth and Properties of Epitaxial $\mathrm{KNbO}_{3}$ Thin Films and $\mathrm{KNbO}_{3} / \mathrm{KTaO}_{3}$ Superlattices," Appl. Phys. Lett., 68 [11] 1488-90 (1996).

${ }^{151}$ J. C. Jiang, X. Q. Pan, W. Tian, C. D. Theis, and D. G. Schlom, "Abrupt $\mathrm{PbTiO}_{3} / \mathrm{SrTiO}_{3}$ Superlattices Grown by Reactive Molecular Beam Epitaxy," Appl. Phys. Lett., 74 [19] 2851-3 (1999).

${ }^{152}$ A. Ohtomo, D. A. Muller, J. L. Grazul, and H. Y. Hwang, "Artificial Charge-Modulation in Atomic-Scale Perovskite Titanate Superlattices," Nature, 419 [6905] 378-80 (2002)

${ }^{153}$ D. A. Muller, N. Nakagawa, A. Ohtomo, J. L. Grazul, and H. Y. Hwang, "Atomic-Scale Imaging of Nanoengineered Oxygen Vacancy Profiles in $\mathrm{SrTiO}_{3}$," Nature, 430 [7000] 657-61 (2004)

${ }^{154}$ C. H. Ahn, K. M. Rabe, and J.-M. Triscone, "Ferroelectricity at the Nanoscale: Local Polarization in Oxide Thin Films and Heterostructures," Science, 303 [5657] 488-91 (2004)

${ }^{155}$ H. N. Lee, H. M. Christen, M. F. Chisholm, C. M. Rouleau, and D. H Lowndes, "Strong Polarization Enhancement in Asymmetric Three-Component Ferroelectric Superlattices," Nature, 433 [7024] 395-9 (2005).

${ }^{156}$ M. Dawber, C. Lichtensteiger, M. Cantoni, M. Veithen, P. Ghosez, K. Johnston, K. M. Rabe, and J.-M. Triscone, "Unusual Behavior of the Ferroelectric Polarization in $\mathrm{PbTiO}_{3} / \mathrm{SrTiO}_{3}$ Superlattices," Phys. Rev. Lett., 95 [17] 177601 (2005).

${ }^{157}$ D. A. Tenne, A. Bruchhausen, N. D. Lanzillotti-Kimura, A. Fainstein, R. S Katiyar, A. Cantarero, A. Soukiassian, V. Vaithyanathan, J. H. Haeni, W. Tian, D. G. Schlom, K. J. Choi, D. M. Kim, C. B. Eom, H. P. Sun, X. Q. Pan, Y. L. Li, L. Q. Chen, Q. X. Jia, S. M. Nakhmanson, K. M. Rabe, and X. X. Xi, "Probing Nanoscale Ferroelectricity by Ultraviolet Raman Spectroscopy," Science, 313 [5793] 1614-6 (2006)

${ }^{158}$ Y. Jia, M. A. Zurbuchen, S. Wozniak, A. H. Carim, D. G. Schlom, L.-N. Zou, S. Briczinski, and Y. Liu, "Epitaxial Growth of Metastable $\mathrm{Ba}_{2} \mathrm{RuO}_{4}$ Films with the $\mathrm{K}_{2} \mathrm{NiF}_{4}$ Structure," Appl. Phys. Lett., 74 [25] 3830-2 (1999).

${ }^{159}$ O. Y. Gorbenko, S. V. Samoilenkov, I. E. Graboy, and A. R. Kaul, "Epitaxial Stabilization of Oxides in Thin Films," Chem. Mater., 14 [10] 4026-43 (2002).

${ }^{160}$ A. F. Moreira dos Santos, A. K. Cheetham, W. Tian, X. Q. Pan, Y. Jia, N. J. Murphy, J. Lettieri, and D. G. Schlom, "Epitaxial Growth and Properties of Metastable $\mathrm{BiMnO}_{3}$ Thin Films," Appl. Phys. Lett., 84 [1] 91-3 (2004).

${ }^{161}$ T. Heeg, M. Roeckerath, J. Schubert, W. Zander, C. Buchal, H. Y. Chen, C. L. Jia, Y. Jia, C. Adamo, and D. G. Schlom, "Epitaxially Stabilized Growth of Orthorhombic $\mathrm{LuScO}_{3}$ Thin Films," Appl. Phys. Lett., 90 [19] 192901 (2007).

${ }^{162}$ G. K. Hubler (ed), "Pulsed Laser Deposition," MRS Bull., 17 [2] 26-9 (1992).

${ }^{163}$ J. Cheung and J. Horwitz, "Pulsed Laser Deposition History and LaserTarget Interactions," MRS Bull., 17 [2] 30-6 (1992).

${ }^{164}$ D. B. Chrisey and A. Inam, "Pulsed Laser Deposition of High Tc Superconducting Thin Films for Electronic Device Applications," MRS Bull., 17 [2] 3743 (1992).

${ }^{165}$ T. Venkatesan, X. D. Wu, R. Muenchausen, and A. Pique, "Pulsed Laser Deposition: Future Directions," MRS Bull., 17 [2] 54-8 (1992).

${ }^{166} \mathrm{~K}$. -H. Hellwege, and A. M. Hellwege (eds), Landolt-Börnstein: Numerical Data and Functional Relationships in Science and Technology, Part a, Vol. 16, p. 233. Springer-Verlag, Berlin, 1981.

${ }^{167}$ J. Lettieri, Y. Jia, M. Urbanik, C. I. Weber, J-P. Maria, D. G. Schlom, H. Li, R. Ramesh, R. Uecker, and P. Reiche, "Epitaxial Growth of (001)-Oriented and (110)-Oriented $\mathrm{SrBi}_{2} \mathrm{Ta}_{2} \mathrm{O}_{9}$ Thin Films," Appl. Phys. Lett., 73 [20] 2923-5 (1998).

${ }^{168}$ J. Lettieri, M. A. Zurbuchen, Y. Jia, D. G. Schlom, S. K. Streiffer, and M. E. Hawley, "Epitaxial Growth of $\mathrm{SrBi}_{2} \mathrm{Nb}_{2} \mathrm{O}_{9}$ on (110) $\mathrm{SrTiO}_{3}$ and the Establishment of a Lower Bound on the Spontaneous Polarization of $\mathrm{SrBi}_{2} \mathrm{Nb}_{2} \mathrm{O}_{9}$," Appl. Phys. Lett., 77 [19] 3090-2 (2000). 
${ }^{169}$ H. L. Kao, J. Kwo, R. M. Fleming, M. Hong, and J. P. Mannaerts, “In Situ Growth and Properties of Single-Crystalline-Like $\mathrm{La}_{2-x} \mathrm{Sr}_{x} \mathrm{CuO}_{4}$ Epitaxial Films by Off-Axis Sputtering," Appl. Phys. Lett., 59 [21] 2748-50 (1991).

${ }^{170}$ O. Wada, K. Kuroda, J. Tanimura, M. Kataoka, K. Kojima, T. Takami, K. Hamanaka, and T. Ogama, "Defence of Crystal Orientation of BiSrCaCuO Thin Films on Off-Angles of Vicinal $\mathrm{SrTiO}_{3}$ (110) Surfaces," Jpn. J. Appl. Phys., 30 [11A] L1881-3 (1991).

${ }^{171}$ J. Tanimura, K. Kuroda, M. Kataoka, O. Wada, T. Takami, K. Kojima, and T. Ogama, "(01n)-Oriented BiSrCaCuO Thin Films Formed on $\mathrm{CeO}_{2}$ Buffer Layers," Jpn. J. Appl. Phys., 32 [2B] L254-6 (1993).

${ }^{172}$ J. Lettieri, M. A. Zurbuchen, Y. Jia, D. G. Schlom, S. K. Streiffer, and M. E. Hawley, "Epitaxial Growth of Non-c-Oriented $\mathrm{SrBi}_{2} \mathrm{Nb}_{2} \mathrm{O}_{9}$ on (111) $\mathrm{SrTiO}_{3}$," Appl. Phys. Lett., 76 [20] 2937-9 (2000).

${ }^{173}$ M. A. Zurbuchen, J. Lettieri, Y. Jia, D. G. Schlom, S. K. Streiffer, and M. E. Hawley, "Transmission Electron Microscopy Study of (103)-Oriented Epitaxial $\mathrm{SrBi}_{2} \mathrm{Nb}_{2} \mathrm{O}_{9}$ Films Grown on (111) $\mathrm{SrTiO}_{3}$ and (111) $\mathrm{SrRuO}_{3} /(111) \mathrm{SrTiO}_{3}, " J$. Mater. Res., 16 [2] 489-502 (2001).

${ }^{174}$ M. Kitabatake, P. Fons, and J. E. Greene, "Molecular Dynamics Simulations of Low-Energy Particle Bombardment Effects During Vapor-Phase Crystal Growth: $10 \mathrm{eV} \mathrm{Si}$ Atoms Incident on $\mathrm{Si}(001) 2 \times 1$ Surfaces," J. Vac. Sci. Technol. A, 8 [5] 3726-35 (1990).

${ }^{175}$ M. Kitabatake and J. E. Greene, "Molecular Dynamics and Quasidynamics Simulations of Low-Energy Particle Bombardment Effects During Vapor-Phase Crystal Growth: Production and Annihilation of Defects Due to $50 \mathrm{eV} \mathrm{Si} \mathrm{Incident}$ on $(2 \times 1)$-Terminated Si(001)," J. Appl. Phys., 73 [7] 3183-94 (1993).

${ }^{176}$ E. J. Tarsa, E. A. Hachfeld, F. T. Quinlan, J. S. Speck, and M. Eddy, "Growth-Related Stress and Surface Morphology in Homoepitaxial $\mathrm{SrTiO}_{3}$ Films," Appl. Phys. Lett., 68 [4] 490-2 (1996).

${ }^{177}$ J.-P. Maria, S. Trolier-McKinstry, D. G. Schlom, M. E. Hawley, and G. W. Brown, "The Influence of Energetic Bombardment on the Structure and Properties of Epitaxial $\mathrm{SrRuO}_{3}$ Thin Films Grown by Pulsed Laser Deposition," J. Appl. Phys., 83 [8] 4373-9 (1998).

${ }^{178}$ T. Ohnishi, M. Lippmaa, T. Yamamoto, S. Meguro, and H. Koinuma, "Improved Stoichiometry and Misfit Control in Perovskite Thin Film Formation at a Critical Fluence by Pulsed Laser Deposition," Appl. Phys. Lett., 87 [24] 2419191 (2005).

${ }^{179}$ T. Ohnishi, K. Shibuya, T. Yamamoto, and M. Lippmaa, "Defects and Transport in Complex Oxide Thin Films," J. Appl. Phys., 103 [10] 103703. (2008).

${ }^{180}$ H. Karl and B. Stritzker, "Reflection High-Energy Electron Diffraction Oscillations Modulated by Laser-Pulse Deposited $\mathrm{YBa}_{2} \mathrm{Cu}_{3} \mathrm{O}_{7-x}$," Phys. Rev. Lett., 69 [20] 2939-42 (1992).

${ }^{181}$ G. J. H. M. Rijnders, A. G. Koster, D. H. A. Blank, and H. Rogalla, “In Situ Monitoring During Pulsed Laser Deposition of Complex Oxides Using Reflection High Energy Electron Diffraction Under High Oxygen Pressure," Appl. Phys. Lett., 70 [14] 1888-90 (1997).

${ }^{182}$ M. H. Yang and C. P. Flynn, "Growth of Alkali Halides from Molecular Beams: Global Growth Characteristics," Phys. Rev. Lett., 62 [21] 2476-9 (1989).

${ }^{183}$ S. Yadavalli, M. H. Yang, and C. P. Flynn, "Low-Temperature Growth of MgO by Molecular-Beam Epitaxy," Phys. Rev. B, 41 [11] 7961-3 (1990).

${ }^{184}$ A. Y. Cho and J. R. Arthur, "Molecular Beam Epitaxy," Progress in SolidState Chemistry, 10 [3] 157-91 (1975).

${ }^{185}$ R. F. C. Farrow (ed), Molecular Beam Epitaxy: Applications to Key Materials. Noyes, Park Ridge, 1995.

${ }^{186}$ M. A. Herman and H. Sitter, Molecular Beam Epitaxy: Fundamentals and Current Status, 2nd edition, Springer-Verlag, Berlin, 1996.

${ }^{187}$ S. Yoshida, "Reactive Molecular Beam Epitaxy"; pp. 287-316 in Critical Reviews $^{\mathrm{TM}}$ in Solid State and Materials Sciences, Vol. 11, Edited by D. E. Schuele, and R. W. Hoffman. CRC Press, Boca Raton, FL, 1984.

${ }^{188}$ K. Iijima, T. Terashima, K. Yamamoto, K. Hirata, and Y. Bando, "Preparation of Ferroelectric $\mathrm{BaTiO}_{3}$ Thin Films by Activated Reactive Evaporation,' Appl. Phys. Lett., 56 [6] 527-9 (1990).

${ }^{89}$ T. Sakamoto, H. Funabashi, K. Ohta, T. Nakagawa, N. J. Kawai, T. Kojima, and Y. Bando, "Well Defined Superlattice Structures Made by Phase-Locked Epitaxy Using RHEED Intensity Oscillations," Superlattices Microstruct., 1 [4] 347-52 (1985)

${ }^{190}$ A. C. Gossard, P. M. Petroff, W. Weigmann, R. Dingle, and A. Savage, "Epitaxial Structures with Alternate-Atomic-Layer Composition Modulation," Appl. Phys. Lett., 29 [6] 323-5 (1976).

${ }^{191}$ A. Y. Cho, "Molecular Beam Epitaxy from Research to Manufacturing," MRS Bull., 20 [4] 21-8 (1995).

${ }^{192}$ R. A. Betts and C. W. Pitt, "Growth of Thin-Film Lithium Niobate by Molecular Beam Epitaxy,” Electron. Lett., 21 [21] 960-2 (1985).

${ }^{193}$ M. Petrucci, C. W. Pitt, and P. J. Dobson, "RHEED Studies on $z$-Cut $\mathrm{LiNbO}_{3}$," Electron. Lett., 22 [18] 954-6 (1986).

${ }^{194}$ Z. Sitar, F. Gitmans, W. Liu, and P. Gunter, "Homo and Heteroepitaxial Growth of $\mathrm{LiTaO}_{3}$ and $\mathrm{LiNbO}_{3}$ by MBE"; pp. 255-60 in Epitaxial Oxide Thin Films II, Vol. 401, Edited by J. S. Speck, D. K. Fork, R. M. Wolf, and T. Shiosaki. Materials Research Society, Pittsburgh, 1996.

${ }^{195}$ W. A. Doolittle, A. G. Carver, and W. Henderson, "Molecular Beam Epitaxy of Complex Metal-Oxides: Where Have We Come, Where Are We Going, and How Are We Going to Get There," J. Vac. Sci. Technol. B, 23 [3] 1272-6 (2005).

${ }^{196}$ R. A. McKee, F. J. Walker, J. R. Conner, E. D. Specht, and D. E. Zelmon, "Molecular Beam Epitaxy Growth of Epitaxial Barium Silicide, Barium Oxide, and Barium Titanate on Silicon," Appl. Phys. Lett., 59 [7] $782-4$ (1991).

${ }^{197}$ R. A. McKee, F. J. Walker, E. D. Specht, G. E. Jellison Jr., and L. A. Boatner, "Interface Stability and the Growth of Optical Quality Perovskites on MgO," Phys. Rev. Lett., 72 [17] 2741-4 (1994).
${ }^{198}$ R. A. McKee, F. J. Walker, and M. F. Chisholm, "Physical Structure and Inversion Charge at a Semiconductor Interface with a Crystalline Oxide," Science, 293 [5529] 468-71 (2001)

${ }^{199}$ T. Tsurumi, T. Suzuki, M. Yamane, and M. Daimon, "Fabrication of Barium Titanate/Strontium Titanate Artificial Superlattice by Atomic Layer Epitaxy," Jpn. J. Appl. Phys., Part 1, 33 [9B] 5192-5 (1994).

${ }^{200}$ H. Shigetani, K. Kobayashi, M. Fujimoto, W. Sugimura, Y. Matsui, and J. Tanaka, "BaTiO 3 Thin Films Grown on $\mathrm{SrTiO}_{3}$ Substrates by a Molecular-BeamEpitaxy Method Using Oxygen Radicals," J. Appl. Phys., 81 [2] 693-7 (1997).

${ }^{201}$ H. P. Sun, W. Tian, X. Q. Pan, J. H. Haeni, and D. G. Schlom, "Evolution of Dislocation Arrays in Epitaxial $\mathrm{BaTiO}_{3}$ Thin Films Grown on (100) $\mathrm{SrTiO}_{3}$," Appl. Phys. Lett., 84 [17] 3298-300 (2004).

${ }^{202}$ H. P. Sun, X. Q. Pan, J. H. Haeni, and D. G. Schlom, "Structural Evolution of Dislocation Half-Loops in Epitaxial $\mathrm{BaTiO}_{3}$ Thin Films During High-Temperature Annealing," Appl. Phys. Lett., 85 [11] 1967-9 (2004).

${ }^{203}$ K. J. Choi, M. D. Biegalski, Y. L. Li, A. Sharan, J. Schubert, R. Uecker, P. Reiche, Y. B. Chen, X. Q. Pan, V. Gopalan, L.-Q. Chen, D. G. Schlom, and C. B. Eom, "Enhancement of Ferroelectricity in Strained $\mathrm{BaTiO}_{3}$ Thin Films," Science, 306 [5698] 1005-9 (2004).

${ }^{204}$ F. J. Walker and R. A. McKee, "High-k Crystalline Gate Dielectrics: A Research Perspective"; pp. 607-37 in High Dielectric Constant Materials: VLSI MOSFET Applications, Edited by H. R. Huff, and D. C. Gilmer. Springer, Berlin, 2005

${ }^{205}$ V. Vaithyanathan, J. Lettieri, W. Tian, A. Kochhar, H. Ma, A. Sharan, A. Vasudevarao, V. Gopalan, Y. Li, L. Q. Chen, P. Zschack, J. C. Woicik, J. Levy, and D. G. Schlom, "c-Axis Oriented Epitaxial $\mathrm{BaTiO}_{3}$ Films on (001) Si," J. Appl. Phys., 100 [2] 024108 (2006).

${ }^{206}$ C. D. Theis and D. G. Schlom, "Epitaxial Lead Titanate Grown by MBE," $J$. Cryst. Growth, 174 [1-4] 473-9 (1997).

${ }^{207}$ C. D. Theis, J. Yeh, D. G. Schlom, M. E. Hawley, G. W. Brown, J. C. Jiang, and X. Q. Pan, "Adsorption-Controlled Growth of $\mathrm{Bi}_{4} \mathrm{Ti}_{3} \mathrm{O}_{12}$ by Reactive MBE," Appl. Phys. Lett., 72 [22] 2817-9 (1998).

${ }^{208}$ S. Migita, H. Ota, H. Fujino, Y. Kasai, and S. Sakai, "Epitaxial $\mathrm{Bi}_{4} \mathrm{Ti}_{3} \mathrm{O}_{12}$ Thin Film Growth using Bi Self-Limiting Function," J. Cryst. Growth, 200 [1-2] 161-8 (1999).

${ }^{209}$ I. Bozovic, J. N. Eckstein, and G. F. Virshup, "Superconducting Oxide Multilayers and Superlattices: Physics, Chemistry, and Nanoengineering," Physica C, 235-240 [1] 178-81 (1994).

${ }^{210}$ R. A. McKee, F. J. Walker, and M. F. Chisholm, "Crystalline Oxides on Silicon: The First Five Monolayers," Phys. Rev. Lett., 81 [14] 3014-7 (1998).

${ }^{211}$ J. H. Haeni, C. D. Theis, and D. G. Schlom, "RHEED Intensity Oscillations for the Stoichiometric Growth of $\mathrm{SrTiO}_{3}$ Thin Films by Reactive Molecular Beam Epitaxy," J. Electroceram., 4 [2/3] 385-91 (2000).

${ }^{212}$ K. Eisenbeiser, J. M. Finder, Z. Yu, J. Ramdani, J. A. Curless, J. A. Hallmark, R. Droopad, W. J. Ooms, L. Salem, S. Bradshaw, and C. D. Overgaard, "Field Effect Transistors with $\mathrm{SrTiO}_{3}$ Gate Dielectric on Si," Appl. Phys. Lett., 76 [10] 1324-6 (2000).

${ }^{213}$ Z. Yu, J. Ramdani, J. A. Curless, C. D. Overgaard, J. M. Finder, R. Droopad, K. W. Eisenbeiser, J. A. Hallmark, W. J. Ooms, and V. S. Kaushik, "Epitaxial Oxide Thin Films on Si(001)," J. Vac. Sci. Technol. B, 18 [4] 2139-45 (2000).

${ }^{214}$ J. Lettieri, "Critical Issues of Complex, Epitaxial Oxide Growth and Integration with Silicon by Molecular Beam Epitaxy"; Ph.D. Thesis, Pennsylvania State University, 2002. Available on-line at http://etda.libraries.psu.edu/theses/approved/WorldWideIndex/ETD-202/index.html

${ }^{215}$ H. Li, X. Hu, Y. Wei, Z. Yu, X. Zhang, R. Droopad, A. A. Demkov, J. Edwards Jr., K. Moore, W. Ooms, J. Kulik, and P. Fejes, "Two-Dimensional Growth of High-Quality Strontium Titanate Thin Films on Si," J. Appl. Phys., 93 [8] 4521-5 (2003).

${ }^{216}$ M. D. Biegalski, Y. Jia, D. G. Schlom, S. Trolier-McKinstry, S. K. Streiffer, V. Sherman, R. Uecker, and P. Reiche, "Relaxor Ferroelectricity in Strained Epitaxial $\mathrm{SrTiO}_{3}$ Thin Films on $\mathrm{DyScO}_{3}$ Substrates," Appl. Phys. Lett., 88 [19] 192907 (2006)

${ }^{217}$ L. Fitting Kourkoutis, C. S. Hellberg, V. Vaithyanathan, H. Li, M. K Parker, K. E. Andersen, D. G. Schlom, and D. A. Muller, "Imaging the Phase Separation in Atomically Thin Buried $\mathrm{SrTiO}_{3}$ Layers by Electron Channeling," Phys. Rev. Lett., 100 [3] 036101 (2008).

${ }^{218}$ M. D. Biegalski, S. Trolier-McKinstry, D. G. Schlom, D. D. Fong, J. A Eastman, P. H. Fuoss, S. K. Streiffer, T. Heeg, J. Schubert, W. Tian, X. Q. Pan, M. E. Hawley, M. Bernhagen, P. Reiche, and R. Uecker, "Critical Thickness of High Structural Quality $\mathrm{SrTiO}_{3}$ Films Grown on Orthorhombic (101) $\mathrm{DyScO}_{3}$," $J$. Appl. Phys., in press.

${ }^{219}$ J. N. Eckstein, I. Bozovic, M. Rzchowski, J. O’Donnell, B. Hinaus, and M. Onellion, "Molecular Beam Epitaxy of Single Crystal Colossal Magneto-Resistive Material"; pp. 467-71 in Epitaxial Oxide Thin Films II, Vol. 401, Edited by J. S. Speck, D. K. Fork, R. M. Wolf, and T. Shiosaki. Materials Research Society, Pittsburgh, 1996.

${ }^{220}$ J. N. Eckstein, I. Bozovic, J. O’Donnell, M. Onellion, and M. S. Rzchowski, "Anisotropic Magnetoresistance in Tetragonal $\mathrm{La}_{1-x} \mathrm{Ca}_{x} \mathrm{MnO}_{\delta}$ Thin Films," Appl. Phys. Lett., 69 [9] 1312-4 (1995).

${ }^{221}$ L. Maritato and A. Y. Petrov, "High Metal-Insulator Transition Temperature in $\mathrm{La}_{1-x} \mathrm{Sr}_{x} \mathrm{MnO}_{3}$ Thin Films Grown in Low Oxygen Partial Pressure by Molecular Beam Epitaxy," J. Magn. Magn. Mater., 272-276 [2] 1135-6 (2004).

${ }^{222}$ G. M. Roesler Jr., M. E. Filipkowski, P. R. Broussard, Y. U. Idzerda, M. S. Osofsky, and R. J. Soulen Jr., "Epitaxial Multilayers of Ferromagnetic Insulators with Nonmagnetic Metals and Superconductors"; pp. 285-90 in Superconducting Superlattices and Multilayers, Vol. 2157, Edited by I. Bozovic. SPIE, Bellingham, 1994.

${ }^{223}$ N. Iwata, G. Pindoria, T. Morishita, and K. Kohn, "Preparation and Magnetic Properties of EuO Thin Films Epitaxially Grown on $\mathrm{MgO}$ and $\mathrm{SrTiO}_{3}$ Substrates," J. Phys. Soc. Jpn., 69 [1] 230-6 (2000). 
${ }^{224}$ P. G. Steeneken, "New Light on EuO Thin Films"; Ph.D. thesis, University of Groningen, 2002.

${ }^{225}$ J. Lettieri, V. Vaithyanathan, S. K. Eah, J. Stephens, V. Sih, D. D. Awschalom, J. Levy, and D. G. Schlom, "Epitaxial Growth and Magnetic Properties of EuO on (001) Si by Molecular-Beam Epitaxy," Appl. Phys. Lett., 83 [5] 975-7 (2003).

${ }^{226}$ A. Schmehl, V. Vaithyanathan, A. Herrnberger, S. Thiel, C. Richter, M. Liberati, T. Heeg, M. Röckerath, L. Fitting Kourkoutis, S. Mühlbaur, P. Böni, D. A. Muller, Y. Barash, J. Schubert, Y. Idzerda, J. Mannhart, and D. G. Schlom, "Epitaxial Integration of the Highly Spin-Polarized Ferromagnetic Semiconductor EuO with Silicon and GaN," Nat. Mater., 6 [11] 882-7 (2007).

${ }^{227}$ R. W. Ulbricht, T. Heeg, D. G. Schlom, A. Schmehl, and J. Schubert, "Adsorption-Controlled Growth of EuO by Molecular-Beam Epitaxy," Appl. Phys. Lett, submitted.

${ }^{228}$ S. A. Chambers, "Epitaxial Growth and Properties of Thin Film Oxides," Surf. Sci. Rep., 39 [5-6] 105-80 (2000).

${ }^{229}$ J. Kabelac, S. Ghosh, P. Dobal, and R. Katiyar, "rf Oxygen Plasma Assisted Molecular Beam Epitaxy Growth of $\mathrm{BiFeO}_{3}$ Thin Films on $\mathrm{SrTiO}_{3}(001)$," J. Vac. Sci. Technol. B, 25 [3] 1049-52 (2007).

${ }^{230}$ J. F. Ihlefeld, A. Kumar, V. Gopalan, D. G. Schlom, Y. B. Chen, X. Q. Pan, T. Heeg, J. Schubert, X. Ke, P. Schiffer, J. Orenstein, L. W. Martin, Y. H. Chu, and R. Ramesh, "Adsorption-Controlled Molecular-Beam Epitaxial Growth of $\mathrm{BiFeO}_{3}, "$ Appl. Phys. Lett., 91 [7] 071922 (2007).

${ }^{231}$ J. F. Ihlefeld, N. J. Podraza, Z. K. Liu, R. C. Rai, X. Xu, T. Heeg, Y. B. Chen, J. Li, R. W. Collins, J. L. Musfeldt, X. Q. Pan, J. Schubert, R. Ramesh, and D. G. Schlom, "Optical Band Gap of $\mathrm{BiFeO}_{3}$ Grown by Molecular-Beam Epitaxy," Appl. Phys. Lett., 92 [14] 142908 (2008).

${ }^{232}$ S. Imada, S. Shouriki, E. Tokumitsu, and H. Ishiwara, "Epitaxial Growth of Ferroelectric $\mathrm{YMnO}_{3}$ Thin Films on $\mathrm{Si}(111)$ Substrates by Molecular Beam Epitaxy," Jpn. J. Appl. Phys., Part 1, 37 [12A] 6497-501 (1998)

${ }^{233}$ Y. Chye, T. Liu, D. Li, K. Lee, D. Lederman, and T. H. Myers, "Molecular Beam Epitaxy of $\mathrm{YMnO}_{3}$ on c-Plane GaN," Appl. Phys. Lett., 88 [13] 132903 (2006).

${ }^{234}$ J. C. Jiang, X. Q. Pan, W. Tian, C. D. Theis, and D. G. Schlom, "Abrupt $\mathrm{PbTiO}_{3} / \mathrm{SrTiO}_{3}$ Superlattices Grown by Reactive Molecular Beam Epitaxy," Appl. Phys. Lett., 74 [19] 2851-3 (1999).

${ }^{235}$ W. Tian, J. C. Jiang, X. Q. Pan, J. H. Haeni, Y. L. Li, L. Q. Chen, D. G. Schlom, J. B. Neaton, K. M. Rabe, and Q. X. Jia, "Structural Evidence for Enhanced Polarization in a Commensurate Short-Period $\mathrm{BaTiO}_{3} / \mathrm{SrTiO}_{3}$ Superlattice," Appl. Phys. Lett., 89 [9] 092905 (2006).

${ }^{236}$ A. Soukiassian, W. Tian, D. A. Tenne, X. X. Xi, D. G. Schlom, N. D. Lanzillotti-Kimura, A. Bruchhausen, A. Fainstein, H. P. Sun, X. Q. Pan, A. Cros, and A. Cantarero, "Acoustic Bragg Mirrors and Cavities Made Using Piezoelectric Oxides," Appl. Phys. Lett., 90 [4] 042909 (2007).

${ }^{237}$ A. Soukiassian, W. Tian, V. Vaithyanathan, J. H. Haeni, L. Q. Chen, X. X Xi, D. G. Schlom, D. A. Tenne, H. P. Sun, X. Q. Pan, K. J. Choi, C. B. Eom, Y. L. Li, Q. X. Jia, C. Constantin, R. M. Feenstra, M. Bernhagen, P. Reiche, and R. Uecker, "Growth of Nanoscale $\mathrm{BaTiO}_{3} / \mathrm{SrTiO}_{3}$ Superlattices by Molecular-Beam Epitaxy," J. Mater. Res., 23 [5] 1417-32 (2008).

${ }^{238}$ R. H. Lamoreaux and D. L. Hildenbrand, "High Temperature Vaporization Behavior of Oxides I. Alkali Metal Binary Oxides," J. Phys. Chem. Ref. Data, 13 [1] 151-73 (1984).

${ }^{239}$ R. H. Lamoreaux and D. L. Hildenbrand, "High-Temperature Vaporization Behavior of Oxides II. Oxides of Be, Mg, Ca, Sr, Ba, B, Al, Ga, In, Tl, Si, Ge, Sn, $\mathrm{Pb}, \mathrm{Zn}, \mathrm{Cd}$, and Hg," J. Phys. Chem. Ref. Data, 16 [3] 419-43 (1987).

${ }^{240}$ M. E. Klausmeier-Brown, J. N. Eckstein, I. Bozovic, and G. F. Virshup, "Accurate Measurement of Atomic Beam Flux by Pseudo-Double-Beam Atomic Absorption Spectroscopy for Growth of Thin-Film Oxide Superconductors," Appl. Phys. Lett., 60 [5] 657-9 (1992).

${ }^{241}$ B. J. Gibbons, M. E. Hawley, S. Trolier-McKinstry, and D. G. Schlom, "Real-Time Spectroscopic Ellipsometry as a Characterization Tool for Oxide Molecular Beam Epitaxy," J. Vac. Sci. Technol. A, 19 [2] 584-90 (2001).

${ }^{242}$ BandiT, k-Space Associates, Ann Arbor, MI

${ }^{243}$ E. S. Hellman and J. S. Harris, "Infrared Transmission Spectroscopy of GaAs during Molecular Beam Epitaxy," J. Cryst. Growth, 81 [1-4] 38-42 (1987).

${ }^{244}$ MOSS, k-Space Associates, Ann Arbor, MI

${ }^{245}$ C. Taylor, D. Barlett, E. Chason, and J. Floro, "Technology," Ind. Phys., 4 [1] 25 (1998)

${ }^{246}$ I. Bozovic and V. Matijasevic, "COMBE: A Powerful New Tool for Materials Science," Mater. Sci. Forum, 352, 1-8 (2000).

${ }^{247}$ S. Y. Wu, W. J. Takei, M. H. Francombe, and S. E. Cummins, "Domain Structure and Polarization Reversal in Films of Ferroelectric Bismuth Titanate," Ferroelectrics, 3 [234] 217-24 (1972).

${ }^{248}$ W. J. Takei, S. Y. Wu, and M. H. Francombe, "Optimization of Epitaxial Quality in Sputtered Films of Ferroelectric Bismuth Titanate," J. Cryst. Growth, 28 [2] 188-98 (1975).

${ }^{249}$ J. Fujita, T. Yoshitake, A. Kamijo, T. Satoh, and H. Igarashi, "Preferentially Oriented Epitaxial Y-Ba-Cu-O Films Prepared by the Ion Beam Sputtering Method," J. Appl. Phys., 64 [3] 1292-5 (1988).

${ }^{250}$ C. B. Eom, A. F. Marshall, S. S. Laderman, R. D. Jacowitz and T. H Geballe, "Epitaxial and Smooth Films of $a$-Axis $\mathrm{YBa}_{2} \mathrm{Cu}_{3} \mathrm{O}_{7}$, " Science, 249 [4976] 1549-52 (1990).

${ }^{251}$ G. Asayama, J. Lettieri, M. A. Zurbuchen, Y. Jia, S. Trolier-McKinstry, D. G. Schlom, S. K. Streiffer, J-P. Maria, S. D. Bu, and C. B. Eom, "Growth of (103) Fiber-Textured $\mathrm{SrBi}_{2} \mathrm{Nb}_{2} \mathrm{O}_{9}$ Films on Pt-Coated Silicon," Appl. Phys. Lett., 80 [13] 2371-3 (2002).

${ }^{2}$ R. Ramesh and D. G. Schlom, "Orienting Ferroelectric Films," Science, 296 [5575] 1975-6 (2002)
${ }^{253}$ H. N. Lee, D. Hesse, N. Zakharov, and U. Gosele, "Ferroelectric $\mathrm{Bi}_{3.25}$ $\mathrm{La}_{0.75} \mathrm{Ti}_{3} \mathrm{O}_{12}$ Films of Uniform $a$-Axis Orientation on Silicon Substrates," Science, 296 [5575] 2006-9 (2002).

${ }^{254}$ Y. Iijima, N. Tanabe, O. Kohno, and Y. Ikeno, "Inplane Aligned $\mathrm{YBa}_{2} \mathrm{Cu}_{3} \mathrm{O}_{7-x}$ Thin-Films Deposited on Polycrystalline Metallic Substrates," Appl. Phys. Lett., 60 [6] 769-71 (1992).

${ }^{255}$ C. P. Wang, K. B. Do, M. R. Beasley, T. H. Geballe, and R. H. Hammond, "Deposition of In-Plane Textured $\mathrm{MgO}$ on Amorphous $\mathrm{Si}_{3} \mathrm{~N}_{4}$ Substrates by IonBeam-Assisted Deposition and Comparisons with Ion-Beam-Assisted Deposited Yttria-Stabilized-Zirconia," Appl. Phys. Lett., 71 [20] 2955-7 (1997).

${ }^{256}$ A. Goyal, D. P. Norton, J. D. Budai, M. Paranthaman, E. D. Specht, D. M. Kroeger, D. K. Christen, Q. He, B. Saffian, F. A. List, D. F. Lee, P. M. Martin, C E. Klabunde, E. Hartfield, and V. K. Sikka, "High Critical Current Density Superconducting Tapes by Epitaxial Deposition of $\mathrm{YBa}_{2} \mathrm{Cu}_{3} \mathrm{O}_{x}$ Thick Films on Biaxially Textured Metals," Appl. Phys. Lett., 69 [12] 1795-7 (1996).

${ }^{257}$ D. P. Norton, A. Goyal, J. D. Budai, D. K. Christen, D. M. Kroeger, E. D Specht, Q. He, B. Saffian, M. Paranthaman, C. E. Klabunde, D. F. Lee, B. C. Sales, and F. A. List, "Epitaxial $\mathrm{YBa}_{2} \mathrm{Cu}_{3} \mathrm{O}_{7}$ on Biaxially Textured Nickel (001): An Approach to Superconducting Tapes with High Critical Current Density," Science, 274 [5288] 755-7 (1996).

${ }^{258}$ A. P. Malozemoff, J. Mannhart, and D. Scalapino, "High-Temperature Cuprate Superconductors get to Work," Phys. Today, 58 [4] 41-6 (2005).

${ }^{259}$ J. Rodriguez, K. Remack, K. Boku, K. R. Udayakumar, S. Aggarwal, S Summerfelt, T. Moise, H. McAdams, J. McPherson, R. Bailey, M. Depner, and G. Fox, "Reliability Properties of Low Voltage PZT Ferroelectric Capacitors and Arrays"; pp. 200-8 in 2004 IEEE International Reliability Physics Symposium, Proceedings 42nd Annual IEEE, Piscataway, NJ, 2004.

${ }^{260}$ R. L. Sandstrom, E. A. Giess, W. J. Gallagher, A. Segmüller, E. I. Cooper, M. F. Chisholm, A. Gupta, S. Shinde, and R. B. Laibowitz, "Lanthanum Gallate Substrates for Epitaxial High-Temperature Superconducting Thin Films," Appl. Phys. Lett., 53 [19] 1874-6 (1988).

${ }^{261}$ R. W. Simon, C. E. Platt, A. E. Lee, G. S. Lee, K. P. Daly, M. S. Wire, J. A Luine, and M. Urbanik, "Low-Loss Substrate for Epitaxial Growth of HighTemperature Superconductor Thin Films," Appl. Phys. Lett., 53 [26] 2677-9 (1988).

${ }^{262}$ G. Koren, A. Gupta, E. A. Giess, A. Segmüller, and R. B. Laibowitz, "Epitaxial Films of $\mathrm{YBa}_{2} \mathrm{Cu}_{3} \mathrm{O}_{7-\delta}$ on $\mathrm{NdGaO}_{3}, \mathrm{LaGaO}_{3}$, and $\mathrm{SrTiO}_{3}$ Substrates Deposited by Laser Ablation," Appl. Phys. Lett., 54 [11] 1054-6 (1989).

${ }^{263}$ R. Feenstra, L. A. Boatner, J. D. Budai, D. K. Christen, M. D. Galloway, and D. B. Poker, "Epitaxial Superconducting Thin Films of $\mathrm{YBa}_{2} \mathrm{Cu}_{3} \mathrm{O}_{7-x}$ on $\mathrm{KTaO}_{3}$ Single Crystals," Appl. Phys. Lett., 54 [11] 1063-5 (1989).

${ }^{264}$ E. A. Giess, R. L. Sandstrom, W. J. Gallagher, A. Gupta, S. L. Shinde, R. F. Cook, E. I. Cooper, E. J. M. O’Sullivan, J. M. Roldan, A. P. Segmüller, and J. Angilello, "Lanthanide Gallate Perovskite-Type Substrates for Epitaxial, High- $T_{\mathrm{c}}$ Superconducting $\mathrm{Ba}_{2} \mathrm{YCu}_{3} \mathrm{O}_{7-\delta}$ Films," IBM J. Res. Dev., 34 [6] 916-26 (1990).

${ }^{265}$ H. Asano, S. Kubo, O. Michikami, M. Satoh, and T. Konaka, "Epitaxia Growth of $\mathrm{EuBa}_{2} \mathrm{Cu}_{3} \mathrm{O}_{7-y}$ Films on $\mathrm{YAlO}_{3}$ Single Crystals," Jpn. J. Appl. Phys., Part 2, 29 [8] L1452-4 (1990).

${ }^{266}$ G. W. Berkstresser, A. J. Valentino, and C. D. Brandle, "Growth of Single Crystals of Rare Earth Gallates," J. Cryst. Growth, 109 [1-4] 457-66 (1991).

${ }^{267}$ G. W. Berkstresser, A. J. Valentino, and C. D. Brandle, "Growth of Single Crystals of Lanthanum Aluminate," J. Cryst. Growth, 109 [1-4] 467-71 (1991).

${ }^{268}$ R. W. Ralston, M. A. Kastner, W. J. Gallagher, and B. Batlogg, "Cooperating on Superconductivity," IEEE Spectrum, 29 [8] 50-5 (1992).

${ }^{269}$ G. W. Berkstresser, A. J. Valentino, and C. D. Brandle, "Congruent Composition for Growth of Lanthanum Aluminate," J. Cryst. Growth, 128 [1-4] 684-8 (1993).

${ }^{270}$ R. Brown, V. Pendrick, D. Kalokitis, and B. H. T. Chai, "Low-Loss Substrate for Microwave Application of High-Temperature Superconductor Films," Appl. Phys. Lett., 57 [13] 1351-3 (1990).

${ }^{271} \mathrm{~S}$. Hontsu, J. Ishii, T. Kawai, and S. Kawai, "LaSrGaO ${ }_{4}$ Substrate Gives Oriented Crystalline $\mathrm{YBa}_{2} \mathrm{Cu}_{3} \mathrm{O}_{7-y}$ Films," Appl. Phys. Lett., 59 [22] 2886-8 (1991)

${ }^{272}$ D. Mateika, H. Kohler, H. Laudan, and E. Volkel, "Mixed-Perovskite Substrates for High- $T_{\mathrm{c}}$ Superconductors," J. Cryst. Growth, 109 [1-4] 447-56 (1991).

${ }^{273}$ J. M. Phillips, "Substrate Selection for High-Temperature Superconducting Thin Films," J. Appl. Phys., 79 [4] 1829-48 (1996).

${ }^{274}$ B. C. Chakoumakos, D. G. Schlom, M. Urbanik, and J. Luine, "Thermal Expansion of $\mathrm{LaAlO}_{3}$ and ( $\left.\mathrm{La}, \mathrm{Sr}\right)(\mathrm{Al}, \mathrm{Ta}) \mathrm{O}_{3}$, Substrate Materials for Superconducting Thin-Film Device Applications," J. Appl. Phys., 83 [4] 1979-82 (1998).

${ }^{275}$ L. Merker, "Method of Prepration of Monocrystalline Strontium Titanate Composition of High Refractive Index"; US Patent No. 2,684,910, July 27, 1954. ${ }^{276}$ J. G. Bednorz and H. J. Scheel, "Flame-Fusion Growth of $\mathrm{SrTiO}_{3}$," J. Cryst. Growth, 41 [1] 5-12 (1977).

${ }^{277}$ P. I. Nabokin, D. Souptel, and A. M. Balbashov, "Floating Zone Growth of High-Quality $\mathrm{SrTiO}_{3}$ Single Crystals," J. Cryst. Growth, 250 [3-4] 397-404 (2003).

${ }^{278}$ H. J. Scheel, J. G. Bednorz, and P. Dill, "Crystal Growth of Strontium Titanate $\mathrm{SrTiO}_{3}$," Ferroelectrics, 13 [1-4] 507-9 (1976).

${ }^{279}$ N. A. Spaldin and M. Fiebig, "The Renaissance of Manetoelectric Multiferroics," Science, 309 [5733] 391-2 (2005).

${ }^{280}$ J. Schubert, O. Trithaveesak, A. Petraru, C. L. Jia, R. Uecker, P. Reiche, and D. G. Schlom, "Structural and Optical Properties of Epitaxial $\mathrm{BaTiO}_{3}$ Thin Films Grown on $\mathrm{GdScO}_{3}(110)$," Appl. Phys. Lett., 82 [20] 3460-2 (2003).

${ }^{281}$ M. D. Biegalski, J. H. Haeni, S. Trolier-McKinstry, D. G. Schlom, C. D. Brandle, and A. J. Ven Graitis, "Thermal Expansion of the New Perovskite Substrates $\mathrm{DyScO}_{3}$ and $\mathrm{GdScO}_{3}$," J. Mater. Res., 20 [4] 952-8 (2005).

${ }^{282}$ R. Uecker, H. Wilke, D. G. Schlom, B. Velickov, P. Reiche, A. Polity, M. Bernhagen, and M. Rossberg, "Spiral Formation during Czochralski Growth of Rare-Earth Scandates," J. Cryst. Growth, 295 [1] 84-91 (2006). 
${ }^{283}$ B. Veličkov, V. Kahlenberg, R. Bertram, and M. Bernhagen, "Crystal Chemistry of $\mathrm{GdScO}_{3}, \mathrm{DyScO}_{3}, \mathrm{SmScO}_{3}$, and $\mathrm{NdScO}_{3}$, , Z. Kristallogr., 222 [9] 466-73 (2007).

${ }^{284}$ R. Uecker, B. Velickov, D. Klimm, R. Bertram, M. Bernhagen, M. Rabe, M. Albrecht, R. Fornari, and D. G. Schlom, "Properties of Rare-Earth Scandate Single Crystals ( $\mathrm{Re}=\mathrm{Nd}-\mathrm{Dy})$, , J. Cryst. Growth, 310 [10] 2649-58 (2008).

${ }^{285}$ M. Kawasaki, K. Takahashi, T. Maeda, R. Tsuchiya, M. Shinohara, O. Ishiyama, T. Yonezawa, M. Yoshimoto, and H. Koinuma, "Atomic Control of the $\mathrm{SrTiO}_{3}$ Crystal Surface," Science, 266 [5190] 1540-2 (1994).

${ }^{286}$ G. Koster, B. L. Kropman, G. J. H. M. Rijnders, D. H. A. Blank, and H. Rogalla, "Quasi-Ideal Strontium Titanate Crystal Surfaces Through Formation of Strontium Hydroxide," Appl. Phys. Lett., 73 [20] 2920-2 (1998).

${ }^{287}$ A. G. Schrott, J. A. Misewich, M. Copel, D. W. Abraham, and Y. Zhang, "A-Site Surface Termination in Strontium Titanate Single Crystals," Appl. Phys. Lett., 79 [12] 1786-8 (2001).

${ }^{288}$. D. H. A. Blank (private communication)

${ }^{289}$ T. Ohnishi, K. Takahashi, M. Nakamura, M. Kawasaki, M. Yoshimoto, and H. Koinuma, " $A$-Site Layer Terminated Perovskite Substrate: $\mathrm{NdGaO}_{3}$," $A p p l$. Phys. Lett., 74 [17] 2531-3 (1999).

${ }^{290}$ H-J. Bae, J. Sigman, D. P. Norton, and L. A. Boatner, "Surface Treatment for Forming Unit-Cell Steps on the (001) $\mathrm{KTaO}_{3}$ Substrate Surface," Appl. Surf. Sci., 241 [3-4] 271-8 (2005).

${ }^{291}$ D. G. Schlom, L. Q. Chen, C. B. Eom, K. M. Rabe, S. K. Streiffer, and J.-M Triscone, "Strain Tuning of Ferroelectric Thin Films," Annu. Rev. Mater. Res., 37, 589-626 (2007)

${ }^{292}$ S. B. Qadri, J. S. Horwitz, D. B. Chrisey, R. C. Y. Auyeung, and K. S Grabowski, "X-Ray Characterization of Extremely High Quality ( $\mathrm{Sr}, \mathrm{Ba}^{\mathrm{T}} \mathrm{TiO}_{3}$ Films Grown by Pulsed Laser Deposition," Appl. Phys. Lett., 66 [13] 1605-7 (1995).

${ }^{293}$ J. F. Ihlefeld and D. G. Schlom (unpublished)

${ }^{294}$ J. H. Lee and D. G. Schlom (unpublished)

${ }^{295}$ C. Adamo, M. Warusawithana, D. G. Schlom, X. Ke, P. Schiffer, and L. Maritato (unpublished)

${ }^{296}$ T. Yamaguti, "Oxidation of a Crystal Surface Studied by Means of Cathode Ray Reflection," Proc. Phys. Math. Soc. Jpn., 17 [11] 443-53 (1935).

${ }^{297}$ R. Sato, "Surface Oxidation of Zincblende Cleavage Face in the Roasting Atmosphere," J. Phys. Soc. Jpn., 6, 527-8 (1951).

${ }^{298}$ S. Matsubara, N. Shohata, and M. Mikami, "Epitaxial Growth of $\mathrm{PbTiO}_{3}$ on $\mathrm{MgAl}_{2} \mathrm{O}_{4} / \mathrm{Si}$ Substrates," Jpn. J. Appl. Phys., 24 [Suppl. 24-3] 10-2 (1985).

${ }^{299}$ S. Miura, T. Yoshitake, S. Matsubara, Y. Miyasaka, N. Shohata, and T. Satoh, "Epitaxial Y-Ba-Cu-O Films on Si with Intermediate Layer by RF Magnetron Sputtering," Appl. Phys. Lett., 53 [20] 1967-9 (1988).

${ }^{300}$ H. Myoren, Y. Nishiyama, H. Fukumoto, H. Nasu, and Y. Osaka, "AsGrown Preparation of Superconducting Epitaxial $\mathrm{Ba}_{2} \mathrm{YCu}_{3} \mathrm{O}_{x}$ Thin Films Sputtered on Epitaxially Grown $\mathrm{ZrO}_{2} / \mathrm{Si}(100)$," Jpn. J. Appl. Phys., Part 1, 28 [3] 351-5 (1989).

${ }^{301}$ D. K. Fork, F. A. Ponce, J. C. Tramontana, and T. H. Geballe, "Epitaxial $\mathrm{MgO}$ on $\mathrm{Si}(001)$ for $\mathrm{Y}-\mathrm{Ba}-\mathrm{Cu}-\mathrm{O}$ Thin-Film Growth by Pulsed Laser Deposition," Appl. Phys. Lett., 58 [20] 2294-6 (1991).

${ }^{302} \mathrm{H}$. Mori and H. Ishiwara, "Epitaxial Growth of $\mathrm{SrTiO}_{3}$ Films on $\mathrm{Si}(100)$ Substrates Using a Focused Electron Beam Evaporation Method," Jpn. J. Appl. Phys., Part 2, 30 [8A] L1415-7 (1991).

${ }^{303}$ A. N. Tiwari, S. Blunier, H. Zogg, P. Lerch, F. Marcenat, and P. Martinoli, "Epitaxial Growth of Superconducting $\mathrm{YBa}_{2} \mathrm{Cu}_{3} \mathrm{O}_{7-x}$ on $\mathrm{Si}(100)$ with $\mathrm{CaF}_{2}$ as Intermediate Buffer," J. Appl. Phys., 71 [10] 5095-8 (1992).

${ }^{304}$ D. K. Fork, "Epitaxial Oxides on Semiconductors"; pp. 393-415 in Pulsed Laser Deposition of Thin Films, Edited by D. B. Chrisey, and G. K. Hubler. Wiley, New York, 1994

${ }^{305}$ M.-B. Lee, M. Kawasaki, M. Yoshimoto, and H. Koinuma, "Heteroepitaxial Growth of $\mathrm{BaTiO}_{3}$ Films on Si by Pulsed Laser Deposition," Appl. Phys. Lett., 66 [11] 1331-3 (1995).

${ }^{306}$ J. Lettieri, J. H. Haeni, and D. G. Schlom, "Critical Issues in the Heteroepitaxial Growth of Alkaline-Earth Oxides on Silicon," J. Vac. Sci. Technol. A, 20 [4] 1332-40 (2002)

${ }^{307}$ E. G. Jacobs, Y. G. Rho, R. F. Pinizzotto, S. R. Summerfelt, and B. E. Gnade, "Effect of a Ge Barrier on the Microstructure of $\mathrm{BaTiO}_{3}$ Deposited on Silicon by Pulsed Laser Ablation"; pp. 379-84 in Laser Ablation in Materials Processing: Fundamentals and Applications, Vol. 285, Edited by B. Braren, J. J. Dubowski, and D. Norton. Materials Research Society, Pittsburgh, 1993.

${ }^{308}$ D. P. Norton, J. D. Budai, and M. F. Chisholm, "Hydrogen-Assisted PulsedLaser Deposition of (001) $\mathrm{CeO}_{2}$ on (001) Ge," Appl. Phys. Lett., 76 [13] 1677-9 (2000).

${ }^{309}$ K. Nashimoto, D. K. Fork, and T. H. Geballe, "Epitaxial Growth of MgO on $\mathrm{GaAs}(001)$ for Growing Epitaxial $\mathrm{BaTiO}_{3}$ Thin Films by Pulsed Laser Deposition," Appl. Phys. Lett., 60 [10] 1199-201 (1992).

${ }^{310}$ Y. Liang, J. Kulik, T. C. Eschrich, R. Droopad, Z. Yu, and P. Maniar, "Hetero-Epitaxy of Perovskite Oxides on GaAs(001) by Molecular Beam Epitaxy," Appl. Phys. Lett., 85 [7] 1217-9 (2004).

${ }^{311}$ E. Vasco, L. Vazquez, M. Aguilo, and C. Zaldo, "Epitaxial Growth of YStabilised Zirconia Films on (100) InP Substrates by Pulsed Laser Deposition," J. Cryst. Growth, 209 [4] 883-9 (2000).

${ }^{312}$ D. P. Norton, S. J. Pearton, H. M. Christen, and J. D. Budai, "HydrogenAssisted Pulsed-Laser Deposition of Epitaxial $\mathrm{CeO}_{2}$ Films on (001) InP," Appl. Phys. Lett., 80 [1] 106-8 (2002).

${ }^{313}$ C.-R. Cho, J.-Y. Hwang, J.-P. Kim, S.-Y. Jeong, S.-G. Yoon, and W.-J. Lee, "Growth and Characterization of $\left(\mathrm{Ba}_{0.5} \mathrm{Sr}_{0.5}\right) \mathrm{TiO}_{3}$ Films Epitaxially Grown on (002) $\mathrm{GaN} /(0006) \mathrm{Al}_{2} \mathrm{O}_{3}$ Electrode," Jpn. J. Appl. Phys., Part 2, 43 [11A] L1425-8 (2004)

${ }^{314}$ H. S. Craft, J. F. Ihlefeld, M. D. Losego, R. Collazo, Z. Sitar, and J-P. Maria, "MgO Epitaxy on GaN (0002) Surfaces by Molecular Beam Epitaxy," Appl. Phys. Lett., 88 [21] 212906 (2006).
${ }^{315}$ W. Tian, V. Vaithyanathan, D. G. Schlom, Q. Zhan, S. Y. Yang, Y. H. Chu, and R. Ramesh, "Epitaxial Integration of (0001) $\mathrm{BiFeO}_{3}$ with (0001) GaN," Appl. Phys. Lett., 90 [17] 172908 (2007).

${ }^{316}$ D. K. Fork, D. B. Fenner, R. W. Barton, J. M. Phillips, G. A. N. Connell, J B. Boyce, and T. H. Geballe, "High Critical Currents in Strained Epitaxial $\mathrm{YBa}_{2} \mathrm{Cu}_{3} \mathrm{O}_{7-\delta}$ on Si," Appl. Phys. Lett., 57 [11] 1161-3 (1990).

${ }^{317}$ H. Ishiwara, N. Tsuji, H. Mori, and H. Nohira, "Preparation of $\mathrm{YbBa}_{2}$ $\mathrm{Cu}_{3} \mathrm{O}_{7 x}$. Films on $\mathrm{Si}(100)$ Substrates Using $\mathrm{SrTiO}_{3}$ Buffer Layers," Appl. Phys. Lett., 61 [12] 1459-61 (1992).

${ }^{318}$ R. Ramesh, H. Gilchrist, T. Sands, V. G. Keramidas, R. Haakenaasen, and D. K. Fork, "Ferroelectric $\mathrm{La}-\mathrm{Sr}-\mathrm{Co}-\mathrm{O} / \mathrm{Pb}-\mathrm{Zr}-\mathrm{Ti}-\mathrm{O} / \mathrm{La}-\mathrm{Sr}-\mathrm{Co}-\mathrm{O}$ Heterostructures on Silicon via Template Growth," Appl. Phys. Lett., 63 [26] 3592-4 (1993).

${ }^{319}$ K. Nashimoto, D. K. Fork, F. A. Ponce, and J. C. Tramontana, "Epitaxial $\mathrm{BaTiO}_{3} / \mathrm{MgO}$ Structure Grown on GaAs(100) by Pulsed Laser Deposition," Jpn J. Appl. Phys., Part 1, 32 [9B] 4099-102 (1993).

${ }^{320}$ V. Srikant, E. J. Tarsa, D. R. Clarke, and J. S. Speck, "Crystallographic Orientation of Epitaxial $\mathrm{BaTiO}_{3}$ Films: The Role of Thermal-Expansion Mismatch with the Substrate," J. Appl. Phys., 77 [4] 1517-22 (1995).

${ }^{321}$ T. Maruyama, M. Saitoh, I. Sakai, T. Hidaka, Y. Yano, and T. Noguchi, "Growth and Characterization of 10-nm-Thick $c$-Axis Oriented Epitaxial $\mathrm{PbZr}_{0.25} \mathrm{Ti}_{0.75} \mathrm{O}_{3}$ Thin Films on (100)Si Substrate," Appl. Phys. Lett., 73 [24] 3524-6 (1998).

${ }^{322}$ A. Lin, X. Hong, V. Wood, A. Verevkin, C. H. Ahn, R. A. McKee, F. J. Walker, and E. D. Specht, "Epitaxial Growth of $\mathrm{Pb}\left(\mathrm{Zr}_{0.2} \mathrm{Ti}_{0.8}\right) \mathrm{O}_{3}$ on $\mathrm{Si}$ and its Nanoscale Piezoelectric Properties," Appl. Phys. Lett., 78 [14] 2034-6 (2001).

${ }^{323}$ B. T. Liu, K. Maki, Y. So, V. Nagarajan, R. Ramesh, J. Lettieri, J. H. Haeni, D. G. Schlom, W. Tian, X. Q. Pan, F. J. Walker, and R. A. McKee, "Epitaxial Ladoped $\mathrm{SrTiO}_{3}$ on Silicon: A Conductive Template for Epitaxial Ferroelectrics on Silicon," Appl. Phys. Lett., 80 [25] 4801-3 (2002).

${ }^{324}$ Y. Liang, J. Kulik, Y. Wei, T. Eschrich, J. Curless, B. Craigo, and S. Smith "Hetero-Epitaxy of Crystalline Perovskite Oxides on GaAs(001)"; pp. 379-84 in Fundamentals of Novel Oxide/Semiconductor Interfaces, Vol. 786, Edited by C. R. Abernathy, E. P. Gusev, D. Schlom, and S. Stemmer. Materials Research Society, Warrendale, 2004.

${ }^{325}$ S. Y. Yang, F. Zavaliche, L. Mohaddes-Ardabili, V. Vaithyanathan, D. G Schlom, Y. J. Lee, Y. H. Chu, M. P. Cruz, Q. Zhan, T. Zhao, and R. Ramesh, "Metalorganic Chemical Vapor Deposition of Lead-Free Ferroelectric $\mathrm{BiFeO}_{3}$ Films for Memory Applications," Appl. Phys. Lett., 87 [10] 102903 (2005).

${ }^{326}$ A. Posadas, J.-B. Yau, C. H. Ahn, J. Han, S. Gariglio, K. Johnston, K. M. Rabe, and J. B. Neaton, "Epitaxial Growth of Multiferroic $\mathrm{YMnO}_{3}$ on GaN," Appl. Phys. Lett., 87 [17] 171915 (2005).

${ }^{327}$ J. K. G. Panitz and C. C. Hu, "Radio-Frequency-Sputtered Tetragonal Barium Titanate Films on Silicon," J. Vac. Sci. Technol., 16 [2] 315-8 (1979).

${ }^{328}$ V. S. Dharmadhikari and W. W. Grannemann, "AES Study on the Chemical Composition of Ferroelectric $\mathrm{BaTiO}_{3}$ Thin Films RF Sputter-Deposited on Silicon," J. Vac. Sci. Technol. A, 1 [2] 483-5 (1983).

${ }^{329}$ S. Matsubara, T. Sakuma, S. Yamamichi, H. Yamaguchi, and Y. Miyasaka, "Interface Structure and Dielectric Properties of $\mathrm{SrTiO}_{3}$ Thin Film Sputter-Deposited onto Si Substrates"; pp. 243-53 in Ferroelectric Thin Films, Materials Research Society Proceedings, Vol. 200, Edited by E. R. Myers, and A. I. Kingon. Materials Research Society, Pittsburgh, PA, 1990.

${ }^{330}$ T. Sakuma, S. Yamamichi, S. Matsubara, H. Yamaguchi, and Y. Miyasaka, "Barrier Layers for Realization of High Capacitance Density in $\mathrm{SrTiO}_{3}$ Thin-Film Capacitor on Silicon," Appl. Phys. Lett., 57 [23] 2431-3 (1990).

${ }^{331}$ H. Yamaguchi, S. Matsubara, and Y. Miyasaka, "Reactive Coevaporation Synthesis and Characterization of $\mathrm{SrTiO}_{3}$ Thin Films," Jpn. J. Appl. Phys., 30 [9B] 2197-9 (1991).

${ }^{332} \mathrm{H}$. Nagata, T. Tsukahara, S. Gonda, M. Yoshimoto, and H. Koinuma, "Heteroepitaxial Growth of $\mathrm{CeO}_{2}(001)$ Films on $\mathrm{Si}(001)$ Substrates by Pulsed Laser Deposition in Ultrahigh Vacuum," Jpn. J. Appl. Phys., 30 [6B] L1136-8 (1991).

${ }^{333}$ Y. Shichi, S. Tanimoto, T. Goto, K. Kuroiwa, and Y. Tarui, "Interaction of $\mathrm{PbTiO}_{3}$ Films with Si Substrate," Jpn. J. Appl. Phys., 33 [9B] 5172-7 (1994).

${ }^{334}$ D. H. Looney, "Semiconducting Translating Device"; US Patent No. 2,791,758, May 7, 1957.

${ }^{335}$ W. L. Brown, "Semiconductive Device"; US Patent No. 2,791,759, May 7, 1957.

${ }^{336}$ I. M. Ross, "Semiconducting Translating Device"; US Patent No. 2,791,760, May 7, 1957.

${ }^{337}$ J. A. Morton, "Electrical Switching and Storage"; US Patent No. 2,791,761, May 7, 1957.

${ }^{338}$ J. L. Moll and Y. Tarui, “A New Solid State Memory Resistor,” IEEE Trans. Electron Devices, 10 [5] 338-9 (1963).

${ }^{339}$ P. M. Heyman and G. H. Heilmeier, "A Ferroelectric Field Effect Device," Proc. IEEE, 54 [6] 842-8 (1966).

${ }^{340}$ G. G. Teather and L. Young, "Non-Destructive Readout of Ferroelectrics by Field Effect Conductivity Modulation," Solid State Electron., 11 [5] 527-33 (1968).

${ }^{341}$ S.-Y. Wu, "A New Ferroelectric Memory Device, Metal-Ferroelectric-Semiconductor Transistor," IEEE Trans. Electron Devices, 21 [8] 499-504 (1974).

${ }^{342}$ M. Suzuki, "Review on Future Ferroelectric Nonvolatile Memory: FeRAM-From the Point of View of Epitaxial Oxide Thin Films," J. Ceram. Soc Jpn., 103 [11] 1099-111 (1995).

${ }^{343}$ M. Suzuki, "Review on Future Ferroelectric Nonvolatile Memory: FeRAM From the Point of View of Epitaxial Oxide Thin Films," J. Ceram. Soc. Jpn. Int Ed., 103 [11] 1088-99 (1995).

${ }^{344}$ K. J. Hubbard and D. G. Schlom, "Thermodynamic Stability of Binary Oxides in Contact with Silicon," J. Mater. Res., 11 [11] 2757-76 (1996).

${ }^{345}$ D. G. Schlom, C. A. Billman, J. H. Haeni, J. Lettieri, P. H. Tan, R. R. M. Held, S. Völk, and K. J. Hubbard, "High- $K$ Candidates for Use as the Gate Dielectric in Silicon MOSFETs"; pp. 31-78 in Thin Films and Heterostructures for Oxide Electronics, Edited by S. B. Ogale. Springer, New York, 2005. 
${ }^{346}$ I. Barin, Thermochemical Data of Pure Substances, Vols. I and II, 3rd edition, VCH, Weinheim, 1995.

${ }^{347}$ E. J. Tarsa, K. L. McCormick, and J. S. Speck, "Common Themes in the Epitaxial Growth of Oxides on Semiconductors"; pp. 73-85 in Epitaxial Oxide Thin Films and Heterostructures, Materials Research Society Proceedings, Vol. 341 , Edited by D. K. Fork, J. M. Phillips, R. Ramesh, and R. M. Wolf. Materials Research Society, Pittsburgh, PA, 1994.

${ }^{348}$ J. M. Phillips, "Substrate Selection for Thin-Film Growth," MRS Bull., 20 [4] 35-9 (1995)

${ }^{349}$ D. G. Schlom and J. H. Haeni, "A Thermodynamic Approach to Selecting Alternative Gate Dielectrics,” MRS Bull., 27 [3] 198-204 (2002).

${ }^{350}$ V. V. Il'chenko, G. V. Kuznetsov, V. I. Strikha, and A. I. Tsyganova, "The Formation of a Barium Silicate Layer on Silicon," Mikroelektron, 27 [5] 3405 (1998).

${ }^{351}$ V. V. Il'chenko, G. V. Kuznetsov, V. I. Strikha, and A. I. Tsyganova, "The Formation of a Barium Silicate Layer on Silicon," Russ. Microelectron., 27 [5] 291-6 (1998).

${ }^{352}$ V. V. Il'chenko and G. V. Kuznetsov, "Effect of Oxygen on the Chemical Reactions and Electron Work Function in $\mathrm{Ba}-\mathrm{Si}$ and BaO-Si Structures," Pis'ma Zh. Tekh. Fiz., 27 [8] 58-63 (2001).

${ }^{353}$ V. V. Il'chenko and G. V. Kuznetsov, "Effect of Oxygen on the Chemical Reactions and Electron Work Function in $\mathrm{Ba}-\mathrm{Si}$ and $\mathrm{BaO}-\mathrm{Si}$ Structures," Sov. Tech. Phys. Lett., 27 [4] 333-5 (2001).

${ }^{354}$ Y. S. Touloukian, R. K. Kirby, R. E. Taylor, and T. Y. R. Lee, Thermal Expansion: Nonmetallic Solids, Vol. 13 of Thermophysical Properties of Matter, $\mathrm{p}$ 154. Plenum, New York, 1977.

${ }^{355}$ D. K. Fork, F. A. Ponce, J. C. Tramontana, N. Newman, J. M. Phillips, and T. H. Geballe, "High Critical Current Densities in Epitaxial $\mathrm{YBa}_{2} \mathrm{Cu}_{3} \mathrm{O}_{7-\delta}$ Thin films on Silicon-on-Sapphire," Appl. Phys. Lett., 58 [21] 2432-4 (1991).

${ }^{356}$ E. S. Machlin and P. Chaudhari, "Theory of 'Pseudomorphic Stabilization' of Metastable Phases in Thin Film Form"; pp. 11-29 in Synthesis and Properties of Metastable Phases, Edited by E. S. Machlin, and T. J. Rowland. The Metallurgical Society of AIME, Warrendale, 1980.

${ }^{357}$ C. P. Flynn, "Strain-Assisted Epitaxial Growth of New Ordered Compounds," Phys. Rev. Lett., 57 [5] 599-602 (1986).

${ }^{358}$ R. Bruinsma and A. Zangwill, "Structural Transitions in Epitaxial Overlayers," J. Phys. (Paris), 47 [12] 2055-73 (1986).

${ }^{359}$ R. F. C. Farrow (ed), Molecular Beam Epitaxy: Applications to Key Materials. Noyes, Park Ridge, 1995.

${ }^{360}$ E. M. Levin, C. R. Robbins, and H. F. McMurdie (eds), Phase Diagrams for Ceramists, Vol. 1, p. 127. American Ceramic Society, Columbus, 1964.

${ }^{361}$ F. Sugawara and S. Iida, "New Magnetic Perovskites $\mathrm{BiMnO}_{3}$ and $\mathrm{BiCrO}_{3}$," J. Phys. Soc. Jpn., 20 [8] 1529 (1965).

${ }^{362}$ H. Faqir, H. Chiba, M. Kikuchi, Y. Syono, M. Mansori, P. Satre, and A. Sebaoun, "High-Temperature XRD and DTA Studies of $\mathrm{BiMnO}_{3}$ Perovskite," J. Solid State Chem., 142 [1] 113-9 (1999).

${ }^{363}$ T. Atou, H. Chiba, K. Ohoyama, Y. Yamaguchi, and Y. Syono, "Structure Determination of Ferromagnetic Perovskite $\mathrm{BiMnO}_{3}$," J. Solid State Chem., 145 [2] 639-42 (1999).

${ }^{364}$ Y. Maeno, T. M. Rice, and M. Sigrist, "The Intriguing Superconductivity of Strontium Ruthenate," Phys. Today, 54 [1] 42-7 (2001).

${ }^{365}$ N. Shirakawa, K. Murata, S. Nishizaki, Y. Maeno, and T. Fujita, "Pressure Dependence of Superconducting Critical Temperature of $\mathrm{Sr}_{2} \mathrm{RuO}_{4}$," Phys. Rev. B, 56 [13] 7890-3 (1997).

${ }^{66}$ C. W. Chu, P. H. Hor, R. L. Meng, L. Gao, Z. J. Huang, and Y. Q. Wang, "Evidence for Superconductivity above $40 \mathrm{~K}$ in the $\mathrm{La}-\mathrm{Ba}-\mathrm{Cu}-\mathrm{O}$ Compound System," Phys. Rev. Lett., 58 [4] $405-7$ (1987).

${ }^{367}$ J. A. Kafalas and J. M. Longo, "High Pressure Synthesis of $\left(\mathrm{ABX}_{3}\right)(\mathrm{AX})$ Compounds," J. Solid State Chem., 4 [1] 55-9 (1972).

${ }^{368}$ I. I. Prosychev and I. S. Shaplygin, "Interaction in the $\mathrm{BaO}-\mathrm{RuO}_{2}$ System," Zh. Neorg. Khim., 25, 876-7 (1980).

${ }^{369}$ I. I. Prosychev and I. S. Shaplygin, Russ. J. Inorg. Chem., 25 [3] 489 (1980),

${ }^{370}$ M. I. Gadzhiev and I. S. Shaplygin, "Reactions in the $\mathrm{BaO}-\mathrm{RuO}_{2}$ System," Zh. Neorg. Khim., 29, 2154-5 (1984).

${ }^{71}$ M. I. Gadzhiev and I. S. Shaplygin, "Reactions in the $\mathrm{BaO}-\mathrm{RuO}_{2}$ System," Russ. J. Inorg. Chem., 29 [8] 1230-1 (1984).

${ }^{372}$ T. L. Popova, N. G. Kisel, V. I. Krivobok, and V. P. Karlov, "Interaction in the $\mathrm{BaO}-\mathrm{RuO}_{2}$ System," Ukr. Khim. Zh., 48 [5] 457-60 (1982).

${ }^{373}$ T. L. Popova, N. G. Kisel, V. I. Krivobok, and V. P. Karlov, "Interaction in the $\mathrm{BaO}-\mathrm{RuO}_{2}$ System," Sov. Prog. Chem., 48, 8-10 (1982).

${ }^{374}$ J. B. Clark, P. W. Richter, and L. Du Toit, "High-Pressure Synthesis of $\mathrm{YScO}_{3}, \mathrm{HoScO}_{3}, \mathrm{ErScO}_{3}$, and $\mathrm{TmScO}_{3}$, and a Reevaluation of the Lattice Constants of the Rare Earth Scandates," J. Solid State Chem., 23 [1-2] 129-34 (1978).

${ }^{5}$ R. P. Liferovich and R. H. Mitchell, "A Structural Study of Ternary Lanthanide Orthoscandate Perovskites," J. Solid State Chem., 177 [6] 2188-97 (2004).

${ }^{376}$ E. M. Levin, C. R. Robbins, and H. F. McMurdie (eds), Phase Diagrams for Ceramists, Vol. 2, p. 93. American Ceramic Society, Columbus, 1969.

${ }^{377}$ N. Orloff, I. Takeuchi, J. C. Booth, D. Gu, A. Lewandoski, J. Mateu, C. J. Fennie, K. M. Rabe, W. Tian, and D. G. Schlom, "Broadband and Temperature Dependent Permittivity Measurements of Ruddlesden-Popper $\operatorname{Sr}_{n+1} \mathrm{Ti}_{n} \mathrm{O}_{3 n+1}$ $(n=1,2,3)$ Thin Films"; (unpublished).

${ }^{378}$ C. J. Fennie and K. M. Rabe, "Structural and Dielectric Properties of $\mathrm{Sr}_{2} \mathrm{TiO}_{4}$ from First Principles," Phys. Rev. B, 68 [18] 184111 (2003).

${ }^{379}$ M. A. Zurbuchen, J. Schubert, Y. Jia, W. Tian, V. Cherman, M. D. Biegalski, D. Fong, M. E. Hawley, A. K. Tagantsev, S. K. Streiffer, and D. G. Schlom, "Charge-Mediated Synthesis of $\mathrm{Sr}_{4} \mathrm{Bi}_{4} \mathrm{Ti}_{7} \mathrm{O}_{24}$ "; (unpublished).

${ }^{380}$ E. C. Subbarao, "A Family of Ferroelectric Bismuth Compounds," J. Phys. Chem. Solids, 23, 665-76 (1962).
${ }^{381}$ R. A. Armstrong and R. E. Newnham, "Bismuth Titanate Solid Solutions," Mater. Res. Bull., 7 [10] 1025-34 (1972).

${ }^{382}$ J.van Suchtelen, "Product Properties: A New Application of Composite Materials," Philips Res. Rep., 27 [1] 28-37 (1972).

${ }^{383}$ J. van den Boomgaard, D. R. Terrell, R. A. J. Born, and H. F. J. I. Giller, "An in Situ Grown Eutectic Magnetoelectric Composite Material: Part 1 Composition and Unidirectional Solidification," J. Mater. Sci., 9 [10] 1705-9 (1974).

${ }^{384}$ A. M. J. G. van Run, D. R. Terrell, and J. H. Scholing, "An in Situ Grown Eutectic Magnetoelectric Composite Material: Part 2 Physical Properties," $J$. Mater. Sci., 9 [10] 1710-4 (1974).

${ }^{385}$ L. P. M. Bracke and R. G. van Vliet, "A Broadband Magneto-Electric Transducer using a Composite Material,” Int. J. Electron., 51 [3] 255-62 (1981).

${ }^{386}$ R. E. Newnham, D. P. Skinner, and L. E. Cross, "Connectivity and Piezoelectric-Pyroelectric Composites," Mater. Res. Bull., 13 [5] 525-36 (1978).

${ }^{387}$ J. van den Boomgaard and R. A. J. Born, "A Sintered Magnetoelectric Composite Material $\mathrm{BaTiO}_{3}-\mathrm{Ni}(\mathrm{Co}, \mathrm{Mn}) \mathrm{Fe}_{2} \mathrm{O}_{4},{ }^{\prime}$ J. Mater. Sci., 13 [7] 1538-48 (1978).

${ }^{388}$ G. Srinivasan, E. T. Rasmussen, A. A. Bush, K. E. Kamentsev, V. F. Meshcheryakov, and Y. K. Fetisov, "Structural and Magnetoelectric Properties of $M \mathrm{Fe}_{2} \mathrm{O}_{4}$-PZT $(M=\mathrm{Ni}, \mathrm{Co})$ and $\mathrm{La}_{x}(\mathrm{Ca}, \mathrm{Sr})_{1-x} \mathrm{MnO}_{3}-\mathrm{PZT}$ Multilayer Composites," Appl. Phys. A, 78 [5] 721-8 (2004).

${ }^{389}$ K. Lefki and G. J. M. Dormans, "Measurement of Piezoelectric Coefficients of Ferroelectric Thin Films,"' J. Appl. Phys., 76 [3] 1764-7 (1994).

${ }^{390}$ M. A. Zurbuchen, S. Saha, T. Wu, J. Mitchell, and S. K. Streiffer, "Multiferroic Composite Ferroelectric-Ferromagnetic Films," Appl. Phys. Lett., 87 [23] 232908 (2005)

${ }^{391}$ H. Zheng, J. Wang, S. E. Lofland, Z. Ma, L. Mohaddes-Ardabili, T. Zhao, L. Salamanca-Riba, S. R. Shinde, S. B. Ogale, F. Bai, D. Viehland, Y. Jia, D. G Schlom, M. Wuttig, A. Roytburd, and R. Ramesh, "Multiferroic $\mathrm{BaTiO}_{3}$ $\mathrm{CoFe}_{2} \mathrm{O}_{4}$ Nanostructures," Science, 303 [5658] 661-3 (2004)

${ }^{392}$ E. Klokholm, J. W. Matthews, A. F. Mayadas, and J. Angilello; pp. 105-9 in Magnetism and Magnetic Materials, Edited by C. D. Graham Jr., and J. J. Rhyne. American Institute of Physics, New York, 1972.

${ }^{393}$ L. B. Freund and S. Suresh, Thin Film Materials: Stress, Defect Formation and Surface Evolution, pp. 60-83, 283-90 Cambridge University Press, Cambridge, 2003.

${ }^{394}$ J. S. Speck, A. C. Daykin, A. Seifert, A. E. Romanov, and W. Pompe, "Domain Configurations due to Multiple Misfit Relaxation Mechanisms in Epitaxial Ferroelectric Thin Films. III. Interfacial Defects and Domain Misorientations," $J$. Appl. Phys., 78 [3] 1696 (1995).

${ }^{395}$ W. D. Nix and B. M. Clemens, "Crystallite Coalescence: A Mechanism for Intrinsic Tensile Stresses in Thin Films," J. Mater. Res., 14 [8] 3467-73 (1999).

${ }^{396}$ T. R. Taylor, P. J. Hansen, B. Acikel, N. Pervez, R. A. York, S. K. Streiffer, and J. S. Speck, "Impact of Thermal Strain on the Dielectric Constant of Sputtered Barium Strontium Titanate Thin Films," Appl. Phys. Lett., 80 [11] 1978-80 (2002).

${ }^{397}$ C. L. Canedy, H. Li, S. P. Alpay, L. Salamanca-Riba, A. L. Roytburd, and R. Ramesh, "Dielectric Properties in Heteroepitaxial $\mathrm{Ba}_{0.6} \mathrm{Sr}_{0.4} \mathrm{TiO}_{3}$ Thin Films: Effect of Internal Stresses and Dislocation-Type Defects," Appl. Phys. Lett., 77 [11] 1695-7 (2000).

${ }^{3}$ I. B. Misirlioglu, A. L. Vasiliev, M. Aindow, S. P. Alpay, and R. Ramesh, "Threading Dislocation Generation in Epitaxial (Ba,Sr)TiO ${ }_{3}$ Films Grown on (001) $\mathrm{LaAlO}_{3}$ by Pulsed Laser Deposition," Appl. Phys. Lett., 84 [10] 1742-4 (2004).

${ }^{399}$ M.-W. Chu, I. Szafraniak, R. Scholz, C. Harnagea, D. Hesse, M. Alexe, and U. Gösele, "Impact of Misfit Dislocations on the Polarization Instability of Epitaxial Nanostructured Ferroelectric Perovskites," Nat. Mater., 3 [2] 87-90 (2004).

${ }^{400}$ S. P. Alpay, I. B. Misirlioglu, V. Nagarajan, and R. Ramesh, "Can Interface Dislocations Degrade Ferroelectric Properties," Appl. Phys. Lett., 85 [11] 2044-6 (2004).

${ }^{401}$ V. Nagarajan, C. L. Jia, H. Kohlstedt, R. Waser, I. B. Misirlioglu, S. P. Alpay, and R. Ramesh, "Misfit Dislocations in Nanoscale Ferroelectric Heterostructures,” Appl. Phys. Lett., 86 [19] 192910 (2005).

${ }^{402}$ N. A. Pertsev, A. G. Zembilgotov, and A. K. Tagantsev, "Effect of Mechanical Boundary Conditions on Phase Diagrams of Epitaxial Ferroelectric Thin Films," Phys. Rev. Lett., 80 [9] 1988-91 (1998).

${ }^{403}$ N. A. Pertsev and V. G. Koukhar, "Polarization Instability in Polydomain Ferroelectric Epitaxial Thin Films and the Formation of Heterophase Structures,' Phys. Rev. Lett., 84 [16] 3722-5 (2000).

${ }^{404}$ V. G. Koukhar, N. A. Pertsev, and R. Waser, "Thermodynamic Theory of Epitaxial Ferroelectric Thin Films with Dense Domain Structures," Phys. Rev. B, 64 [21] 214103 (2001).

${ }^{405}$ Y. L. Li, S. Y. Hu, Z. K. Liu, and L. Q. Chen, "Phase-Field Model of Domain Structures in Ferroelectric Thin Films," Appl. Phys. Lett., 78 [24] 3878-80 (2001).

${ }^{406}$ Y. L. Li, S. Y. Hu, Z. K. Liu, and L. Q. Chen, "Effect of Substrate Constraint on the Stability and Evolution of Ferroelectric Domain Structures in Thin Films," Acta Mater., 50 [2] 395-411 (2002).

${ }^{407}$ O. Diéguez, S. Tinte, A. Antons, C. Bungaro, J. B. Neaton, K. M. Rabe, and D. Vanderbilt, "Ab Initio Study of the Phase Diagram of Epitaxial $\mathrm{BaTiO}_{3}$," Phys. Rev B, 69 [21] 212101 (2004).

${ }^{408}$ Y. L. Li and L. Q. Chen, "Temperature-Strain Phase Diagram for $\mathrm{BaTiO}_{3}$ Thin Films," Appl. Phys. Lett., 88 [7] 072905 (2006).

${ }^{409}$ N. A. Pertsev, V. G. Kukhar, H. Kohlstedt, and R. Waser, "Phase Diagrams and Physical Properties of Single-Domain Epitaxial $\mathrm{Pb}\left(\mathrm{Zr}_{1-x} \mathrm{Ti}_{x}\right) \mathrm{O}_{3}$ Thin Films," Phys. Rev. B, 67 [5] 54107 (2003).

${ }^{410}$ Y. L. Li, S. Choudhury, Z. K. Liu, and L. Q. Chen, "Effect of External Mechanical Constraints on the Phase Diagram of Epitaxial $\mathrm{PbZr}_{1-x} \mathrm{Ti}_{x} \mathrm{O}_{3}$ Thin 
Films-Thermodynamic Calculations and Phase-Field Simulations," Appl. Phys. Lett., 83 [8] 1608-10 (2003).

${ }^{411}$ S. Choudhury, Y. L. Li, and L. Q. Chen, "A Phase Diagram for Epitaxial $\mathrm{PbZr}_{1-x} \mathrm{Ti}_{x} \mathrm{O}_{3}$ Thin Films at the Bulk Morphotropic Boundary Composition," $J$. Am. Ceram. Soc., 88 [6] 1669-72 (2005).

${ }^{412}$ N. A. Pertsev, A. K. Tagantsev, and N. Setter, "Phase Transitions and StrainInduced Ferroelectricity in $\mathrm{SrTiO}_{3}$ Epitaxial Thin Films," Phys. Rev. B, 61 [2] R825-9 (2000).

${ }^{413}$ N. A. Pertsev, A. K. Tagantsev, and N. Setter, "Erratum: Phase Transitions and Strain-Induced Ferroelectricity in $\mathrm{SrTiO}_{3}$ Epitaxial Thin Films [Phys. Rev. B 61, R825 (2000)]," Phys. Rev. B, 65 [21] 219901 (2002).

${ }^{414}$ A. Antons, J. B. Neaton, K. M. Rabe, and D. Vanderbilt, "Tunability of the Dielectric Response of Epitaxially Strained $\mathrm{SrTiO}_{3}$ from First Principles," Phys. Rev. B, 71 [2] 024102 (2005).

${ }^{415}$ Y. L. Li, S. Choudhury, J. H. Haeni, M. D. Biegalski, A. Vasudevarao, A. Sharan, H. Z. Ma, J. Levy, V. Gopalan, S. Trolier-McKinstry, D. G. Schlom, Q. X. Jia, and L. Q. Chen, "Phase Transitions and Domain Structures in Strained Pseudocubic (100) $\mathrm{SrTiO}_{3}$ Thin Films," Phys. Rev. B, 73 [18] 184112 (2006).

${ }^{416}$ A. Vasudevarao, A. Kumar, L. Tian, J. H. Haeni, Y. L. Li, C.-J. Eklund, Q X. Jia, R. Uecker, P. Reiche, K. M. Rabe, L. Q. Chen, D. G. Schlom, and V. Gopalan, "Mutiferroic Domain Dynamics in Strained Strontium Titanate," Phys. Rev. Lett., 97 [25] 257602 (2006).

${ }^{417}$ Y. L. Li, S. Choudhury, J. H. Haeni, M. D. Biegalski, A. Vasudevarao, A Sharan, H. Z. Ma, J. Levy, V. Gopalan, S. Trolier-McKinstry, D. G. Schlom, Q X. Jia, and L. Q. Chen, "Phase Transitions and Domain Structures in Strained Pseudocubic (100) $\mathrm{SrTiO}_{3}$ Thin Films," Phys. Rev. B, 73 [18] 184112 (2006).

${ }^{418}$ P. Irvin, J. Levy, J. H. Haeni, and D. G. Schlom, "Localized Microwave Resonances in Strained $\mathrm{SrTiO}_{3}$ Thin Films," Appl. Phys. Lett., 88 [4] 042902 (2006).

${ }^{419}$ S. Denev, A. Kumar, M. D. Biegalski, H. W. Jang, C. M. Folkman, A. Vasudevarao, Y. Han, I. M. Reaney, S. Trolier-McKinstry, C. B. Eom, D. G. Schlom, and V. Gopalan, "Magnetic Color Symmetry of Lattice Rotations in a Diamagnetic Material," Phys. Rev. Lett., 100 [25] 257601 (2008).

${ }^{420}$ H. Z. Ma, J. Levy, M. D. Biegalski, D. G. Schlom, and S. Trolier-McKinstry, "Room-Temperature Electrooptic Properties of Strained $\mathrm{SrTiO}_{3}$ Films Grown on $\mathrm{DyScO}_{3}, "$ J. Appl. Phys., submitted.

${ }^{421}$ A. Vasudevarao, S. Denev, M. D. Biegalski, Y. L. Li, L. Q. Chen, S. TrolierMcKinstry, D. G. Schlom, and V. Gopalan, "Polarization Rotation Transitions in Anisotropically Strained $\mathrm{SrTiO}_{3}$ Thin Films," Appl. Phys. Lett., 92 [19] 192902 (2008).

${ }^{422}$ M. D. Biegalski, S. Trolier-McKinstry, D. G. Schlom, S. K. Streiffer, M Bernhagen, P. Reiche, and R. Uecker, "Asymmetric Dielectric Properties of $\mathrm{SrTiO}_{3}$ Thin Films on $\mathrm{DyScO}_{3}$ Substrates," J. Appl. Phys., submitted.

${ }^{423}$ S. Kamba, D. Nuzhnyy, V. Goian, S. Veljko, C. M. Brooks, J. H. Lee, D. G. Schlom, J.-H. Lee, J. Schubert, E. John, T. Katsufuji, and J. Petzelt, "Ferroelectricity in $\mathrm{SrTiO}_{3}$ and $\mathrm{EuTiO}_{3}$ Strained Thin Films: Polar Phonon Properties", Presented at Fundamental Physics of Ferroelectrics, Williamsburg, Virginia, 2008

${ }^{424}$ S. K. Streiffer, J. A. Eastman, D. D. Fong, C. Thompson, A. Munkholm, M. V. R. Murty, O. Auciello, G. R. Bai, and G. B. Stephenson, "Observation of Nanoscale $180^{\circ}$ Stripe Domains in Ferroelectric $\mathrm{PbTiO}_{3}$ Thin Films," Phys. Rev. Lett., 89 [6] 067601 (2002).

${ }^{425}$ E. D. Specht, H.-M. Christen, D. P. Norton, and L. A. Boatner, "X-Ray Diffraction Measurement of the Effect of Layer Thickness on the Ferroelectric Transition in Epitaxial $\mathrm{KTaO}_{3} / \mathrm{KNbO}_{3}$ Multilayers," Phys. Rev. Lett., 80 [19] 4317-20 (1998).

${ }^{426}$ H.-M. Christen, L. A. Knauss, and K. S. Harshavardhan, "Field-Dependent Dielectric Permittivity of Paraelectric Superlattice Structures,"' Mater. Sci. Eng. B, 56 [2-3] 200-3 (1998).

${ }^{427}$ H. M. Christen, E. D. Specht, S. S. Silliman, and K. S. Harshavardhan, "Ferroelectric and Antiferroelectric Coupling in Superlattices of Paraelectric Perovskites at Room Temperature," Phys. Rev. B, 68 [2] 20101 (2003).

${ }^{428}$ K. Abe, N. Yanase, K. Sano, M. Izuha, N. Fukushima, and T. Kawakubo, "Modification of Ferroelectricity in Heteroepitaxial (Ba,Sr)TiO ${ }_{3}$ Films for NonVolatile Memory Applications," Integr. Ferroelectr., 21 [1-4] 197-206 (1998).

${ }^{429}$ N. Yanase, K. Abe, N. Fukushima, and T. Kawakubo, "Thickness Dependence of Ferroelectricity in Heteroepitaxial $\mathrm{BaTiO}_{3}$ Thin Film Capacitors," Jpn. J. Appl. Phys., Part 1, 38 [9B] 5305-8 (1999).

${ }^{430}$ M. Sepliarsky, S. R. Phillpot, M. G. Stachiotti, and R. L. Migoni, "Ferroelectric Phase Transitions and Dynamical Behavior in $\mathrm{KNbO}_{3} / \mathrm{KTaO}_{3}$ Superlattices by Molecular-Dynamics Simulation," J. Appl. Phys., 91 [5] 3165-71 (2002).

${ }^{431}$ V. Gopalan and R. Raj, "Domain Structure-Second Harmonic Generation Correlation in Potassium Niobate Thin Films Deposited on a Strontium Titanate Substrate," J. Am. Ceram. Soc., 79 [12] 3289-96 (1996).

${ }^{432}$ V. Gopalan and R. Raj, "Electric Field Induced Domain Rearrangement in Potassium Niobate Thin Films Studied by in Situ Second Harmonic Generation Measurements," J. Appl. Phys., 81 [2] 865-75 (1997).

${ }^{433}$ Y. Barad, J. Lettieri, C. D. Theis, D. G. Schlom, V. Gopalan, J. C. Jiang, and X. Q. Pan, "Probing Domain Microstructure in Ferroelectric $\mathrm{Bi}_{4} \mathrm{Ti}_{3} \mathrm{O}_{12}$ Thin Films by Optical Second Harmonic Generation," J. Appl. Phys., 89 [2] 1387-92 (2001).

${ }^{434}$ Y. Barad, J. Lettieri, C. D. Theis, D. G. Schlom, V. Gopalan, J. C. Jiang, and X. Q. Pan, "Erratum: 'Probing Domain Microstructure in Ferroelectric $\mathrm{Bi}_{4} \mathrm{Ti}_{3} \mathrm{O}_{12}$ Thin Films by Optical Second Harmonic Generation,' [J. Appl. Phys. 89, 1387 (2001)]," J. Appl. Phys., 89 [9] 5230 (2001).

${ }^{435}$ M. Fiebig, D. Fröhlich, T. Lottermoser, and M. Maat, "Probing of Ferroelectric Surface and Bulk Domains in $R \mathrm{MnO}_{3}(R=\mathrm{Y}, \mathrm{Ho})$ by Second Harmonic Generation," Phys. Rev. B, 66 [14] 144102 (2002).

${ }^{436}$ K. A. Müller and H. Burkard, "SrTiO ${ }_{3}$ : An Intrinsic Quantum Paraelectric below 4K," Phys. Rev. B, 19 [7] 3593-602 (1979).
${ }^{437}$ R. C. Neville, B. Hoeneisen, and C. A. Mead, "Permittivity of Strontium Titanate," J. Appl. Phys., 43 [5] 2124-31 (1972).

${ }^{438}$ P. W. Forsbergh Jr., "Effect of a Two-Dimensional Pressure on the Curie Point of Barium Titanate," Phys. Rev., 93 [4] 686-92 (1954).

${ }^{439}$ C. J. Fennie and K. M. Rabe, "Magnetic and Electric Phase Control in Epitaxial $\mathrm{EuTiO}_{3}$ from First Principles," Phys. Rev. Lett., 97 [26] 267602 (2006)

${ }^{440}$ T. Ando, A. B. Fowler, and F. Stern, "Electronic Properties of Two-Dimensional Systems," Rev. Mod. Phys., 54 [2] 437-672 (1982).

${ }^{441}$ A. Tsukazaki, A. Ohtomo, T. Kita, Y. Ohno, H. Ohno, and M. Kawasaki, "Quantum Hall Effect in Polar Oxide Heterostructures," Science, 315 [5817] 138891 (2007).

${ }^{442}$ H. P. R. Frederikse, W. R. Thurber, and W. R. Hosler, "Electronic Transport in Strontium Titanate," Phys. Rev., 134 [2A] A442-5 (1964).

${ }^{443}$ H. P. R. Frederikse and G. A. Candela, "Magnetic Susceptibility of Insulating and Semiconducting Strontium Titanate," Phys. Rev., 147 [2] 583-4 (1966)

${ }^{444}$ H. Suzuki, H. Bando, Y. Ootuka, I. H. Inoue, T. Yamamoto, K. Takahashi, and Y. Nishihara, "Superconductivity in Single-Crystalline $\mathrm{Sr}_{1-x} \mathrm{La}_{x} \mathrm{TiO}_{3}, " J$. Phys. Soc. Jpn., 65 [6] 1529-32 (1996)

${ }^{445}$ M. Gurvitch, H. L. Stormer, R. C. Dynes, J. M. Graybeal, and D. C. Jacobson, "Field Effect on Superconducting Surface Layers of $\mathrm{SrTiO}_{3}$;" pp. 47-9, Extended Abstracts Superconducting Materials, Vol. EA-9, Edited by J. Bevk, and A. I. Braginski. Materials Research Society, Pittsburgh, 1986.

${ }^{446}$ R. Dingle, H. L. Störmer, A. C. Gossard, and W. Wiegmann, "Electron Mobilities in Modulation-Doped Semiconductor Heterojunction Superlattices," Appl. Phys. Lett., 33 [7] 665-7 (1978).

${ }^{447}$ R. J. Cava, "Structural Chemistry and the Local Charge Picture of Copper Oxide Superconductors," Science, 247 [4943] 656-62 (1990).

${ }^{448}$ J. H. Haeni, "Nanoengineering of Ruddlesden-Popper Phases using Molecular Beam Epitaxy"; Ph.D. Thesis, Pennsylvania State University, 2002. Available on-line at http://etda.libraries.psu.edu/theses/approved/WorldWideIndex/ETD181/index.html

${ }^{449}$ G. B. Stringfellow (ed), Phase Equilibria Diagrams, Vol. 9, pp. 126, 130. American Ceramic Society, Westerville, 1992.

${ }^{450} \mathrm{~T}$. Ikeda, "A Few Quarternary Systems of Perovskite Type $A^{2+} B^{4+} \mathrm{O}_{3}$ Solid Solutions," J. Phys. Soc. Jpn., 14 [10] 1286-94 (1959).

${ }^{451}$ E. M. Levin, C. R. Robbins, and H. F. McMurdie (eds), Phase Diagrams for Ceramists, Vol. 1, p. 195. American Ceramic Society, Columbus, 1964.

${ }^{452}$ A. K. Gutakovskii, L. I. Fedina, and A. L. Aseev, "High Resolution Electron Microscopy of Semiconductor Interfaces," Phys. Status Solidi A, 150 [1] 127-40 (1995).

${ }^{453}$ S. Thoma and H. Cerva, "Comparison of the Information Content in < $110\rangle$ - and $\langle 100\rangle$-Projected High-Resolution Transmission Electron Microscope Images for the Quantitative Analysis of AlAs/GaAs Interfaces," Ultramicroscopy, 53 [1] 37-51 (1994).

${ }^{454}$ S. Li, J. A. Eastman, J. M. Vetrone, R. E. Newnham, and L. E. Cross, "Dielectric Response in Ferroelectric Superlattices," Philos. Mag. B, 76 [1] 47-57 (1997).

${ }^{455}$ N. Sai, B. Meyer, and D. Vanderbilt, "Compositional Inversion Symmetry Breaking in Ferroelectric Perovskites," Phys. Rev. Lett., 84 [24] 5636 9 (2000).

${ }^{456}$ J. B. Neaton and K. M. Rabe, "Theory of Polarization Enhancement in Epitaxial $\mathrm{BaTiO}_{3} / \mathrm{SrTiO}_{3}$ Superlattices,” Appl. Phys. Lett., 82 [10] 1586-8 (2003).

${ }^{457}$ S. M. Nakhmanson, K. M. Rabe, and D. Vanderbilt, "Polarization Enhancement in Two- and Three-Component Ferroelectric Superlattices," Appl. Phys. Lett., 87 [10] 102906 (2005).

${ }^{458}$ S. M. Nakhmanson, K. M. Rabe, and D. Vanderbilt, "Predicting Polarization Enhancement in Multicomponent Ferroelectric Superlattices," Phys. Rev. B, 73 [6] 060101 (2006).

${ }^{459}$ J. Chaloupka and G. Khaliullin, "Orbital Order and Possible Superconductivity in $\mathrm{LaNiO}_{3} / \mathrm{LaMO}_{3}$ Superlattices," Phys. Rev. Lett., 100 [1] 016404 (2008).

${ }^{460}$ T. Shimuta, O. Nakagawara, T. Makino, S. Arai, H. Tabata, and T. Kawai, "Enhancement of Remanent Polarization in Epitaxial $\mathrm{BaTiO}_{3} / \mathrm{SrTiO}_{3}$ Superlattices with 'Asymmetric Structure'," J. Appl. Phys., 91 [4] 2290-4 (2002).

${ }^{461}$ M. H. Corbett, R. M. Bowman, J. M. Gregg, and D. T. Foord, "Enhancement of Dielectric Constant and Associated Coupling of Polarization Behavior in Thin Film Relaxor Superlattices," Appl. Phys. Lett., 79 [6] 815-7 (2001).

${ }^{462}$ L. Kim, D. Jung, J. Kim, J. S. Kim, and J. Lee, "Strain Manipulation in $\mathrm{BaTiO}_{3} / \mathrm{SrTiO}_{3}$ Artificial Lattice Toward High Dielectric Constant and its Nonlinearity," Appl. Phys. Lett., 82 [13] 2118-20 (2003).

${ }^{463}$ D. O'Neill, R. M. Bowman, and J. M. Gregg, "Dielectric Enhancement and Maxwell-Wagner Effects in Ferroelectric Superlattice Structures," Appl. Phys. Lett., 77 [10] 1520-2 (2000).

${ }^{464}$ G. Catalan, D. O'Neill, R. M. Bowman, and J. M. Gregg, "Relaxor Features in Ferroelectric Superlattices: A Maxwell-Wagner Approach," Appl. Phys. Lett., 77 [19] 3078-80 (2000)

${ }^{465}$ H. Zheng, Q. Zhan, F. Zavaliche, M. Sherburne, F. Straub, M. P. Cruz, L.-Q. Chen, U. Dahmen, and R. Ramesh, "Controlling Self-Assembled PerovskiteSpinel Nanostructures," Nano Lett., 6 [7] 1401-7 (2006).

${ }^{466}$ S. Ríos, A. Ruediger, A. Q. Jiang, J. F. Scott, H. Lu, and Z. Chen, “Orthorhombic Strontium Titanate in $\mathrm{BaTiO}_{3}-\mathrm{SrTiO}_{3}$ Superlattices," J. Phys. Cond. Matter, 15 [21] L305-9 (2003).

${ }^{467}$ K. Johnston, X. Y. Huang, J. B. Neaton, and K. M. Rabe, "FirstPrinciples Study of Symmetry Lowering and Polarization in $\mathrm{BaTiO}_{3} / \mathrm{Sr}$ $\mathrm{TiO}_{3}$ Superlattices with in-Plane Expansion," Phys. Rev. B, 71 [10] 100103(R) (2005).

${ }^{468}$ Y. L. Li, S. Y. Hu, D. Tenne, A. Soukiassian, D. G. Schlom, L. Q. Chen, X. X. Xi, K. J. Choi, C. B. Eom, A. Saxena, T. Lookman, and Q. X. Jia, "Interfacial 
Coherency and Ferroelectricity of $\mathrm{BaTiO}_{3} / \mathrm{SrTiO}_{3}$ Superlattice Films," Appl. Phys. Lett., 91 [25] 252904 (2007).

${ }^{469}$ Y. L. Li, S. Y. Hu, D. Tenne, A. Soukiassian, D. G. Schlom, X. X. Xi, K. J. Choi, C. B. Eom, A. Saxena, T. Lookman, Q. X. Jia, and L. Q. Chen, "Prediction of Ferroelectricity in $\mathrm{BaTiO}_{3} / \mathrm{SrTiO}_{3}$ Superlattices with Domains," Appl. Phys. Lett., 91 [11] 112914 (2007).

${ }^{470} \mathrm{C}$. Ederer and N. A. Spaldin, "Effect of Epitaxial Strain on the Spontaneous Polarization of Thin Film Ferroelectrics," Phys. Rev. Lett., 95 [25] 257601 (2005).

${ }^{471}$ K. M. Rabe, "Theoretical Investigations of Epitaxial Strain Effects in Ferroelectric Oxide Thin Films and Superlattices," Curr. Opin. Solid State Mater. Sci., 9 [3] 122-7 (2006)

${ }^{472}$ C. Ederer and N. A. Spaldin, "Recent Progress in First-Principles Studies of Magnetoelectric Multiferroics," Curr. Opin. Solid State Mater. Sci., 9 [3] 128-39 (2006).

${ }^{473}$ J. B. Neaton, C. Ederer, U. V. Waghmare, N. A. Spaldin, and K. M. Rabe, "First-Principles Study of Spontaneous Polarization in Multiferroic $\mathrm{BiFeO}_{3}$," Phys. Rev. B, 71 [1] 014113 (2005).

${ }^{474}$ O. Dieguez, K. M. Rabe, and D. H. Vanderbilt, "First-Principles Study of Epitaxial Strain in Perovskites," Phys. Rev. B, 72 [14] 144101 (2005).

${ }^{475}$ M. Dawber, K. M. Rabe, and J. F. Scott, "Physics of Thin-Film Ferroelectric Oxides," Rev. Mod. Phys., 77 [4] 1083-130 (2005).

${ }^{476}$ H. W. Jang, S. H. Beak, D. Ortiz, C. M. Folkman, R. R. Das, Y. H. Chu, P. Shafer, J. X. Zhang, S. Choudhury, V. Vaithyanathan, Y. B. Chen, X. Q. Pan, D. G. Schlom, L. Q. Chen, R. Ramesh, and C. B. Eom, "Strain-Induced Polarization Rotation in Epitaxial (001) $\mathrm{BiFeO}_{3}$ Thin Films," Phys. Rev. Lett., in press.

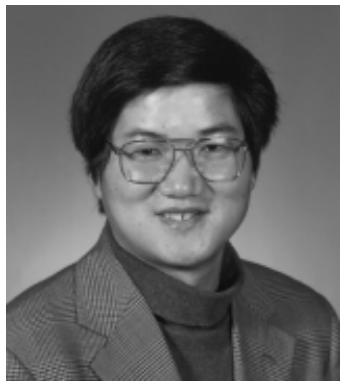

Long-Qing Chen is Professor of Materials Science and Engineering at Penn State University. He received a B.S. degree from Zhejiang University in China, a M.S. degree from State University of New York at Stony Brook, and a Ph.D. degree from MIT. After a 2-year post-doc appointment at Rutgers University, he joined the faculty at Penn State in 1992. His main research interest is in developing computational models for predicting mesoscale microstructure evolution in advanced materials. Prof. Chen is the author or co-author of more than 200 papers and has delivered more than 150 invited presentations. He received numerous awards including an ONR Young Investigator Award, a NSF special research creativity award, a Wilson Award for Excellence in Research from his college, a University Faculty Scholar Medal in Engineering at Penn State, a Outstanding Overseas Young Scholar by the Chinese Natural Science Foundation, a Changjiang Chair Professorship by the Chinese Ministry of Education, a Guggenheim Fellowship, a Royal Society Kan Tong Po Fellowship, and the 2006 ASM Materials Research Silver Medal.

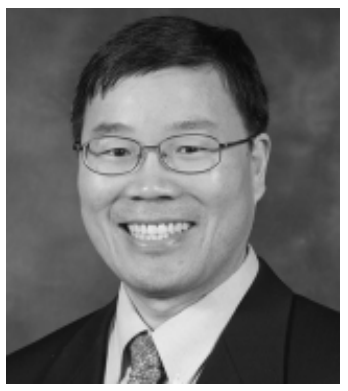

Xiaoqing Pan is a Professor in the Department of Materials Science and Engineering at the University of Michigan, Ann Arbor. He received B.S. and M.S. degrees in condensed matter physics from Nanjing University in China and a Ph.D. degree from Universität des Saarlandes in Germany. After a post-doc at the Max-Planck Institute für Metallforschung in Stuttgart, he joined the faculty at the University of Michigan. His research interests involve the epitaxial growth and structural characterization of functional materials including catalysts, oxide semiconductors, dielectric, and ferroelectric oxides. He is particularly interested in the structure-property relationships of interfaces and defects at the atomic scale. He is best known for his atomic scale characterization of oxide materials using high-resolution transmission electron microscopy. He has published over 200 papers. He has received the National Science Foundation's CAREER Award and the Chinese Natural Science Foundation's Outstanding Young Investigator Award.

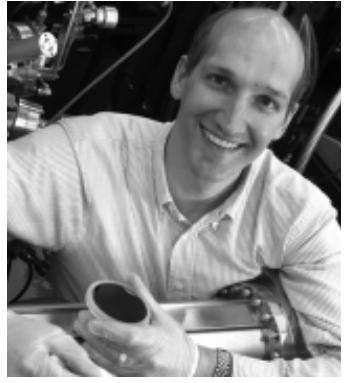

Darrell Schlom is a Professor in the Department of Materials Science and Engineering at Cornell University. He received a B.S. degree from Caltech, and M.S. and Ph.D. degrees from Stanford University. After a post-doc at IBM's research lab in Zurich, Switzerland, he joined the faculty at Penn State University where the work described in this paper was performed. His research interests involve the heteroepitaxial growth and characterization of oxide thin films, especially those with functional properties (ferroelectric, piezoelectric, ferromagnetic, or a combination of these properties), including their epitaxial integration with semiconductors. He is particularly interested in the preparation of high quality oxide heterostructures with electronic applications (e.g., superlattices and metastable phases of dielectric and ferroelectric oxides) by MBE. He has published over 300 papers and has seven patents. He has been awarded invention achievement awards by IBM and SRC; young investigator awards by ONR, NSF, and the American Association for Crystal Growth; an Alexander von Humboldt Research Fellowship, and the ASM International Bradley Stoughton Award for Young Teachers. He is a Fellow of the American Physical Society.

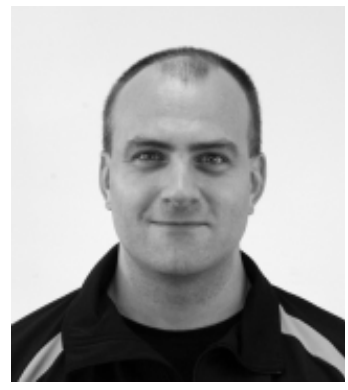

Andreas Schmehl is a researcher in the group of Prof. Jochen Mannhart at the Center for Electronic Correlations and Magnetism at the University of Augsburg, Germany. He received a physics diploma and a Ph.D. degree in physics from the University of Augsburg. As part of a Feodor Lynen research scholarship, awarded by the Alexander von Humboldt foundation, he spent 2 years as post-doc in the group of Prof. Darrell G. Schlom at Penn State University. His research interests involve the electronic properties of interfaces in materials with strong electronic correlations, electronics based on oxide thin films, and semiconductor-based spin electronics. His main focus is the preparation of high-quality metal-oxide thin films (spin polarized semiconductors, superconductors, ferromagnets) and their utilization for novel device concepts as well as for basic research. He has published over 30 papers and owns four patents. He is currently working on his habilitation.

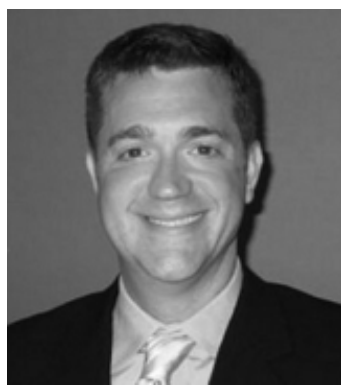

Mark Zurbuchen is a senior member of the technical staff in the Microelectronics Technology Department at The Aerospace Corporation. He received a B.S. degree from U. Missouri, an M.S. from Rensselaer, and a Ph.D. from Penn State. He worked in R\&D at a small tech firm and as a post-doc at Argonne. He was at NIST prior to joining the staff at Aerospace, and is owner of TAECO LLC (www.tae company.com). His interest centers on synthesis and characterization of heteroepitaxial systems, particularly for the integration of heterogeneous materials and the formation of new compounds for microelectronic applications. His current work focuses on formation dynamics of epitaxial systems having differing anion chemistries (e.g., oxides, nitrides, fluorides, and sulfides), and on 3D analysis of nanoscale structures by TEM tomography. His main expertise are in TEM and X-ray diffraction methods, and film growth by pulsed-laser deposition. He has published 27 papers and has 10 patents awarded or pending. He has been awarded invention achievement awards by Aerospac e Corp., and an NRC Postdoctoral Fellowship award. 